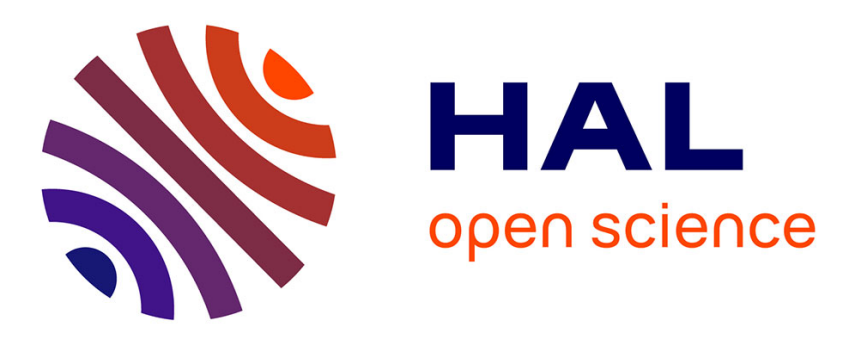

\title{
Applications of Chiral Three-membered Rings for Total Synthesis: A Review
}

\author{
Renato Dalpozzo, Alessandra Lattanzi, Helene Pellissier
}

\section{To cite this version:}

Renato Dalpozzo, Alessandra Lattanzi, Helene Pellissier. Applications of Chiral Three-membered Rings for Total Synthesis: A Review. Current Organic Chemistry, 2017, 21 (13), pp.1143-1191. 10.2174/1385272821666170221151356 . hal-01683218

\section{HAL Id: hal-01683218 https://hal.science/hal-01683218}

Submitted on 16 Apr 2018

HAL is a multi-disciplinary open access archive for the deposit and dissemination of scientific research documents, whether they are published or not. The documents may come from teaching and research institutions in France or abroad, or from public or private research centers.
L'archive ouverte pluridisciplinaire HAL, est destinée au dépôt et à la diffusion de documents scientifiques de niveau recherche, publiés ou non, émanant des établissements d'enseignement et de recherche français ou étrangers, des laboratoires publics ou privés. 


\title{
Applications of Chiral Three-Membered Rings for Total Synthesis: A Review
}

\author{
Renato Dalpozzo ${ }^{\mathrm{a}}$, Alessandra Lattanzi ${ }^{\mathrm{b}}$ and Hélène Pellissier ${ }^{*}$
}

\begin{abstract}
${ }^{a}$ Dipartimento Chimica e Tecnologie Chimiche, Ponte Bucci Cubo 12/c VI piano, 87036 Arcavacata di Rende (Cs), Italy; ${ }^{b}$ Università di Salerno, Dipartimento di Chimica e Biologia, Via Giovanni Paolo II, 132, 84084, Fisciano, Italy; ${ }^{c}$ Aix Marseille Univ, CNRS, Centrale Marseille, iSm2, Marseille, France
\end{abstract}

\begin{abstract}
This review updates recent applications of asymmetric aziridination, azirination, thiirination, epoxidation, and cyclopropanation in the total synthesis of biologically active compounds, including natural products, using chiral substrates or chiral catalysts, covering the literature since 2000. The interest towards these synthetic methodologies of chiral three-membered rings has increased in the last decade, dictated either by the biological activities that display many naturally occurring products bearing a three-membered unit or by the ring strain of three-membered rings making them useful precursors of many more complex interesting molecules. Classic as well as modern protocols in asymmetric aziridinations, azirinations, epoxidations, thiirinations, and cyclopropanations have been widely applied as key steps of a number of syntheses of important products. Although the use of chiral substrates and auxiliaries is still highly employed particularly in asymmetric aziridination and cyclopropanation, the development of enantioselective catalytic methodologies has witnessed exponential growth during the last decade. The present review is subdivided into three parts, dealing successively with the use of chiral nitrogen-containing three-membered rings, chiral epoxides and thiiranes, and chiral cyclopropanes in total synthesis.
\end{abstract}

\section{INTRODUCTION}

Chiral three-membered rings are useful building blocks in synthesis, as well as important synthetic targets. The interest towards synthetic methodologies for their preparation has increased in the last decade, dictated either by the biological activities displayed by many naturally occurring products bearing a three-membered unit or by being useful precursors for accessing more complex interesting molecules [1]. The goal of the present review is to highlight the major developments and applications in the use of asymmetric three-membered ring formations in total synthesis reported in the last fifteen years. It must be noted that a range of reviews, which will be cited in the respective sections of the present review, have been separatively devoted to asymmetric aziridinations, epoxidations, or cyclopropanations [2]. On the other hand, to the best of our knowledge, no previous review compiling all types of chiral threemembered rings and their synthetic applications exists. In 2000, a book dedicated to cyclopropanes in synthesis was published by de Meijere [3], while a special issue published in Chemical Reviews in 2014 was consecrated to small heterocycles in synthesis but did not especially focus on the asymmetric total synthesis of bioactive and natural products [4]. The present review is subdivided into three parts, dealing successively with the use of chiral nitrogencontaining three-membered rings, chiral epoxides and thiiranes, and chiral cyclopropanes in total synthesis. The first part is subdivided into two sections successively devoted to chiral aziridines and

*Address correspondence to this author at the Aix Marseille Univ, CNRS, Centrale Marseille, iSm2, Marseille, France; Tel: 33491282765;

E-mail: h.pellissier@univ-amu.fr chiral azirines. The second part of the review is also subdivided into two sections, dealing successively with chiral epoxides and thiiranes. The third part of the review is subdivided into four sections, treating successively asymmetric Simmons-Smith cyclopropanations as key steps, asymmetric transition-metal decomposition of diazoalkanes as key steps, asymmetric Michael-initiated ring closures as key steps, and miscellaneous asymmetric cyclopropanations as key steps.

\section{CHIRAL NITROGEN-CONTAINING MEMBERED RINGS IN TOTAL SYNTHESIS}

THREE-

\subsection{Chiral Aziridines}

Aziridines are among the most fascinating heterocyclic intermediates in organic synthesis [5], acting as precursors of many complex molecules including natural and biologically active products due to the high strain incorporated in their skeletons [6]. The last decade has witnessed tremendous activity in the area of discovering new methodologies for their synthesis and transformations [7]. This growing interest is related to their striking chemical properties. The high strain energy associated with the aziridine ring enables easy cleavage of the $\mathrm{C}-\mathrm{N}$ bond, leading to a series of important nitrogen-containing products [8]. Obtaining aziridines, especially optically active aziridines, has become of great importance in organic chemistry for many reasons. These reasons may include the antitumor, antibacterial and other biological properties associated with a great number of aziridine-containing compounds, such as mitomycins, azinomycins, and epothilones [9]. Indeed, as powerful alkylating agents, aziridines have an inherent in vivo potency through their ability to act as DNA cross-linking agents via nucleo- 


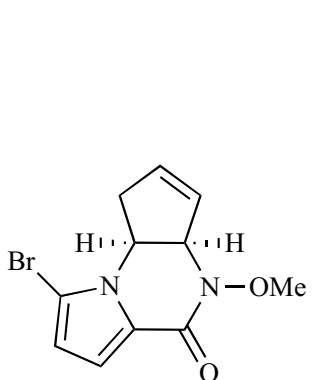

1

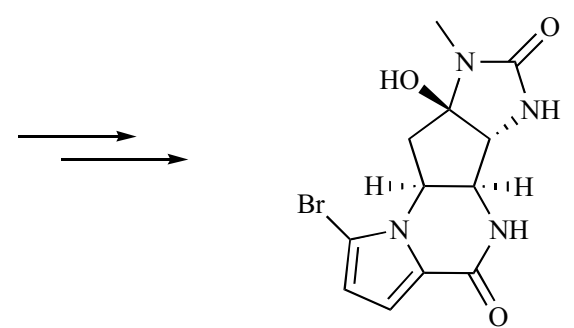<smiles>CCCc1cccc(C(C)C)c1-n1ccn(-c2c(C(C)C)cccc2C(C)C)c1=[Cr]Cl</smiles>

$\mathrm{PhI}=\mathrm{NTs}$

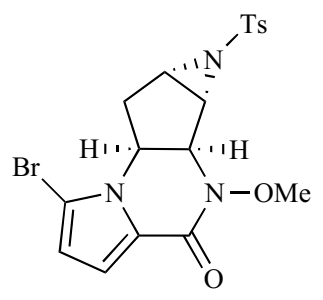

$52 \%,>99 \%$ ee

(+)-agelastatin A

Scheme 1. Synthesis of (+)-agelastatin A.<smiles>[R]OOC(C)=O</smiles>

Scheme 2. Synthesis of a pregnanolone and minaxolone analogue.

philic ring opening of the aziridine moiety. Structure-activity relationships have identified the aziridine ring is very essential for the antitumor activity, and a vast amount of work has concentrated on synthesizing derivatives of these natural products with increased potency. Various antitumor agents related to mitosanes and mitomycins, for example, have been synthesized and demonstrated to possess activity against a variety of cancers. A number of other synthetic chiral aziridines have also been shown to exhibit other useful biological properties such as enzyme-inhibitory activities. In addition to these important biological activities related to the aziridine unit, these molecules constitute key chiral building blocks for the easy construction of other types of biologically relevant as well as naturally occuring chiral nitrogen-containing compounds. Chiral aziridines can be prepared by either asymmetric catalytic methods or from chiral substrates. The main approaches to the synthesis of chiral aziridines can be classified as asymmetric nitrene transfer to alkenes, asymmetric carbene transfer to imines such as ylide-mediated aziridinations, asymmetric cyclization reactions through addition/elimination processes such as Gabriel-Cromwell reactions, and miscellaneous asymmetric reactions such as intramolecular substitutions [7].

\subsubsection{Asymmetric Aziridinations of Chiral Substrates as Key Steps}

\section{Nitrene Transfer to Alkenes}

Nitrogen-atom transfer to alkenes is a particularly appealing strategy for the generation of aziridines because of the ready avail- ability of olefinic starting materials and the direct nature of such a process.

The nitrene (or nitrenoid) source for this reaction can be generated from various methodologies, such as the metal-catalyzed reaction of [ $N$-( $p$-toluenesulfonyl)imino]aryliodinanes [10]. In 2006, Trost and Dong reported a total synthesis of $(+)$-agelastatin A, possessing nanomolar activity against several cancer cell lines, which was based on the aziridination of chiral piperazinone 1 (Scheme 1) [11]. This process was performed in the presence of $\mathrm{PhI}=\mathrm{NTs}$ as the nitrene source and a catalytic amount of copper $N$-heterocyclic carbene complex $\mathbf{2}$, providing the corresponding aziridine $\mathbf{3}$ as the only detected stereoisomer in 52\% yield. This chiral aziridine was further converted into the expected (+)-agelastatin A in four supplementary steps. This natural product is also known to inhibit glycogen synthase kinase- $3 b$, a behaviour that might provide an approach for the treatment of Alzheimer's disease.

In 2003, Dauban and Dodd applied the Ses iminoiodane $(\mathrm{PhI}=\mathrm{NSes})$ to the copper-catalyzed aziridination of 11-pregnane derivatives to prepare chiral 11,12-aziridino analogues of neuroactive steroids [12]. As shown in Scheme 2, the reaction of chiral 11pregnene-3,20-dione $4 \mathbf{a}$ or 3- $\alpha$-acetoxy-11-pregnen-20-one $\mathbf{4 b}$ with $\mathrm{PhI}=\mathrm{NSes}$ in the presence of CuOTf led to the corresponding $\alpha, \alpha$ 11,12 -aziridino steroids 5 a-b in moderate yields (45-53\%). The $3 \alpha$ acetoxy-11-pregnen-20-one derivative $\mathbf{5 b}$ was further converted via TASF-mediated removal of the $N$-Ses blocking group into $N$-methyl-11,12-aziridino-3 $\alpha$-hydroxy-5 $\beta$-pregnan-20-one, which is a conformationally constrained analogue of the endogenous neuros- 


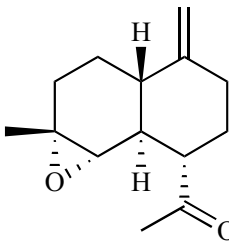<smiles>CC(=O)[C@H]1CC[C@@]2(CN2S(=O)(=O)OCC(Cl)(Cl)Cl)[C@H]2CC[C@@]3(C)O[C@@H]1[C@H]23</smiles>

$73 \%, 66 \%$ de

Scheme 3. Formal synthesis of (+)-kalihinol A.<smiles>CCOC(=O)C1=CC=C[C@H](Nc2ccccc2)C1</smiles>

10:1 regiomeric mixture<smiles>O=C(O)C1=C[C@@H]2[C@H]([C@H](Nc3ccccc3)C1)N2[SiH3]</smiles>

9

$86 \%,>99 \%$ de

\section{$\mathrm{Rh}_{2}(\mathrm{pfm})_{4}$ \\ $\mathrm{PhI}(\mathrm{OAc})_{2}$ \\ $\mathrm{MgO}$}

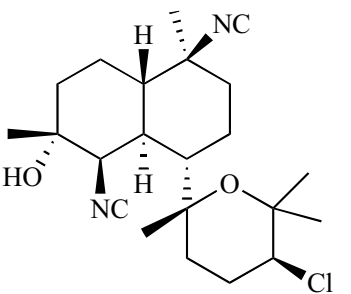

(+)-kalihinol A

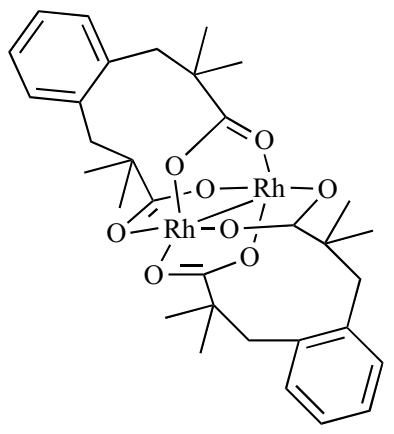

$\mathrm{SesNH}_{2}$ (1.1 equiv)<smiles>[R10]C(C)O[C@H]1C=C(C(=O)OCC)C[C@H](N)[C@H]1NC(C)CC</smiles>

(-)-oseltamivir

Scheme 4. Synthesis of (-)-oseltamivir.

teroid, pregnanolone, and a structural analogue of the synthetic general anesthetic, minaxolone.

In 2005, Wood and Keaney explored the use of rhodium perfluorobutyramide $\left(\mathrm{Rh}_{2}(\mathrm{pfm})_{4}\right)$ for the aziridination of olefins [13]. The authors found that the treatment of chiral olefin 6 by trichloroethylsulfamate ester in the presence of a combination of $\mathrm{Rh}_{2}(\mathrm{pfm})_{4}$ with $\mathrm{PhI}(\mathrm{OAc})_{2}$ provided the expected trichloroethoxysulfonylaziridine 7 in good yield and moderate diastereoselectivity $(66 \%$ de), as shown in Scheme 3. Notably, this product constituted a potent intermediate for the formal synthesis of $(+)$-kalihinol A.

With the aim of developing a synthesis for the orally active neuraminidase inhibitor, (-)-oseltamivir, Trost and Zhang investigated the asymmetric aziridination of chiral diene 8 (Scheme 4)
[14]. In this case, the best result for the aziridination was obtained when the reaction was performed in the presence of $\mathrm{SesNH}_{2}$ as the nitrene source, $\mathrm{PhI}(\mathrm{OPiv})_{2}$ as the oxidant, bis-[rhodium $\left(\alpha, \alpha, \alpha^{\prime}, \alpha^{\prime}-\right.$ tetramethyl-1,3-benzenedipropionate] $\left[\mathrm{Rh}_{2}(\mathrm{esp})_{2}\right]$ as the catalyst, and chlorobenzene as the solvent, as shown in Scheme 4. Under these reaction conditions, the corresponding $\gamma, \delta$-aziridine 9 was obtained as the only detected stereoisomer in $86 \%$ yield. This chiral product was further converted into required (-)-oseltamivir through four supplementary steps with an overall yield of $30 \%$.

Another methodology to generate nitrenes consists of the in situ oxidation of hydrazine derivatives in the presence of $\mathrm{Pb}(\mathrm{OAc})_{4}$. In 2005 , Vederas et al. applied this methodology to the asymmetric aziridination of a camphor derivative in the presence of 3-amino-2- 


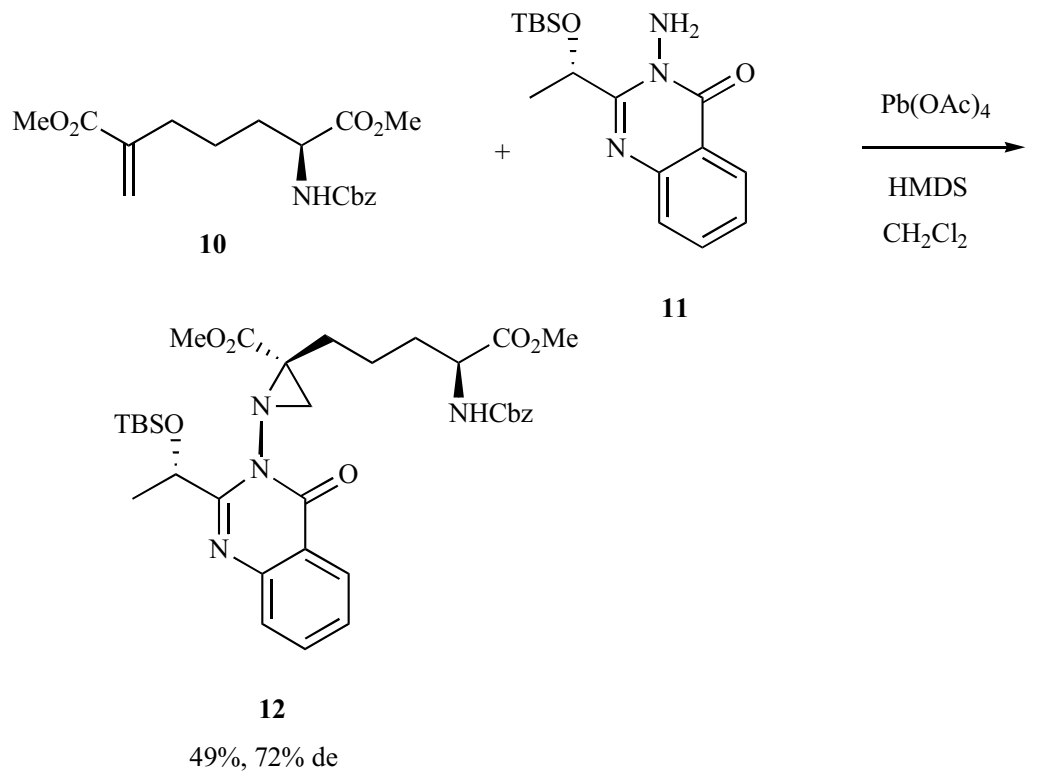

Scheme 5. Synthesis of an analogue of diaminopimelic acid.<smiles>N#Cc1cccn1[C@H]1C=C[C@H](OC(=O)N[N+]#N)C1</smiles>

13

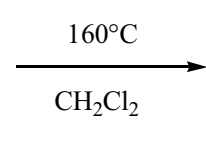

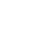<smiles>N#Cc1cccn1[C@H]1C[C@@H]2OC(=O)N3[C@H]2C1[C@H]3O</smiles>

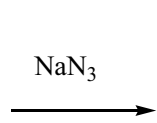<smiles>N#Cc1cccn1[C@H]1C[C@@H]2OC(=O)N[C@H]2[C@H]1N</smiles><smiles>C#CCCC</smiles>

(-)-agelastatin A

Scheme 6. Synthesis of (-)-agelastatin A.

ethyl-3,4-dihydroquinazolin-4-one combined with $\mathrm{Pb}(\mathrm{OAc})_{4}$ and hexamethyldisilazide (HMDS) [15]. An asymmetric version of this method was developed by these authors by using chiral 3acetoxyaminoquinazolinones for the aziridination of unsaturated $\alpha$ aminopimelic ester in order to prepare aziridine analogues of diaminopimelic acid which is an inhibitor of diaminopimelic acid epimerase [15]. As shown in Scheme 5, the reaction of chiral alkene 10, performed in the presence of chiral aminoquinazolinone $\mathbf{1 1}$ and $\mathrm{Pb}(\mathrm{OAc})_{4}$, led to the expected corresponding aziridine $\mathbf{1 2}$ in $49 \%$ yield along with moderate diastereoselectivity of $72 \%$ de.

Another methodology to prepare aziridines is based on the thermolytic or photolytic decomposition or organic azides [16]. In 2008, Tanaka et al. employed this methodology as key step of a total synthesis of (-)-agelastatin A, a potent antineoplastic agent [17]. Indeed, the nitrogen functionality of the agelastatin core was installed through thermolytic intramolecular aziridination of chiral azidoformate 13. The formed tricyclic aziridine $\mathbf{1 4}$ obtained as the only detected stereoisomer was further submitted to a regioselective azidation, leading to trans-diamination of the double bond. The obtained chiral azide was subsequently converted into the expected (-)-agelastatin A (structure in Scheme 1), as shown in Scheme 6.
Earlier in 2006, Lowary et al. reported the synthesis of Ldaunosamine and L-ristosamine glycosides based on photoinduced intramolecular aziridinations of acylnitrenes derived from Lrhamnose [18]. As shown in Scheme 7, upon exposure to UV light (254 nm), chiral acyl azide 15 was converted to the corresponding aziridine 16 in $79 \%$ yield and as the only detected stereoisomer through the generation of a presumed acylnitrene intermediate. This aziridine was further converted into expected glycoside L-daunosamine derivative. Similarly, the irradiation of a 2:1 $\alpha: \beta$ anomeric mixture of acyl azide $\mathbf{1 7}$ of an L-erythro-hex-2-enopyranoside derivative led to a mixture of the corresponding aziridines $\mathbf{1 8}$ in $91 \%$ yield (Scheme 7). These products were further separated by chromatography and then converted into important glycoside L-ristosamine derivatives.

\section{Gabriel-Cromwell Reactions}

The Gabriel-Cromwell aziridine synthesis involves a nucleophilic addition of a formal nitrene equivalent to a 2-haloacrylate or similar reagent. It involves an initial Michael addition, followed by protonation and 3-exo-tet ring closure. In 2003, Maycock et al. reported the Gabriel-Cromwell reaction of chiral $\alpha$-iodocyclohexe- 


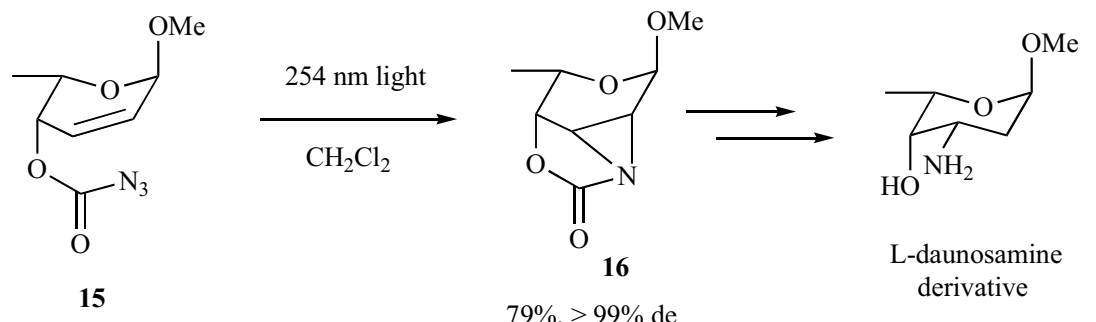

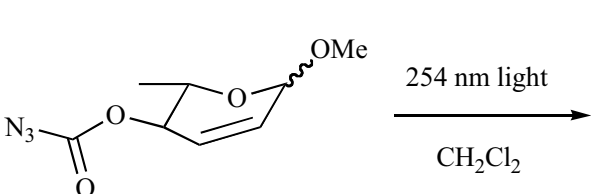

17

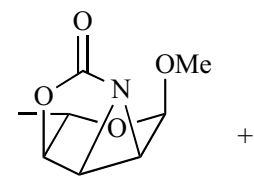

$61 \%$

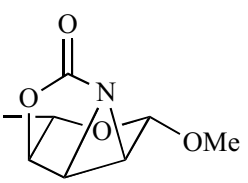

18

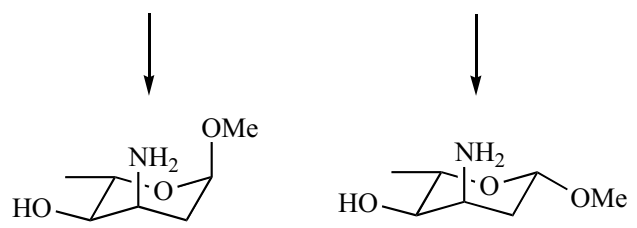

L-ristosamine derivatives

Scheme 7. Syntheses of L-daunosamine and L-ristosamine derivatives.<smiles>COc1ccc(CN2O[C@@H]3[C@H]4OC(C)(C)O[C@@H]4CC(=O)[C@@H]32)cc1</smiles>

$84 \%, 60 \%$ de<smiles>O=C1C(Br)=C[C@H](O)[C@H]2O[C@@H]12</smiles>

(+)-bromoxone

Scheme 8. Synthesis of (+)-bromoxone

none 19 derived from (-)-quinic acid [19]. The aziridination, performed in the presence of 4-methoxybenzylamine and $\mathrm{Cs}_{2} \mathrm{CO}_{3}$ as a base, afforded the corresponding aziridine $\mathbf{2 0}$ in good yield (84\%) as an 80:20 mixture of diastereomers, as shown in Scheme 8. This reaction constituted the key step of a short synthesis of $(+)$ bromoxone, the acetate of which showed potent antitumor activity.

In the same context, Dodd et al. have developed a total synthesis of the non-natural enantiomer of polyoxamic acid on the basis of the domino aza-Michael-type addition/elimination reaction of chiral triflate 21 derived from D-ribonolactone [20]. This triflate reacted with 3,4-dimethoxybenzylamine to provide the corresponding aziridine $\mathbf{2 2}$ as the only detected stereoisomer in good yield (Scheme 9). The complete diasteroselectivity of the reaction was explained as a result of a aza-Michael-type addition of 3,4-dimethoxybenzylamine to the face opposite to that of the bulky silyl group at C-5. This aziridine was further converted through six supplementary steps into the expected $(-)$-polyoxamic acid with an overall yield of $10 \%$. 
<smiles>CCOC1=C[C@@H](CO[18OH])OC1=O</smiles>

21

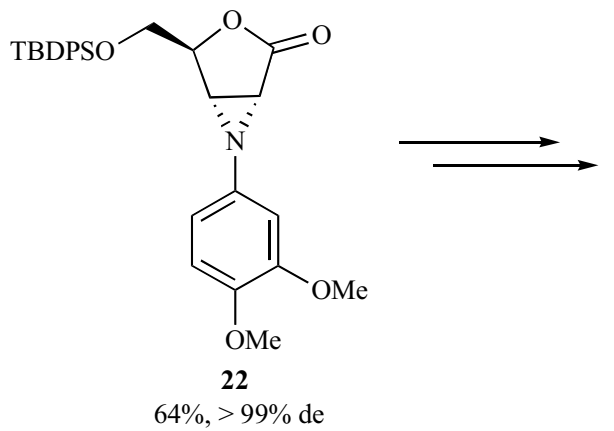<smiles>COc1ccc(N)cc1OC</smiles>

DMF<smiles>N[C@@H](C(=O)O)[C@@H](O)[C@H](O)CO</smiles>

(-)-polyoxamic acid

Scheme 9. Synthesis of (-)-polyoxamic acid.

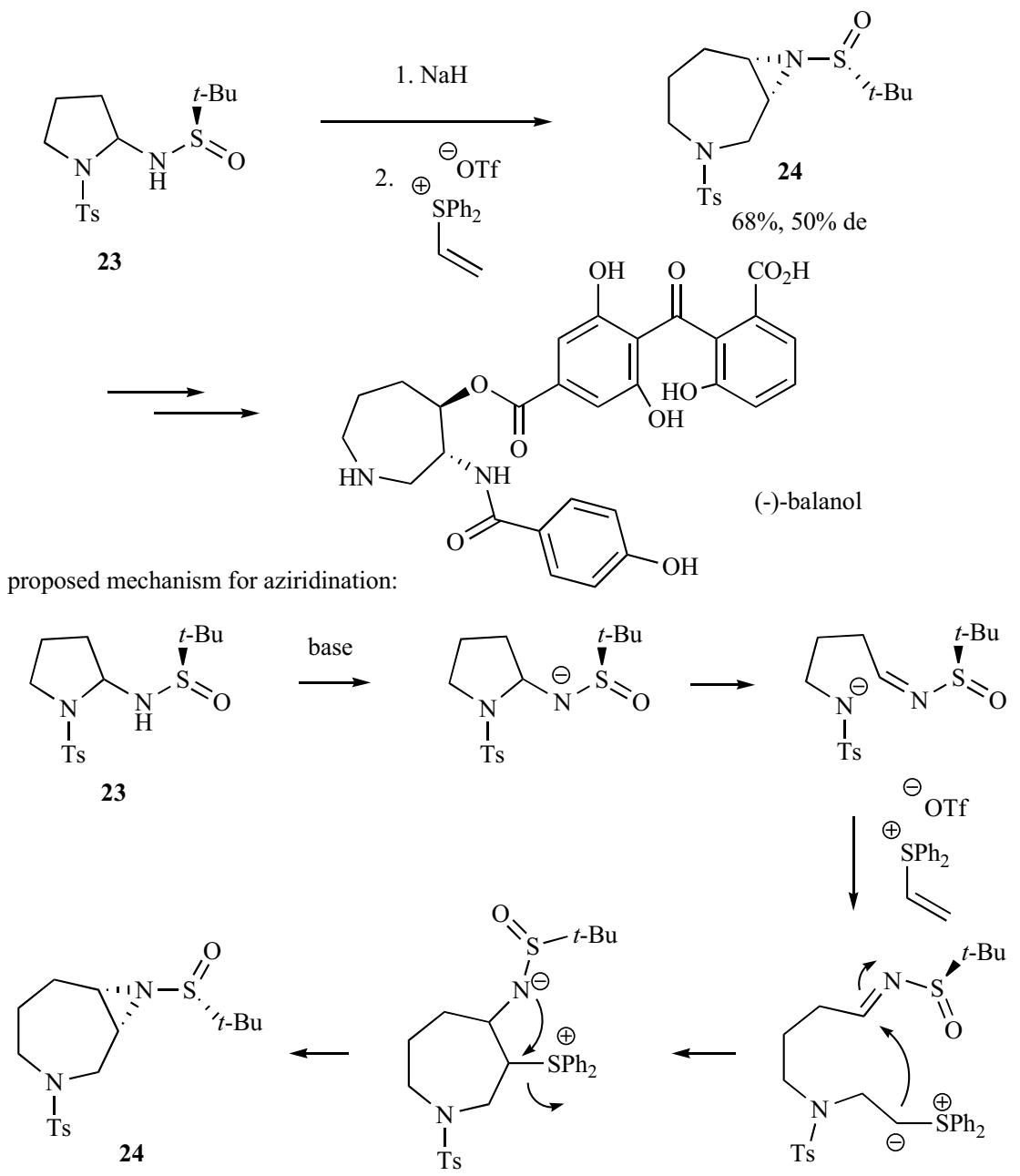

Scheme 10. Synthesis of (-)-balanol.

\section{Ylide-Mediated Aziridinations}

In 2006, Aggarwal et al. developed a total synthesis of the protein kinase $\mathrm{C}$ inhibitor (-)-balanol [21]. The key step of this synthesis was the reaction of diphenyl vinyl sulfonium triflate salt with chiral aminal 23 in the presence of $\mathrm{NaH}$ as the base, which led to the corresponding aziridine $\mathbf{2 4}$ in moderate yield (68\%) and diastereoselectivity (50\% de), as shown in Scheme 10. The mecha- nism of the key step of the synthesis, evolving through ylidemediated aziridination, is depicted in Scheme $\mathbf{1 0}$.

\section{Intramolecular Substitutions}

The asymmetric aziridination based on the use of 1,2-amino alcohols has been applied by several groups for developing total syntheses of various biologically active products. As an example, the 
key step of a formal synthesis of the antitumor antibiotic, (+)FR900482, developed by Paleo et al., was based on the aziridination of chiral 1,2-amino alcohol $\mathbf{2 5}$ derived from L-vinylglycine mediated by benzenesulfonic anhydride in pyridine (Scheme 11) [22]. The formed aziridine $\mathbf{2 6}$ was obtained as the only detected stereoisomer and further converted into a protected precursor of (+)-FR900482.<smiles>CCCN[C@@H](C(=O)O)[C@H](O)CNc1cc(C(C)=O)cc(OC)c1C</smiles>

25<smiles></smiles>

26

$76 \%,>99 \%$ ee<smiles>NC(=O)C[C@H]1c2c(O)cc(C=O)cc2N2C[C@@H]3N[C@H]3[C@]1(O)O2</smiles>

$(+)-F R 900482$
Scheme 11. Formal synthesis of (+)-FR900482.

A total synthesis of 7-Epi (+)-FR900482, exhibiting equal potency as antitumor agent than natural product (+)-FR900482, was later reported by Trost and O'Boyle, involving the asymmetric aziridination of chiral amino diol 27 (Scheme 12), which was selectively silylated and mesylated [23]. The mesylate was then exposed to cesium carbonate, affording the expected aziridine $\mathbf{2 8}$ as the only detected stereoisomer in $77 \%$ yield, which was further transformed into expected 7-Epi (+)-FR900482.

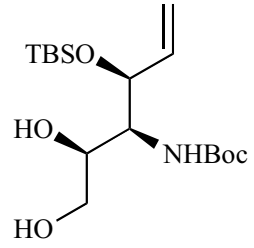

27

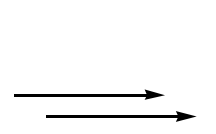

1. $t-\mathrm{BuPh}_{2} \mathrm{SiCl}$

\section{DMAP, TEA} then $\mathrm{MesCl}$

2. $\mathrm{Cs}_{2} \mathrm{CO}_{3}$

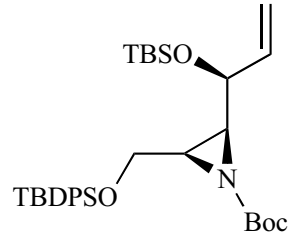

28
$77 \%,>99 \%$ ee<smiles>NC(=O)OC[C@H]1c2c(O)cc(C=O)cc2N2C[C@@H]3N[C@H]3OC12O</smiles>

7-Epi (+)-FR900482

Scheme 12. Synthesis of 7-Epi (+)-FR900482.

In 2003, Terashima et al. developed the synthesis of the C1C17 fragment of the antitumor antibiotic, carzinophilin, that involved as a key step the asymmetric aziridination of chiral pyrrolidin-2-ylidenemalonate 29 derived from $\beta$-D-arabinofuranose [24]. As shown in Scheme 13, the treatment of this pyrrolidin-2ylidenemalonate with KHMDS as base provided the corresponding aziridine 30 as the only detected stereoisomer in $63 \%$ yield. The latter was further converted into the expected $\mathrm{C} 1-\mathrm{C} 17$ fragment of carzinophilin.<smiles>CCCC(C(=O)OCC)=C1N[C@H](COC)[C@H](OCc2ccccc2)[C@@H]1C(=O)OCC</smiles>

29

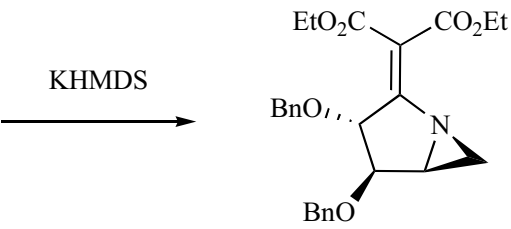

30<smiles>COc1cc(C(=O)O[C@H](C(=O)N/C(C(=O)N/C(=C\O)C(C)=O)=C2/[C@H](O)[C@H](O)[C@H]3CN23)[C@]2(C)CO2)c2cccc(C)c2c1</smiles>

Scheme 13. Synthesis of the C1-C17 fragment of carzinophilin.

Later, Vedejs et al. reported the synthesis of enantiopure aziridinomitosene, the key step of which was the asymmetric aziridination of chiral oxazole 1,2-amino alcohol $\mathbf{3 1}$ derived from $\mathrm{L}$-serine (Scheme 14) [25]. The reaction yielded the corresponding aziridine 32 as the only detected stereoisomer in $65 \%$ yield which was further converted into aziridinomitosenes among which the first C6,C7-unsubstituted one, a DNA alkylating agent depicted in Scheme 14<smiles>C#CCOC[C@@H](Cc1ncco1)N[PH3+]</smiles><smiles>CCOCCOCCOC(N)=O</smiles>

Scheme 14. Synthesis of an aziridinomitosene.

In 2015, Kongkathip et al. reported a novel total synthesis of oseltamivir phosphate (structure of oseltamivir in Scheme 4) which was based on the asymmetric aziridination of chiral 1,2-amino mesylate 33 derived from D-glucose into aziridine $\mathbf{3 4}$ as the only detected stereoisomer, as shown in Scheme 15 [26]. The complete strategy gave rise to oseltamivir phosphate in $7.2 \%$ overall yield.

The last step of an enantioselective synthesis of an aziridinomitosane, reported by Miller et al., was based on the cyclization of chiral tricyclic 1,2-azido alcohol $\mathbf{3 5}$ into aziridine $\mathbf{3 6}$ as the only detected stereoisomer (Scheme 16) [27]. This process was achieved in two steps with resin-bound $\mathrm{PPh}_{3}$, affording the expected enantiopure aziridinomitosane with the trans configuration in moderate yield (Scheme 16). 
<smiles>[R]C([R])(CC(=C)C(=O)OCC)[C@@H](OC)[C@@H](C=C)NC(=O)c1ccccc1</smiles><smiles>CCO[S+](=O)(=O)[O-]</smiles>

33

$\mathrm{R}^{1}=\mathrm{H}, \mathrm{R}^{2}=$ OMes: $88 \%,>99 \%$ ee

$\mathrm{R}^{1}=$ OMes, $\mathrm{R}^{2}=\mathrm{H}: 44 \%,>99 \%$ ee

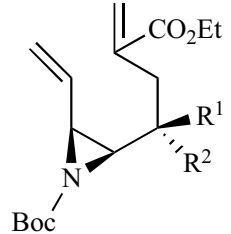

34

\section{$\longrightarrow$ oseltamivir phosphate}

Scheme 15. Synthesis of oseltamivir phosphate.<smiles>CO[C@]12C(=O)c3ccccc3N1C[C@@H](N)[C@H]2O</smiles>

35
1. $\mathrm{MesCl}$, TEA

2. resin-bound $\mathrm{PPh}_{3}$ Hunig's base<smiles>CO[C@]12C(=O)c3ccccc3N1C[C@@H]1N[C@H]12</smiles>

36

$42 \%,>99 \%$ ee

Scheme 16. Synthesis of an aziridinomitosane.<smiles>CC(=O)CC/C=C\C[C@@H](N)[C@H](O)C(C)C</smiles>

resin-bound $\mathrm{PPh}_{3}$

THF<smiles>CC(=O)C/C=C/C[C@H](N=P)[C@@H]([14CH3])O</smiles>

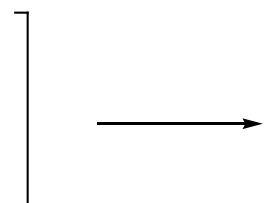<smiles>CCCCCC1N[Pb]2CCCCC1O2</smiles><smiles>[CH2-]C</smiles><smiles>CC(=O)CC/C=C/C[C@@H]1N[C@@H]1CP</smiles>

38

$75 \%,>99 \%$ de

Scheme 17. Synthesis of a fat-derived chiral aziridine.

In the same area, Metzger and Fürmeier reported the first preparation of chiral fat-derived aziridines, with the aim of gaining insight into their biological properties [28]. The same methodology as described in Scheme 16, based on the use of resin-bound $\mathrm{PPh}_{3}$, was applied to the enantiopure azido alcohol $\mathbf{3 7}$ derived from chiral methyl vernolate (Scheme 17). Under these reaction conditions, the corresponding unsaturated cis-aziridine $\mathbf{3 8}$ was isolated in $75 \%$ yield as the only detected stereoisomer, according to the mechanism summarized in Scheme 17. This represented the first enantiomerically pure aziridine based on fats and oils.

In 2010, the cyclization of other chiral 2-azido alcohols was investigated by Coates et al. in the course of synthesizing aziridine analogues of presqualene diphosphates as inhibitors of squalene synthase [29]. As shown in Scheme 18, 2,3-aziridinofarnesol 39 was prepared as the only detected stereoisomer in $83 \%$ yield from the corresponding azido mesylate $\mathbf{4 0}$ by treatment with $\mathrm{LiAlH}_{4}$. The 


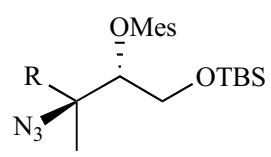

40

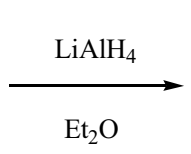<smiles>[R]CCN1[C@H](COP(=O)([O-])OP(=O)([O-])O[Na])[C@@]1([R])C</smiles>

39

$\mathrm{R}=$<smiles>CCCC=C(C)CCC=C(C)C</smiles>
homogeranyl

Scheme 18. Synthesis of a squalene synthase inhibitor.<smiles>CC(C)C(C(=O)O)N(C)c1ccccc1C=O</smiles>

41
1) $\mathrm{NaH} / \mathrm{DMF},-20{ }^{\circ} \mathrm{C}$

2) $\mathrm{SiO}_{2} / \mathrm{CHCl}_{3}$, r.t.

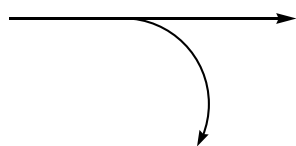<smiles>CN1C(=O)N(C)[C@H](c2ccccc2)[C@@H]1c1ccccc1</smiles><smiles>CC(C)C(C(=O)OCc1ccccc1)N(C)c1ccccc1[C@@H]1[C@@H](C(=O)OCc2ccccc2)N1Cc1ccccc1</smiles>

43<smiles>CC(C)[C@H]1C(=O)N[C@H](CO)Cc2ccccc2N1C</smiles>

(-)-benzolactam-V8

Scheme 19. Synthesis of (-)-benzolactam-V8.

latter was subsequently converted into a diphosphate exhibiting squalene synthase inhibitory activity.

\section{Miscellaneous Aziridinations}

In 2012, Ishikawa et al. reported the synthesis of (-)-benzolactam-V8, an artificially-designed cyclic dipeptide exhibiting strong tumor-promoter activity [30]. The key step of the synthesis consisted in the reaction of chiral guanidinium bromide $\mathbf{4 1}$ with benzyl (S)-N-(2-formylphenyl)- $N$-methylvalinate $\mathbf{4 2}$ to give the corresponding syn-aziridine $\mathbf{4 3}$ in $59 \%$ yield and a moderate diastereoselectivity of $36 \%$ de (Scheme 19). The latter was further converted into the expected (-)-benzolactam-V8 in five supplementary steps.

The total synthesis of (-)-oseltamivir, elaborated by Fukuyama et al. in 2007, included the formation of a bicyclic aziridine $\mathbf{4 4}$ by rearrangement of chiral allyl carbamate 45 [31]. Therefore, treat- ment of this carbamate with NaOEt resulted in ethanolysis of $\mathrm{N}$ Boc lactam, dehydrobromination, and aziridine formation, which provided the desired aziridine $\mathbf{4 4}$ as the only detected stereoisomer in high yield (87\%), as shown in Scheme 20. This aziridine was further converted into the final (-)-oseltamivir (structure in Scheme 4) in four steps.

In 2005, a photocyclization reaction providing chiral aziridines was developed by Mariano et al., starting from chiral pyridinium perchlorate 46 derived from D-glucose [32]. Irradiation of this substrate in aqueous $\mathrm{NaHCO}_{3}$ produced a mixture of isomeric $\mathrm{N}$ glycosyl-bicyclic-aziridines, which could be partially separated by chromatography to yield the major aziridine $\mathbf{4 7}$ (Scheme 21) as the only detected stereoisomer in $15 \%$ yield. This aziridine was subsequently converted into trehazolamine which is the aminocyclitol core of the potent trehalase inhibitor, trehazolin. 


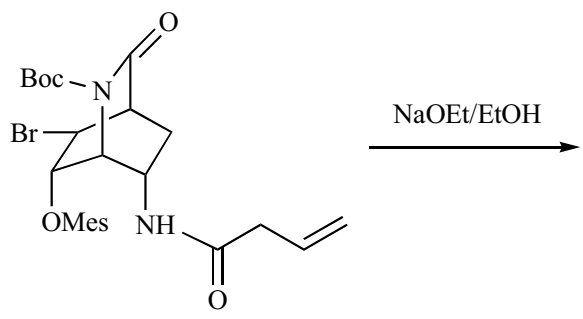

45<smiles>C=CCC(=O)N[C@H]1CC(C(=O)OCC)=CC2C1N2C(=O)c1ccccc1</smiles>

44

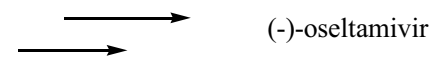

proposed mechanism for the formation of the aziridine intermediate:<smiles>C=CCC(=O)NC1CC2C(=O)N(C(=O)c3ccccc3)C(Br)C1C2OC</smiles>

$\mathrm{NaOEt} / \mathrm{EtOH}$<smiles>C#CCC(=O)NC1CC2(C(=O)OCC)C(Br)C(OC)C1C2(Br)Br</smiles><smiles>C=CCC(=O)N[C@H]1C[C@H](COCC)[C@H](NC(=O)Cc2ccccc2)[C@H](OC)[C@]1(C)Br</smiles>

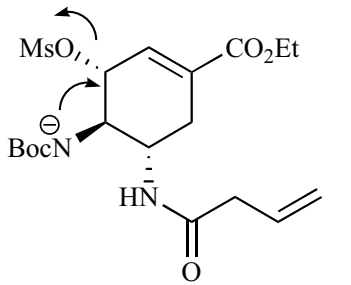<smiles>C=CCC(=O)N[C@H]1CC(C(=O)OCC)=CC2C1N2C(=O)c1ccccc1</smiles>

44

Scheme 20. Synthesis of (-)-oseltamivir.

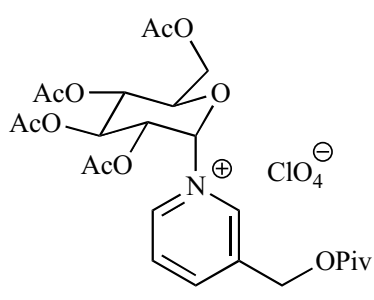

46

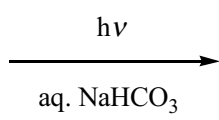

aq. $\mathrm{NaHCO}_{3}$

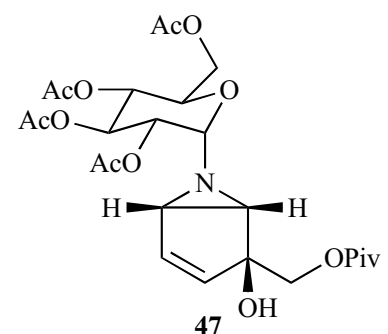

$15 \%,>99 \%$ ee

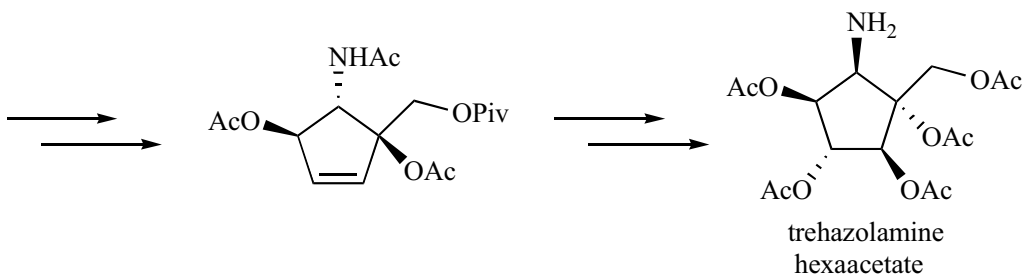

Scheme 21. Synthesis of hexaacetylated trehazolamine. 


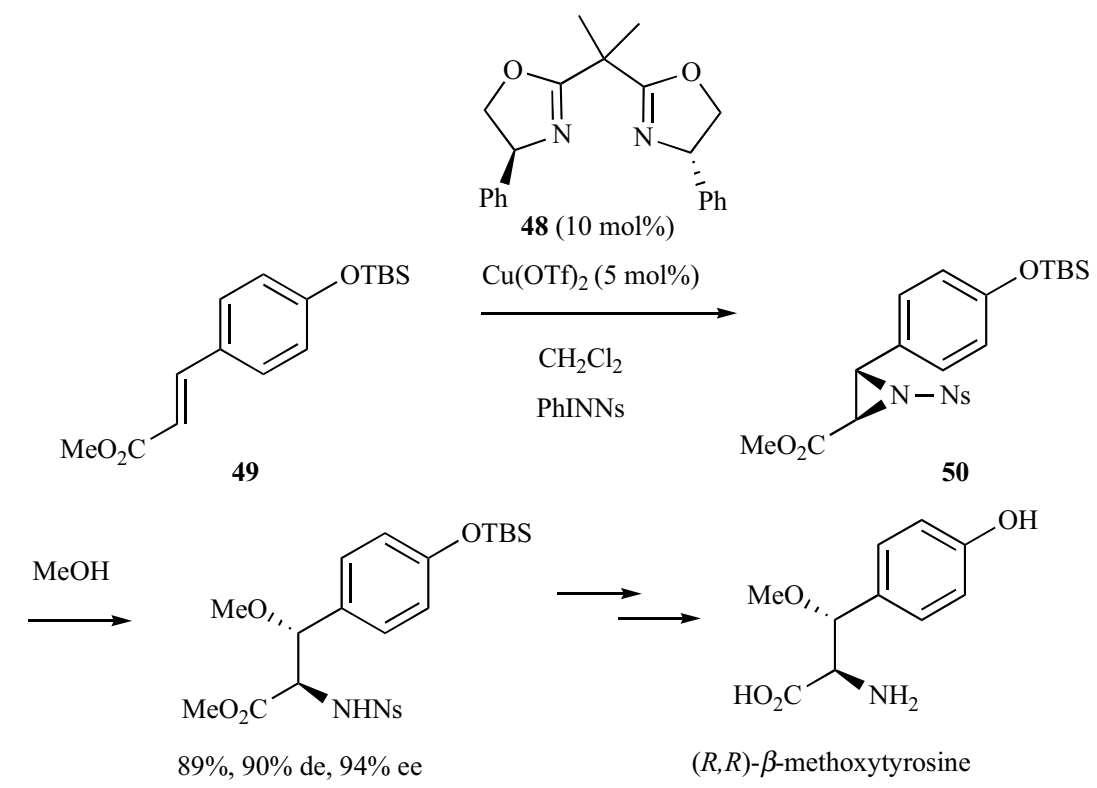

Scheme 22. Synthesis of $(R, R)-\beta$-methoxytyrosine.<smiles>O=C/C=C/c1ccccc1[N+](=O)[O-]</smiles>

51

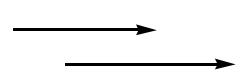

Scheme 23. Synthesis of $(R)$-sumanirole.

\subsubsection{Enantioselective Aziridinations as Key Steps}

\section{Copper-Catalyzed Nitrene Transfer to Alkenes}

In addition to chiral dirhodium catalysts [33], the most commonly employed chiral catalyst systems in enantioselective aziridination via nitrene transfer to alkenes are based on copper complexes of chiral bisoxazolines early reported by Evans et al., in 1991 [34]. In 2007, Cranfill and Lipton reported the use of Evans' bisoxazoline ligand $\mathbf{4 8}$ for the asymmetric aziridination of $\alpha, \beta$ unsaturated ester 49 in the presence of $\mathrm{Cu}(\mathrm{OTf})_{2}$ and $\mathrm{PhINNs}(\mathrm{N}$ ( $p$-nitrophenylsulfonyl)iminophenyliodinane) as the nitrene source [35]. This process allowed the corresponding chiral trans-aziridine 50 to be obtained in $89 \%$ yield, and with $90 \%$ de and $94 \%$ ee, (Scheme 22). This nice reaction constituted the key step of a total synthesis of $(R, R)$ - $\beta$-methoxytyrosine, which is a constituent of several cyclic depsipeptide natural products.

\section{Organocatalyzed Nitrene Transfer to Alkenes}

In 2014, Hamada et al. developed a total synthesis of $(R)$ sumanirole that exhibits selective dopamine D2 receptor agonist activity [36]. The key step of the synthesis was the aziridination of $\alpha, \beta$-unsaturated aldehyde 51 organocatalyzed by chiral diphenyl- prolinol triethylsilyl ether $\mathbf{5 2}$ in the presence of three equivalents of a base, such as $\mathrm{NaOAc}$, allowing the key intermediate aziridine $\mathbf{5 3}$ to be obtained in $94 \%$ yield and $97 \%$ ee (Scheme 23) [37]. The latter was subsequently converted into the desired $(R)$-sumanirole.

\section{Carbene Transfer to Imines Through Carbene Methodology}

Although most of the catalytic methods for synthesizing chiral aziridines proceeded through the transfer of a nitrogen group to an alkene, methods based on the less-studied enantioselective transfer of a carbenoid to an imine have been successfully developed in recent years [38]. For example, the formation of aziridines based on transition metal- or Lewis acid-catalyzed decomposition of diazo compounds in the presence of imines is well established. The synthetic utility of this approach was illustrated by Wulff et al. in the total synthesis of a leukointegrin LFA-1 antagonist, BIRT-377, an agent for the treatment of inflammatory and immune disorders [39]. As shown in Scheme 24, the key step of this synthesis provided chiral cis-aziridine 54, arisen from the reaction of ethyl diazoacetate with $N$-benzhydryl imine 55 in the presence of a combination of $\mathrm{B}(\mathrm{OPh})_{3}$ as Lewis acid and $(S)$-VAPOL as chiral ligand.

In 2011, the highly efficient asymmetric Wulff's aziridination methodology was applied by Chen et al. to develop a total synthesis 

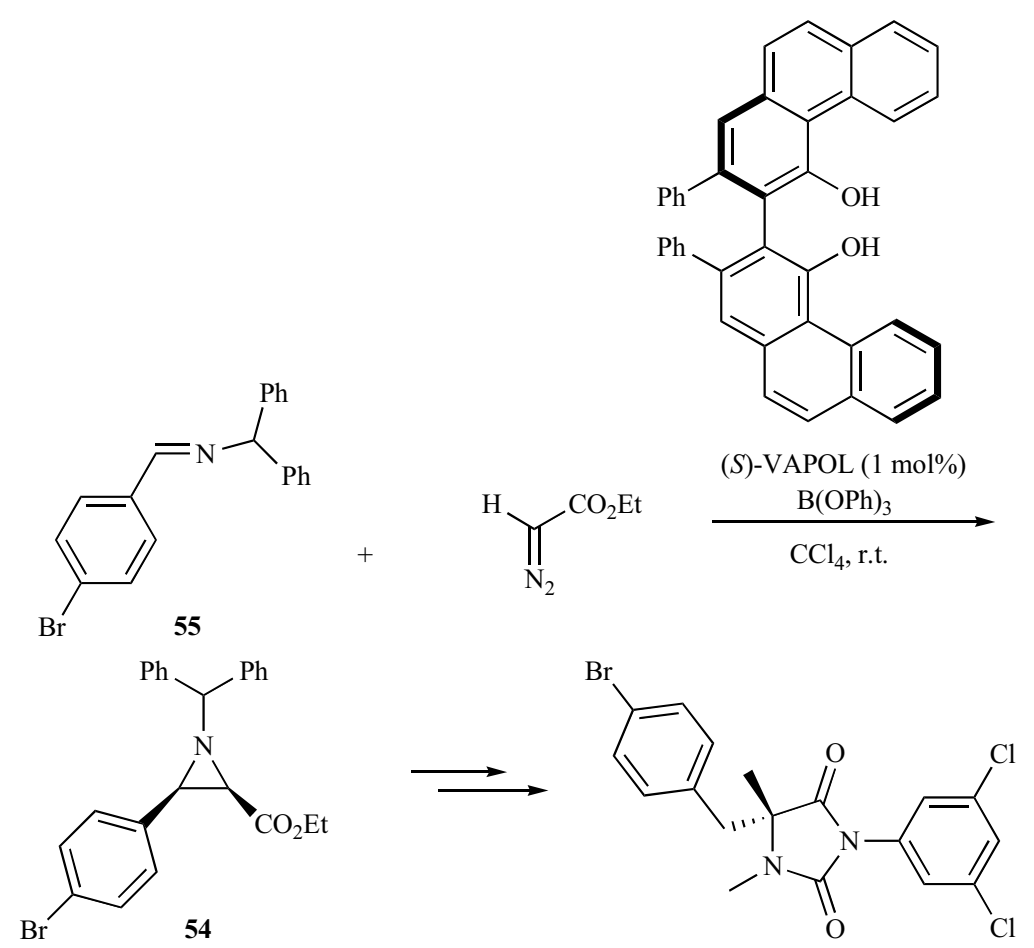

87\%, > 98:2 cis:trans, $94 \%$ ee

BIRT-377

Scheme 24. Synthesis of BIRT-377.<smiles>COc1ccc(/C=N/C(c2ccccc2)c2ccccc2)cc1</smiles>

56<smiles>CCOC(=O)C=[W]</smiles>

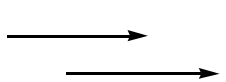<smiles>Oc1cc2ccccc2c(O)c1-c1cc2ccccc2cc1-c1ccccc1</smiles>

$(R)$-VANOL (10 $\mathrm{mol} \%)$ $\mathrm{B}(\mathrm{OPh})_{3}(40 \mathrm{~mol} \%)$<smiles>CO[SH](=O)(O)c1ccc([C@@H](O)[C@H](CF)NC(=O)C(Cl)Cl)cc1</smiles>

Scheme 25. Synthesis of florfenicol.

of antibacterial florfenicol shown in Scheme 25 [40]. In this case, the authors employed (R)-VANOL-boroxinate to aziridinate benzhydryl aldimine 56 with ethyl diazoacetate, providing the key chiral aziridine intermediate $\mathbf{5 7}$ in $93 \%$ yield as a single cisdiastereomer in $85 \%$ ee. The latter was further converted into expected florfenicol in $45 \%$ overall yield from commercially available p-(methylsulfonyl)benzaldehyde.
In 2014, Wulff et al. reported a three-component version of their methodology to the synthesis of all four stereoisomers of sphinganine, an important biologically active sphingolipid involved in cell structure and regulation [41]. As shown in Scheme 26, the syntheses all started from hexadecanal 58, MEDAM amine 59, and ethyl diazoacetate as starting materials. Using either $(R)$-VANOLor $(S)$-VAPOL-boroxinate catalysts, the multicomponent reaction of 
<smiles>CCCC=O</smiles>

58<smiles>CO[C@H](O)[C@@H](N)CO</smiles>

D-threo-sphinganine<smiles>CCOC(=O)C=N</smiles>

D-erythro-sphinganine<smiles>[SeH]/N=C/c1ccoc1</smiles><smiles>[AlH2]N([I-])/N=C/c1ccccc1</smiles><smiles>[AsH2]N1[C@@H](c2ccccc2)[C@H]1c1ccco1</smiles>

64 $98 \%$ ee (trans)

catalytic cycle:<smiles>[R]CC</smiles>
$\oplus \ominus$

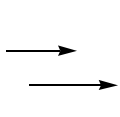<smiles>CC(=O)[C@H](O)[C@H](NC(=O)c1ccccc1)c1ccccc1</smiles>

taxol side chain
$52 \%$, trans: cis $=89: 11$
(R)-VANOL ( $5 \mathrm{~mol} \%$ ) $\mathrm{B}(\mathrm{OPh})_{3}(15 \mathrm{~mol} \%)$

toluene, $-10^{\circ} \mathrm{C}$

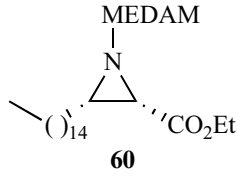

$97 \%, 98 \%$ ee

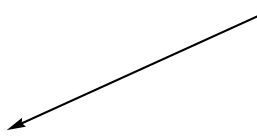<smiles>CO[C@H](O)[C@@H](N)CO</smiles>

L-erythro-sphinganine

$(S)$-VAPOL (5 mol\%) $\mathrm{B}(\mathrm{OPh})_{3}(15 \mathrm{~mol} \%)$

toluene, $-10{ }^{\circ} \mathrm{C}$<smiles>CCOC(=O)[C@@H]1[C@@H](OC)N1[14CH3]</smiles>

$85 \%, 96 \%$ ee

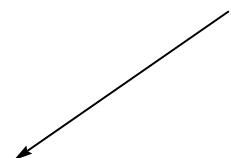

$\overbrace{-}^{O}$

L-threo-sphinganine hydrolysis. Aziridinations

vely. Access to all four stereoisomers of sphinganine was achieved upon ring-opening of the enantiopure aziridine-2-carboxylate at the C-3 position through a direct $\mathrm{S}_{\mathrm{N}} 2$ attack of an oxygen nucleophile, which occurred with inversion of configuration and by ring expansion of an $N$-acyl aziridine to an oxazolidinone followed by

\section{Carbene Transfer to Imines Through Sulfur Ylide-Mediated}

Aggarwal has developed an asymmetric aziridination methodology based on the generation of a carbene from diazo decomposition with $\left[\mathrm{Rh}_{2}(\mathrm{OAc})_{4}\right]$, its association to a chiral sulfide, and subsequent transfer to an imine [42]. This approach was applied in 2003 to build the taxol side chain with a high degree of enantioselectivity via a trans-aziridine [43]. As shown in Scheme 27, the reaction of $\mathrm{N}$-Ses imine $\mathbf{6 1}$ with tosylhydrazone salt $\mathbf{6 2}$ derived from benzaldehyde in the presence of a phase-transfer catalyst (PTC), $\mathrm{Rh}_{2}(\mathrm{OAc})_{4}$, and $20 \mathrm{~mol} \%$ of chiral sulfide $\mathbf{6 3}$ provided the corresponding aziridine 64 in 52\% yield as a 89:11 trans/cis diastereoisomeric ratio. The expected trans-aziridine was obtained with an enantiomeric excess of $98 \%$ ee and was further converted into the desired final taxol side chain. A catalytic cycle was proposed, involving the decomposition of the diazo compound in the presence of the rhodium complex, to yield the metallocarbene. The latter was then transferred to the chiral sulfide, forming a sulfur ylide, which underwent a reaction with the imine to give the expected aziridine, returning the sulfide to the cycle to make it available for further catalysis (Scheme 27).

\subsection{Chiral Azirines}

$2 \mathrm{H}$-Azirines constitute the smallest nitrogen unsaturated heterocyclic system, bearing two carbon atoms and one double bond in a three-membered ring. Their stability can be attributed not only to

hexadecanal with MEDAM amine and ethyl diazoacetate led to almost enantiopure aziridine-2-carboxylates 60 or ent-60, respecti- 


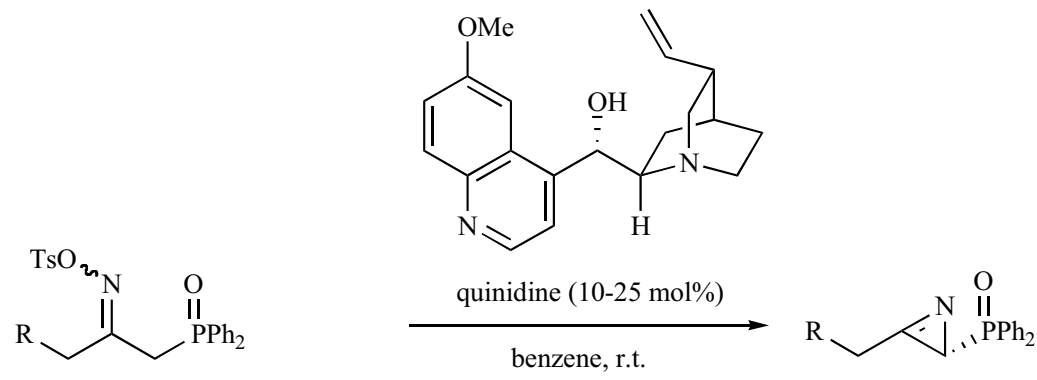

65<smiles>[R6]N=C([R])C[P+](=O)OCC</smiles>

68
$\mathrm{R}=\mathrm{H}, \mathrm{Me}: 95-96 \%, 30-82 \%$ ee

$$
\begin{aligned}
& \text { quinidine }(5-25 \mathrm{~mol} \%) \\
& \mathrm{K}_{2} \mathrm{CO}_{3}(5-10 \mathrm{~mol} \%) \\
& \text { benzene, r.t. }
\end{aligned}
$$

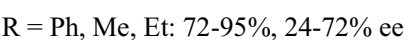

66

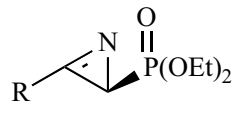

67

Scheme 28. Synthesis of constituants of naturally occurring antibiotics.<smiles>CCCC#CC(CC(C)=O)=NO</smiles>

69

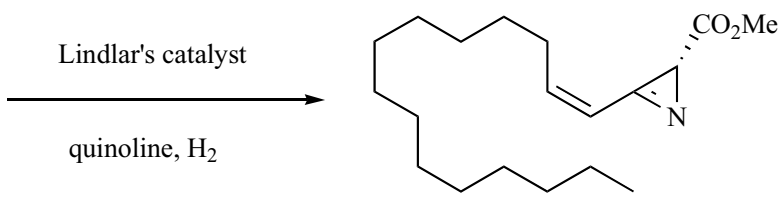

(-)-Z-dysidazirine<smiles>CCC(C#CC(=O)O)C#CC1N[C@@H]1C(C)=O</smiles>

$84 \%, 59 \%$ ee

$52 \%, 59 \%$ ee

Scheme 29. Synthesis of (-)-Z-dysidazirine.

the combined effects of bond shortening and angle compression, but also to the presence of the electron-rich nitrogen atom [44]. The biological applications and the chemistry of these molecules have been widely investigated [8h, 45]. The chemistry of $2 \mathrm{H}$-azirines is related to their ring strain, reactive $\pi$-bond, and ability to undergo regioselective ring cleavage. For example, they can act as nucleophiles as well as electrophiles in organic reactions, but they can also interact as dienophiles and dipolarophiles in cycloaddition reactions. Therefore, they constitute useful precursors for the synthesis of a variety of nitrogen-containing heterocyclic systems. In particular, $2 \mathrm{H}$-azirines containing a carboxylic ester group are constituents of naturally occurring antibiotics. Several synthetic approaches are available to reach $2 \mathrm{H}$-azirines, such as Neber rearrangement of oxime sulfonates, and elimination reaction of $N$-substituted aziridines, such as $N$-sulfinylaziridines or $N$-chloroaziridines. Several asymmetric versions of these methodologies have been recently applied in total synthesis.

\subsubsection{Asymmetric Azirination Through Neber Approaches}

In 2000, an asymmetric Neber reaction was developed by Palacios et al. for the preparation of constituants of naturally occurring antibiotics, such as alkyl- and aryl-substituted $2 \mathrm{H}$-azirines bearing a phosphonate group in the 2-position of the ring [46]. As shown in
Scheme 28, the Neber reaction of $\beta$-phosphorylated tosyloximes $\mathbf{6 5}$ provided the corresponding $2 \mathrm{H}$-azirines $\mathbf{6 6}$ in excellent yields along with low to good enantioselectivities of up to $82 \%$ ee when employing quinidine as organocatalyst. The scope of this methodology was extended to the synthesis of enantioenriched $2 \mathrm{H}$-azirines derived from phosphonates albeit with lower enantioselectivities ranging from 20 to $52 \%$ ee along with high yields (85-95\%) [47]. Later, better enantioselectivities of up to $72 \%$ ee were reported by the same authors in the synthesis of chiral $2 \mathrm{H}$-azirine phosphonates 67 performed with the same catalyst in the presence of $\mathrm{K}_{2} \mathrm{CO}_{3}$ (Scheme 28) [48]. These three-membered heterocycles constitute important building blocks in the preparation of biologically active compounds of interest in medicinal chemistry including naturally occurring antibiotics.

Later, Molinski et al. reported a total synthesis of marine natural and antifungal product (-)-Z-dysidazirine the key step of which was an enantioselective Neber reaction catalyzed by the same organocatalyst quinidine (Scheme 29) [49]. The Neber reaction of tosyloxime 69 derived from pentadecyne led to the corresponding key chiral azirine $\mathbf{7 0}$ in good yield and moderate enantioselectivity $(59 \%$ ee). This product was further converted into expected (-)-Zdysidazirine through partial hydrogenation using Lindlar's catalyst. 

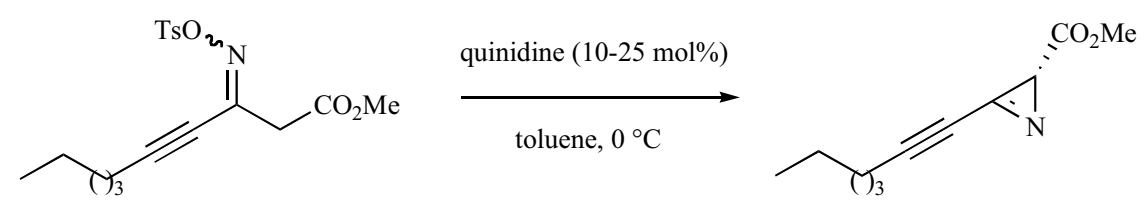

toluene, $0{ }^{\circ} \mathrm{C}$

$91 \%, 61 \%$ ee
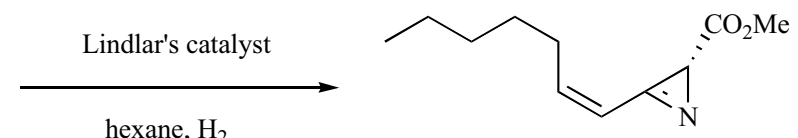

71

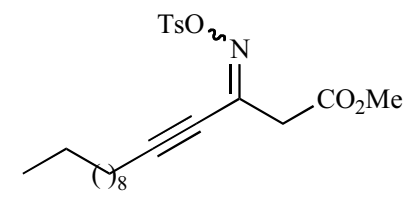

$61 \%, 61 \%$ ee
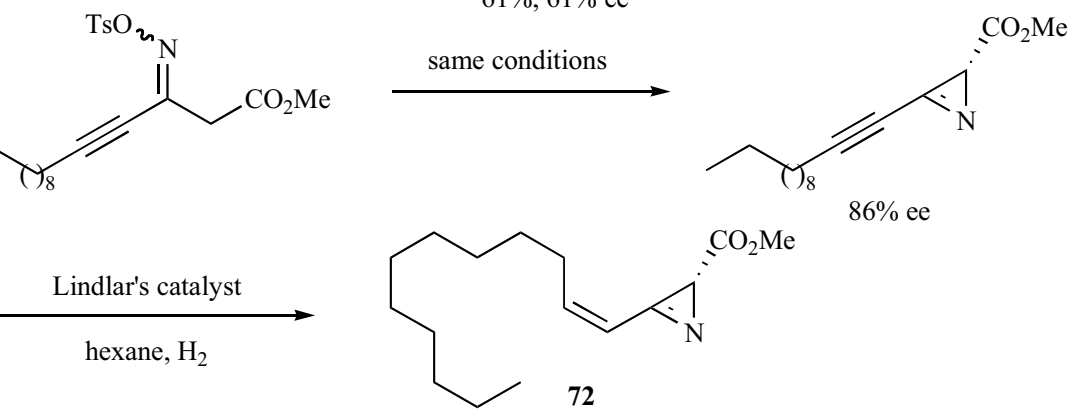

$86 \%$ ee

Scheme 30. Synthesis of shorter chain analogues of (-)-Z-dysidazirine.<smiles>[X]C(=O)CC([R])=NO[Sb]([O-])(O)c1ccccc1[R]</smiles>

73<smiles>N[C@@H]1CCCC[C@H]1NC(=S)N[Al]</smiles>

$$
\begin{gathered}
\mathrm{Ar}=3,5-\left(\mathrm{CF}_{3}\right)_{2} \mathrm{C}_{6} \mathrm{H}_{3} \\
\mathbf{7 4}(5 \mathrm{~mol} \%) \\
\underset{\mathrm{Na}_{2} \mathrm{CO}_{3}(10 \text { equiv })}{\longrightarrow}
\end{gathered}
$$

toluene, r.t.

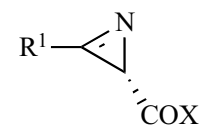

75

$$
\begin{aligned}
& \mathrm{R}^{1}=\mathrm{Me}, \mathrm{Et}, n-\mathrm{Pr}, \mathrm{Bn}, \mathrm{BnCH}_{2}, i-\mathrm{Pr},(E)-\mathrm{PhCH}=\mathrm{CH}, \\
& (E)^{-4}-\mathrm{MeOC}_{6} \mathrm{H}_{4} \mathrm{CH}=\mathrm{CH},(E)^{-4}-\mathrm{FC}_{6} \mathrm{H}_{4} \mathrm{CH}=\mathrm{CH}, \\
& \mathrm{R}^{2}=4-\mathrm{Me}, 4-\mathrm{NO}_{2}, 2-\mathrm{NO}_{2}, 2-\mathrm{Me}, 3,5-\mathrm{Me}_{2}, 3,5-\left(\mathrm{CF}_{3}\right)_{2}, \\
& \mathrm{X}=\mathrm{O} t-\mathrm{Bu}, \mathrm{X}=\mathrm{NPh}_{2}, \mathrm{X}=\mathrm{OBn}, \mathrm{OEt}, \mathrm{OCHPh}_{2} \\
& 64-96 \%, 49-93 \% \text { ee }
\end{aligned}
$$
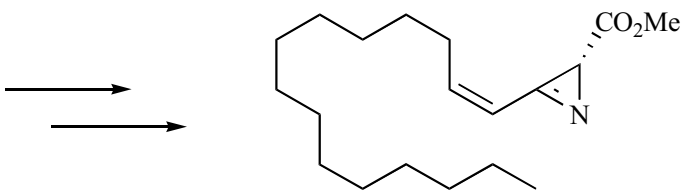

(-)-Z-dysidazirine

Scheme 31. Synthesis of (-)-Z-dysidazirine.

In 2010, the same conditions were applied by these authors to the synthesis of shorter chain analogues 71 and 72 of (-)-Zdysidazirine to be evaluated as antifungal agents [50]. As depicted in Scheme 30, these products were obtained in 61 and $86 \%$ ee, respectively. Their antifungal activity was found comparable to that of (-)-Z-dysidazirine.

The first enantioselective Neber reaction of $\beta$-ketoxime sulfonates $\mathbf{7 3}$ catalyzed by bifunctional thiourea $\mathbf{7 4}$ was reported by Takemoto et al., in 2011 [51]. The reaction was performed in the presence of only $5 \mathrm{~mol} \%$ of catalyst loading and 10 equivalents of $\mathrm{Na}_{2} \mathrm{CO}_{3}$ to provide the corresponding $2 \mathrm{H}$-azirine carboxylic esters 75 in good yields and moderate to high enantioselectivities of up to
93\% ee (Scheme 31). The utility of this novel methodology was demonstrated by an asymmetric synthesis of (-)-Z-dysidazirine.

\section{CHIRAL EPOXIDES AND THIIRANES IN TOTAL SYN- THESIS}

\subsection{Chiral Epoxides}

Epoxides are strained three-membered rings of wide importance as versatile synthetic intermediates in total synthesis of a number of important products. Their strain energy allows an easy ring-opening by reacting with nucleophiles to provide a range of 1,2functionalized products, such as amino alcohols, diols, hydroxy 

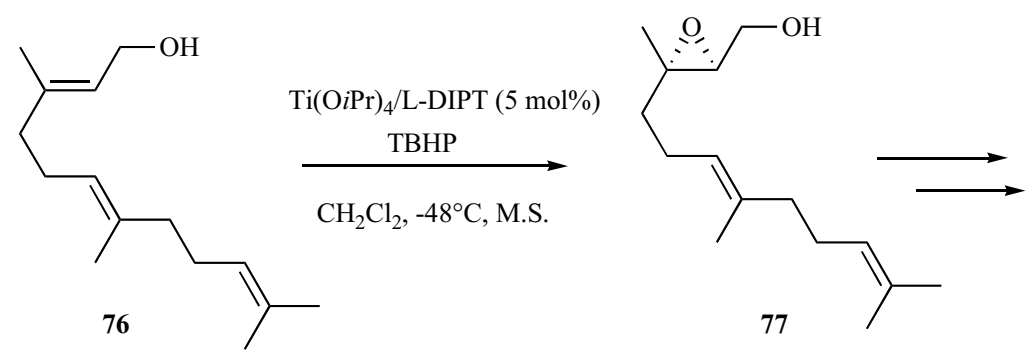

$88 \%, 82 \%$ ee

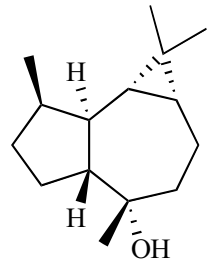

(-)-epiglobulol

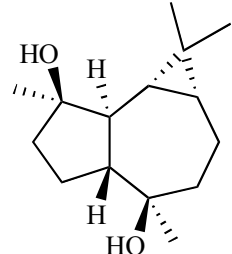

$(-)-4 \alpha, 7 \alpha$-aromadendranediol

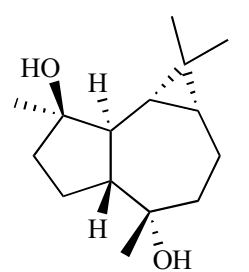

$(-)-4 \beta, 7 \alpha$-aromadendranediol

Scheme 32. Synthesis of natural aromadendrane sesquiterpenes based on Katsuki-Sharpless asymmetric epoxidation.

sulfides, hydrazino alcohols, 1,2-halohydrins, 1,2-cyanohydrins, alcohols and pharmaceuticals [81, 52]. Given the considerable number of asymmetric methodologies accessible to synthesize chiral epoxides, chemists have judiciously applied the combination of asymmetric epoxidation/ring-opening reactions to achieve various total syntheses of natural and biologically active compounds [53]. For example, $\beta$-adrenergic blocking agents used for the treatment of hypertension and angina pectoris, can be easily obtained from ringopening of chiral terminal epoxides including (S)-propranolol [54], and $(R)$-dichloroisoproterenol [55]. Carboxypeptidase A, a zinccontaining proteolytic enzyme of physiological importance, has been found to be irreversibly inactivated, with the highest activity among all the possible stereoisomers, by terminal epoxide $(2 R, 3 S)$ 2-benzyl-3,4-epoxybutanoic acid via $\mathrm{S}_{\mathrm{N}} 2$ type ring-cleavage [56]. Moreover, [3+2] asymmetric cycloaddition reactions of epoxides have also recently emerged as valuable tools to obtain chiral dihydro- or tetrahydrofuran derivatives, important core structures present in natural products [57]. Besides the relevance of chiral epoxides in synthesis, a great number of natural products and bioactive compounds exhibit the epoxide subunit in their structure as exemplified by sex pheromone for gypsy moth (+)-disparlure [58], antibiotic agent monocillin I [59], potent oral hypoglycemic and antiketogenic agent in mammals $(R)$-methyl palmoxirate [60], and anticancer agents ovalicin, fumagillin and ephothilones A and B [61]. The epoxidation of alkenes is undoubtedly the most investigated and convenient approach to obtain epoxides [62]. In the last decade, total syntheses of many important natural and biologically relevant products have been based on asymmetric metal- or organocatalyzed epoxidations of alkenes, kinetic resolution of racemic epoxides, asymmetric sulfur ylide-mediated epoxidations of carbonyl compounds, and asymmetric Darzens reactions as key steps.

\subsubsection{Asymmetric Metal-Catalyzed Epoxidations as Key Steps}

In the last decade, many studies have focused on the development of asymmetric metal-catalyzed procedures for the epoxidation of alkenes [63]. As a recent example, Echavarren et al. have developed a short total synthesis of three natural aromadendrane sesquiterpenes, such as (-)-epiglobulol, (-)- $4 \alpha, 7 \alpha$-aromadendranediol, and $(-)-4 \beta, 7 \alpha$-aromadendranediol, the first step of which was the Katsuki-Sharpless asymmetric epoxidation of (E,E)-farnesol $\mathbf{7 6}$
(Scheme 32) [64]. These products, widespread in plant species, are endowed with a variety of antiviral, antibacterial, antifungal activities [65]. The epoxidation of $\mathbf{7 6}$ was performed in the presence of 5 $\mathrm{mol} \%$ of $\mathrm{Ti}(\mathrm{O} i \mathrm{Pr})_{4} / \mathrm{L}$-DIPT as catalyst system, leading to the corresponding chiral epoxide 77 in $88 \%$ yield and $82 \%$ ee. The latter was further converted into expected (-)-epiglobulol, (-)-4 $4 \alpha, 7 \alpha-$ aromaden-dranediol, and (-)-4 $\beta, 7 \alpha$-aromadendranediol.

Very recently, this methodology was also employed by Muthukrishnan et al. as key step in a simple synthesis of (R)-2-benzylmorpholine, an appetite suppressant agent [66]. As shown in Scheme 33, the Katsuki-Sharpless asymmetric epoxidation of $(E)$ cinnamyl alcohol $\mathbf{7 8}$ led to the corresponding chiral epoxy alcohol 79 in high yield (86\%) and excellent enantioselectivity under standard conditions. The latter was further converted into expected $(R)$ 2-benzylmorpholine in $24 \%$ overall yield (Scheme 33).

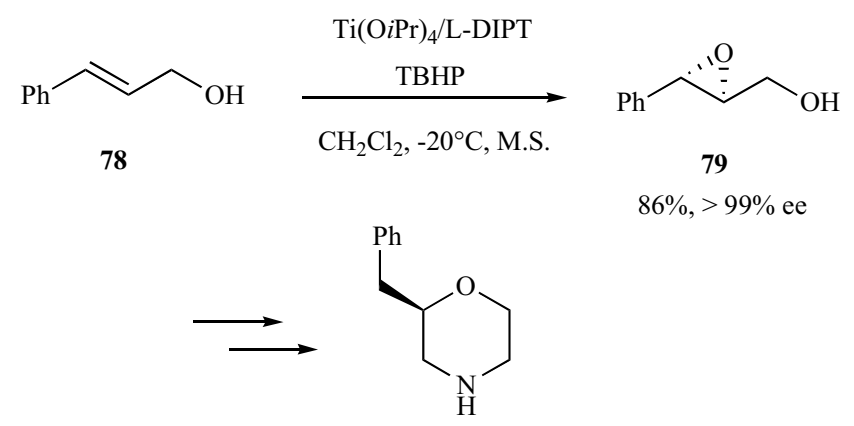

(R)-2-benzyl morpholine

Scheme 33. Synthesis of (R)-2-benzylmorpholine based on KatsukiSharpless asymmetric epoxidation.

The Katsuki-Sharpless asymmetric epoxidation was also applied by Voight et al. to the total synthesis of potent antibiotic GSK966587 (Scheme 34) [67]. The epoxidation of allylic alcohol 80 smoothly proceeded with $10 \mathrm{~mol} \%$ of the same metal complex, in the presence of cumyl hydroperoxide (CHP) to give the key chiral epoxy alcohol $\mathbf{8 1}$ in $81 \%$ yield and $90 \%$ ee. The synthesis afforded the target compound in eight steps and $25 \%$ overall yield.

Zirconium catalysts have been of limited use in the area of asymmetric epoxidation, with a particular focus on homoallylic 
<smiles>C=C(CO)c1c(F)cnc2ccc(OC)nc12</smiles><smiles>O=C1C=CC2N=CC(F)=C3CC1(CN1CCC(NCc4cc5c(cn4)OCCO5)CC1)C32</smiles>

Scheme 34. Synthsesis of GSK966587 based on Katsuki-Sharpless asymmetric epoxidation.

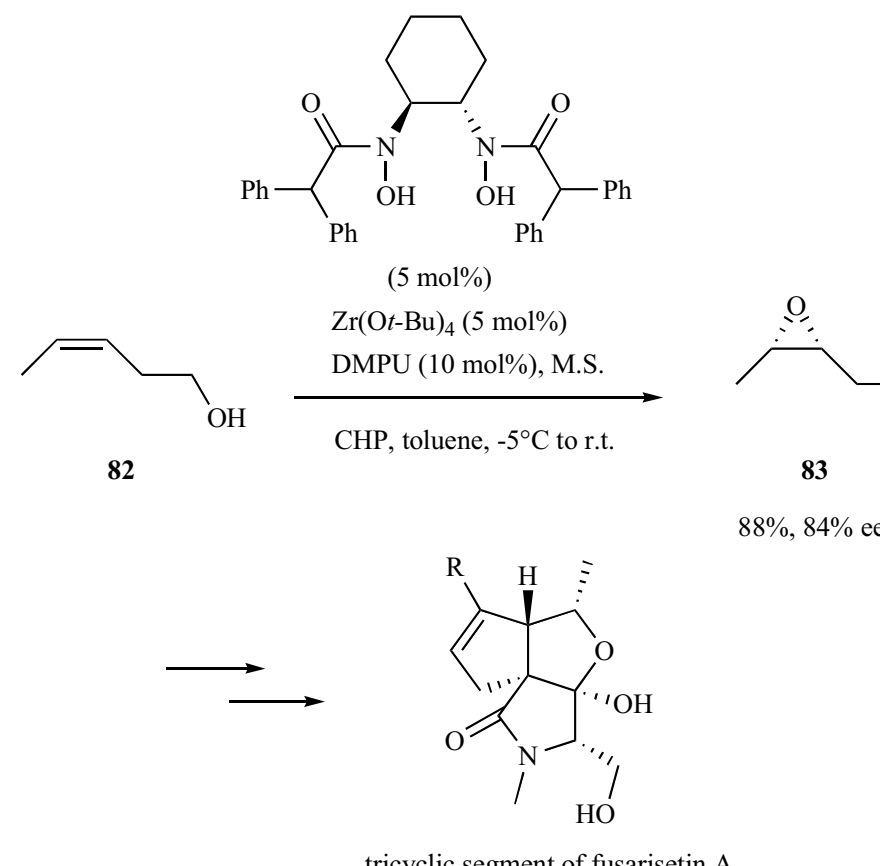

tricyclic segment of fusarisetin A

Scheme 35. Synthesis of the tricyclic polar segment of fusarisetin A through Zr-catalyzed epoxidation of an homoallylic alcohol.

alcohols. As a rare example, an asymmetric $\mathrm{Zr}(\mathrm{O} t \text { - } \mathrm{Bu})_{4} /$ bishydroxamic acid-catalyzed asymmetric epoxidation of an homoallylic alcohol was very recently applied as key step in the synthesis of the tricyclic polar segment of fusarisetin A [68], which is a fungal metabolite with anticancer activity, due to potent inhibition against acinar morphogenesis, cell migration, and cell invasion in MDAMB-231 cells [69]. The synthesis began with the epoxidation of (Z)-pent-3-en-1-ol 82, which yielded the corresponding key chiral epoxyalcohol 83 in $88 \%$ yield with $84 \%$ ee (Scheme 35 ).

Chiral vanadium complexes have also been applied to catalyze asymmetric epoxidation. An example of the synthetic utility of this methodology was demonstrated in the synthesis of the fragrance abisabolol reported by Yamamoto et al., in 2003 [70]. The key step to install the second stereocenter of the molecule was based on asymmetric epoxidation of the $(S)$-limonene-derived homoallylic alcohol 84 using the vanadium/ligand $85 / \mathrm{CHP}$ catalytic system. The required epoxide intermediate $\mathbf{8 6}$ was isolated in good yield and
90\% de (Scheme 36). More recently, an enantioselective synthesis of florfenicol, a fluorinated derivative of thiamphenicol albeit exhibiting superior antibacterial spectrum, was developed by Chen et al. [71]. The product was obtained in $37 \%$ overall yield from commercially available 4-methylthiobenzaldehyde. The key epoxidation step was performed on the trans-cinnamyl alcohol derivative 87 in the presence of $5 \mathrm{~mol} \%$ of the Yamamoto vanadium complex 88 and TBHP to give the key epoxide $\mathbf{8 9}$ in $75 \%$ yield and $>90 \%$ ee (Scheme 36). This chiral epoxide was further converted into the antibacterial agent florfenicol (structure in Scheme 25).

In 1990, a pivotal discovery was illustrated by the groups of Jacobsen [72] and Katsuki [73], who independently reported the asymmetric epoxidation of a variety of unfunctionalized alkenes with optically pure $\mathrm{Mn}(\mathrm{III}) /$ salen complexes using readily available $\mathrm{PhIO}$, bleach, $\mathrm{H}_{2} \mathrm{O}_{2}$, oxone as the terminal oxidants, providing good levels of enantioselectivity [74]. Soon after their discovery, enantioselective epoxidations catalyzed by Jacobsen-Katsuki complexes 


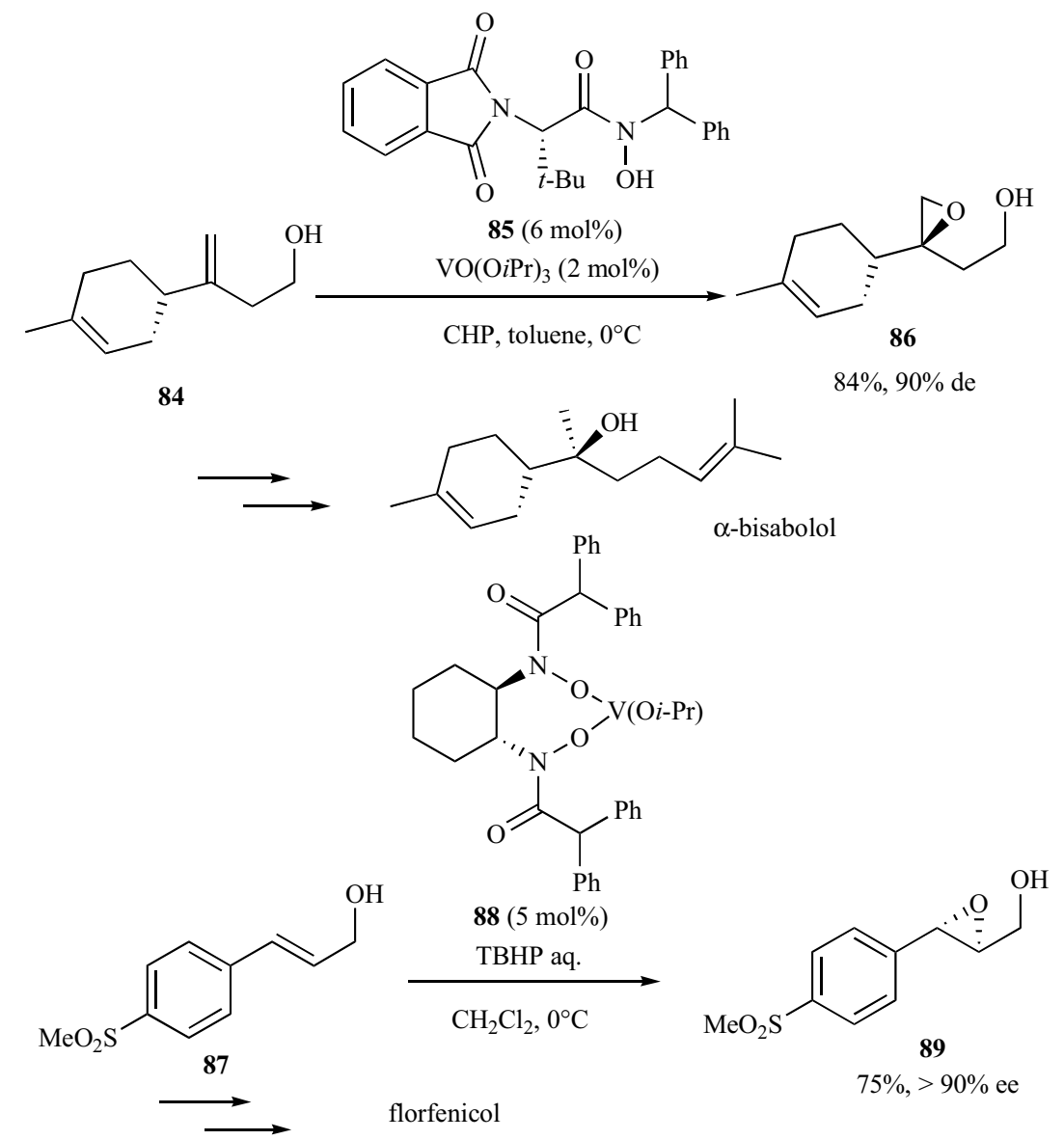

Scheme 36. Syntheses of $\alpha$-bisabolol and florfenicol through V-catalyzed epoxidations.

were employed as key steps in the synthesis of biologically active products, such as anti-HIV compound indinavir $\left(\operatorname{crixivan}^{\mathbb{B}}\right)$ [75], and Iks-channel blockers (Scheme 37) [76].

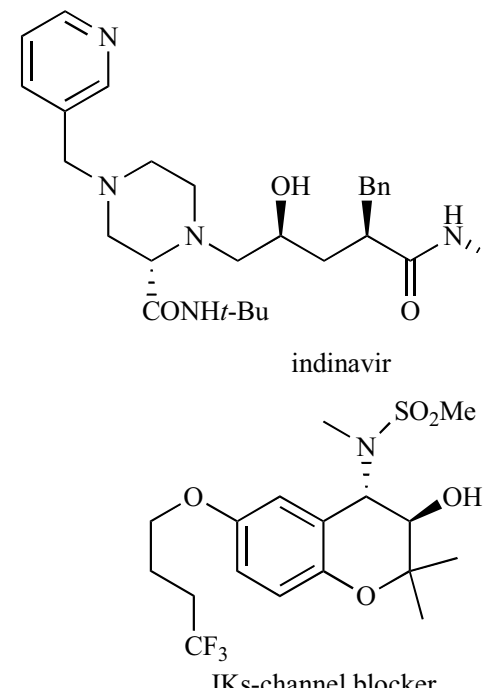

Scheme 37. Biologically active products synthesized through Jacobsen/Katsuki epoxidations.

In more than a decade, Fuchs et al. applied and optimized this methodology for the asymmetric epoxidation of cyclic dienyl sulfones and triflates to the corresponding chiral monoepoxides [77]. These compounds proved to be very useful intermediates to access

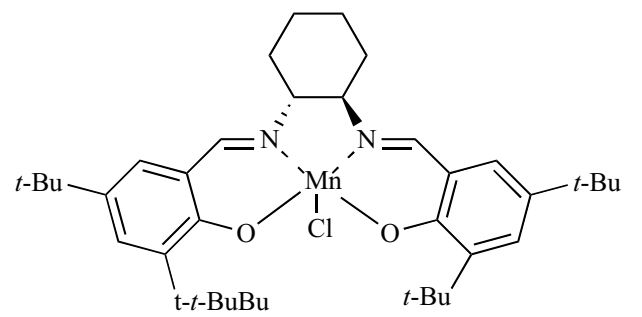<smiles>CCOC1=CCCC=C1</smiles>

91

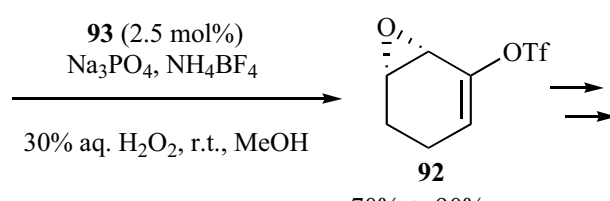

$70 \%,>90 \%$ ee

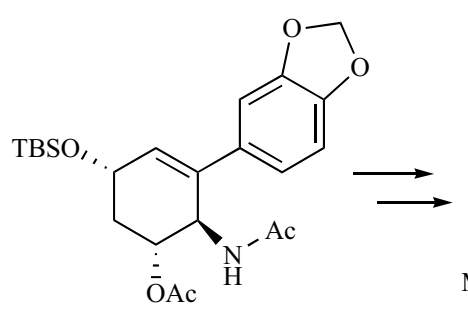

90

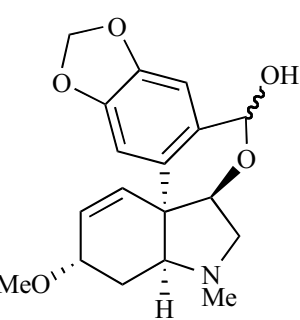

(+)-pretazettine
Scheme 38. Synthesis of (+)-pretazettine through Jacobsen/Katsuki epoxidation.

a variety of natural products such as $(+)$-pretazettine alkaloid core 90. As shown in Scheme 38, the epoxidation of dienyl triflate 91 


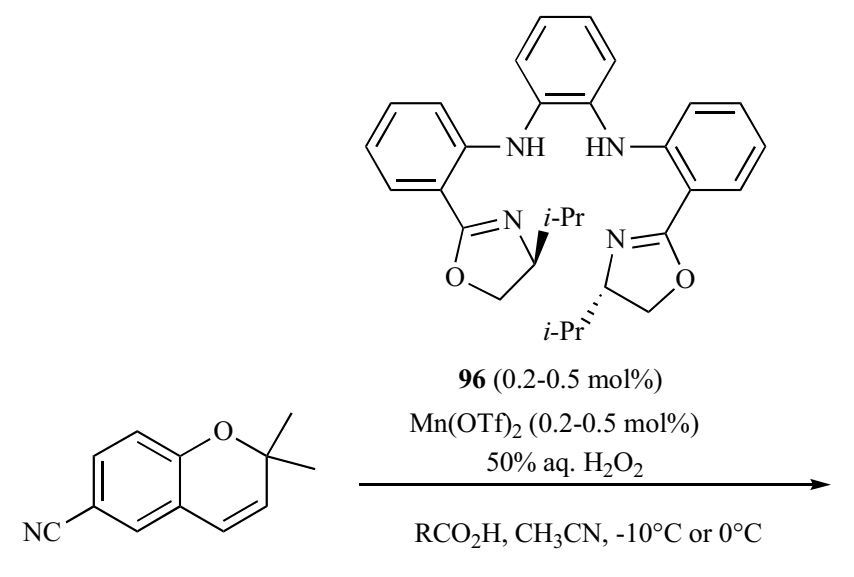<smiles>CC1(C)Oc2ccc(C#N)cc2C2OC21</smiles>

95

$92 \%, 94 \%$ ee

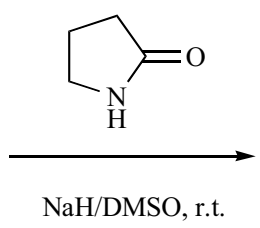

$\mathrm{NaH} / \mathrm{DMSO}$, r.t.<smiles>CC1(C)Oc2ccc(C#N)cc2[C@@H](N2CCCC2=O)[C@@H]1O</smiles>

$61 \%, 97 \%$ ee

Scheme 39. Synthesis of levcromakalim.

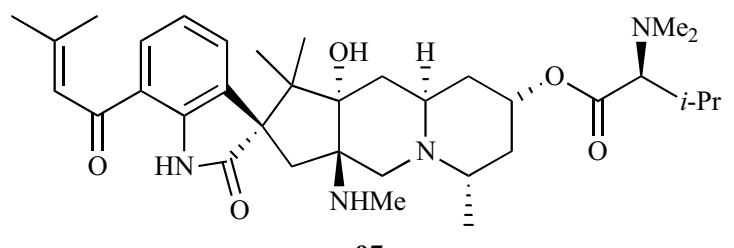

97<smiles>C[C@@H]([C@@H](O)c1ccccc1)N(C)C</smiles>

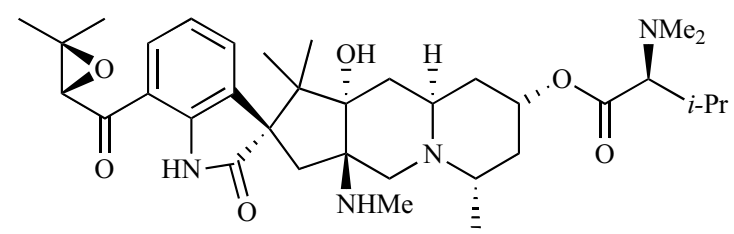

citrinadrin A

$81 \%, 66 \%$ de

Scheme 40. Synthesis of citrinadrin A.

led to the key intermediate epoxide 92 in $70 \%$ yield and high enantioselectivity of $>90 \%$ ee by using catalyst 93 and $\mathrm{H}_{2} \mathrm{O}_{2}$ as oxidant. Epoxide 92 was further converted into $(+)$-pretazettine.

In 2013, Gao et al. reported the total synthesis of potassium channel activator levcromakalim the key step of which was the enantioselective Mn-catalyzed epoxidation of alkene 94 into functionalized epoxide 95 performed in the presence of porphyrininspired ligand 96 bearing chiral oxazoline groups as ligand with 92\% yield and 94\% ee (Scheme 39) [78].

Up to date, a few examples have been reported on stereoselective epoxidations mediated by chiral zinc complexes. In 2014, Martin et al. reported the epoxidation of trans- $\alpha, \beta$-unsaturated ketone 97 mediated by overstoichiometric amounts of a complex generated from $\mathrm{Et}_{2} \mathrm{Zn}$ and $(1 R, 2 R)-N$-methylpseudoephedrine 98 in the presence of molecular oxygen as a benign oxidant. This reaction constituted the final step in the total synthesis of citrinadrin A, an alkaloid isolated from marine-derived fungus Penicillium citrinum (Scheme 40) [79]. Indeed, the asymmetric epoxidation of enone 97 under these conditions led to citrinadrin A in $81 \%$ yield and moderate diastereoselectivity ( $66 \% \mathrm{de})$.

In 2005, Shibasaki et al. developed a catalytic system generated in the presence of molecular sieves from $\mathrm{Y}(\mathrm{O} i-\mathrm{Pr})_{3},(\mathrm{Ph})_{3} \mathrm{As}=\mathrm{O}$ as additive, and ligand 99 in 1:1:1 ratio, suitable for the asymmetric epoxidation of $\beta$-aromatic and aliphatic $\alpha, \beta$-unsaturated esters $\mathbf{1 0 0}$ into epoxides 101 with up to $99 \%$ ee (Scheme 41) [80] Shibasaki's systems based on similar chiral-lanthanide catalysts and applied to 
<smiles>[R]C=CC(=O)OCC</smiles>

100<smiles>OCCOCCOc1cccc(O)c1-c1c(O)cccc1O</smiles>

99 (2-10 mol\%)

$\mathrm{Y}(\mathrm{O} i-\mathrm{Pr})_{3}(2-10 \mathrm{~mol} \%)$

$\mathrm{Ph}_{3} \mathrm{As}=\mathrm{O}(2-10 \mathrm{~mol} \%)$

TBHP, M.S., THF, r.t.<smiles>CC(C)=CC(=O)O[C@H]1Cc2cc3ccc(=O)oc3cc2OC1(C)C</smiles>

(+)-decursin<smiles>O=C1C=CC[C@H](/C=C/C[C@H](O)C[C@@H](O)CCc2ccccc2)O1</smiles>

(+)-strictifolione<smiles></smiles>

101

$74-94 \%, 86-99 \%$ ee

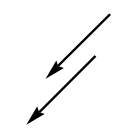<smiles>CC(C)(O)[C@@H]1Cc2cc3ccc(=O)oc3cc2O1</smiles>

(-)-marmesin<smiles></smiles>

fluoxetin

Scheme 41. Syntheses of biologically active products through Shibasaki's epoxidation.

$\alpha, \beta$-unsaturated amines [81] and imidazolides [82] have been successfully employed in key epoxidation steps of total syntheses of various biologically active products, such as anticancer agent $(+)-$ decursin [83], antifeedant (-)-marmesin [84], antifungal agent (+)strictifolione [85], and antidepressant drug fluoxetin [86] (Scheme 41).

\subsubsection{Asymmetric Organocatalyzed Epoxidations as Key Steps}

Asymmetric organocatalysis has increasingly become one of the most useful and practical tool to perform a synthetic transformation [87]. In particular, the organocatalyzed asymmetric epoxidation of olefins is an important part of this field, and a number of these processes have been successfully applied to the total synthesis of various important molecules in the last 15 years. Actually, this topic was reviewed in 2014 by Shi et al. [88], consequently only some representative examples will be detailed in this Section. The readers are invited to consult this comprehensive coverage for a complete coverage of the field. Asymmetric phase transfer catalysis (PTC) includes valuable methodologies for building carbon-carbon and carbon-heteroatom bonds [89]. The mildness and often environmentally friendly reaction conditions of asymmetric PTC reactions cope well for large-scale and industrial applications [90]. In 2006, an interesting application of the cinchona alkaloid-derived PTCcatalyzed diastereo- and enantioselective epoxidation to access potent naturally-occurring cysteine protease inhibitor, the epoxysuccinyl peptide E-64c, was reported by Lygo et al. [91]. The key epoxidation of $\alpha, \beta$-unsaturated amide $\mathbf{1 0 2}$ into the corresponding functionalized epoxide $\mathbf{1 0 3}$ occurred with $70 \%$ yield and moderate diastereoselectivity of $66 \%$ de when catalyzed with cinchona alkaloid salt 104, as shown in Scheme 42.

The most efficient class of oxidants to perform the epoxidation of alkenes are dioxiranes [92]. In contrast to similar oxidizing agents, such as percarboxylic acids, the development of chiral dioxiranes for asymmetric epoxidations has met great success over the last decades [8, 93]. In late 1990s, Shi and co-workers introduced a variety of pseudo $\mathrm{C}_{2}$-symmetric six-membered carbocyclic ketones derived from quinic acid as stoichiometric precursors of in situ generated chiral dioxiranes to be used in asymmetric epoxidation of trans-disubstituted, trisubstitued, terminal alkenes, and electronpoor alkenes. Oxone was used in DME under basic buffered conditions at $0{ }^{\circ} \mathrm{C}$ in the presence of only $5-10 \mathrm{~mol} \%$ of the chiral ketone [94]. More recently, a comparable methodology was applied by Chandrasekhar and Kumar to the total synthesis of pladienolide B, a natural anticancer macrolide [95]. The key step of the synthesis was the epoxidation of homoallylic alcohol 105 performed in the presence of superstoichiometric amounts of ketone $\mathbf{1 0 6}$ and oxone to give epoxide 107 in $64 \%$ yield and $95 \%$ de (Scheme $\mathbf{4 3}$ ). 


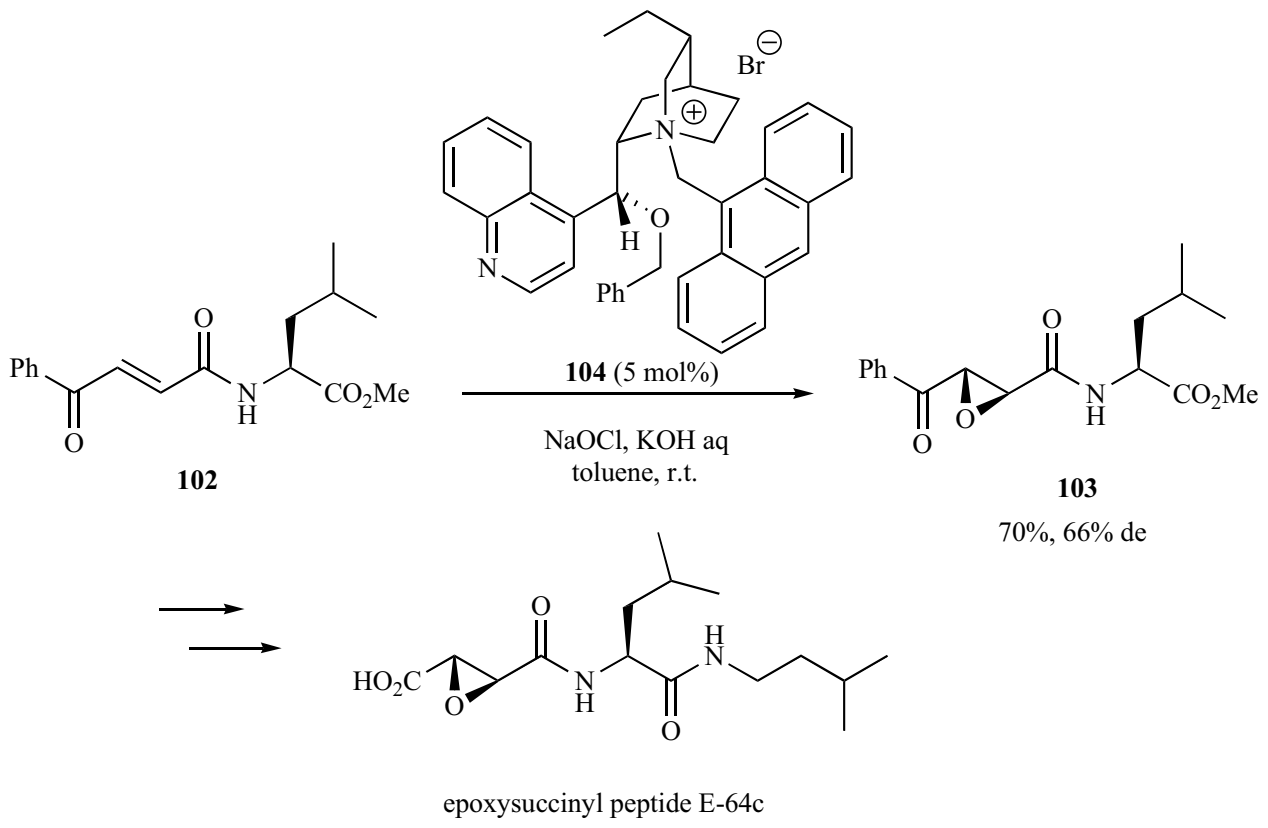

Scheme 42. Synthesis of cysteine protease inhibitor peptide E-64c through PTC-catalyzed epoxidation.

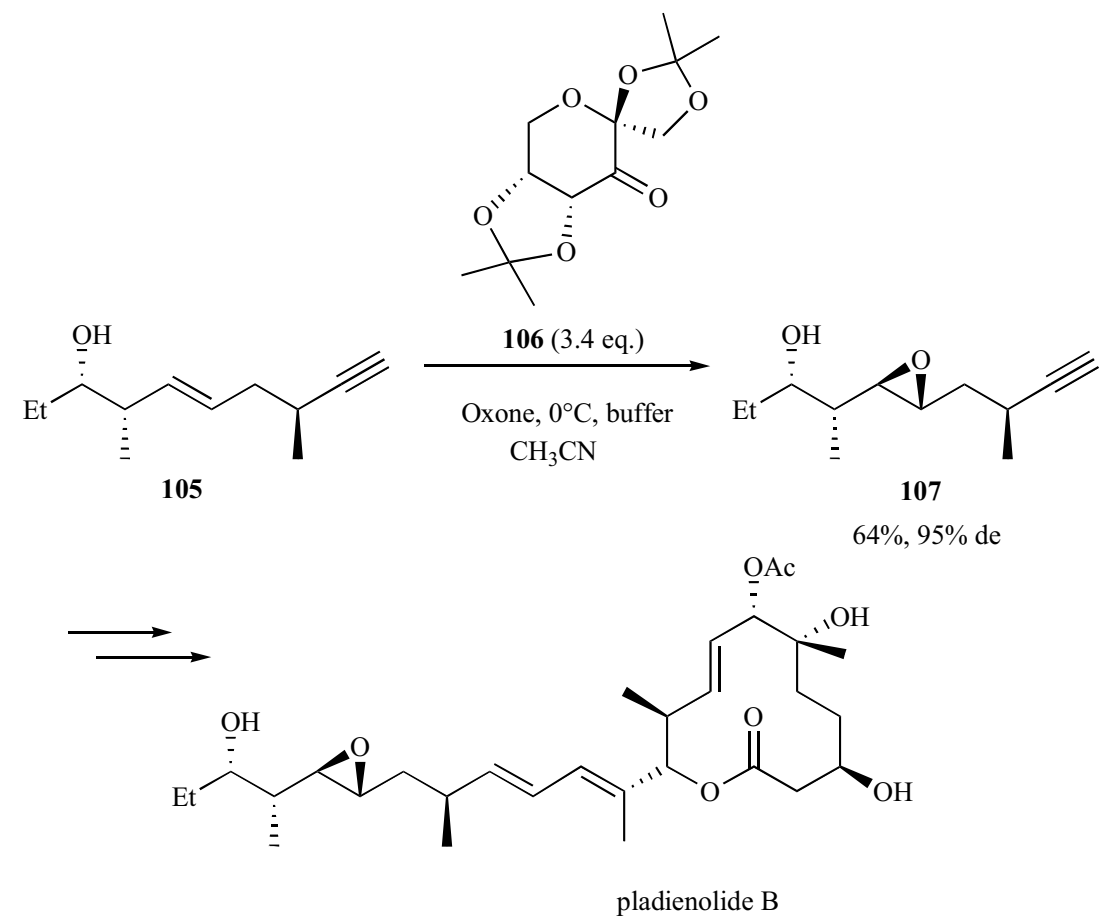

Scheme 43. Synthesis of pladienolide B through Shi's epoxidation.

In 2012, a simple total synthesis of (+)-ambrisentan, a drug clinically used for the treatment of pulmonary arterial hypertension, was reported by Shi et al. [96]. It began with the asymmetric epoxidation of ethyl 3,3-diphenylacrylate 108 (Scheme 44). This electron-poor alkene was epoxidized with the most effective ketone 109 to provide the corresponding chiral epoxide $\mathbf{1 1 0}$ in $90 \%$ yield and $85 \%$ ee. The reaction crude was then directly subjected to other steps to finally afford $(+)$-ambrisentan in $53 \%$ overall yield and $>99 \%$ ee.

Biomimetic synthesis based on intramolecular cascade ringopening reaction of chiral epoxides has been also reported by McDonald et al. (Scheme 45) [97]. With the aim of developing a synthetic route to abudinols $\mathrm{A}$ and $\mathrm{B}$, oxygenated triterpenoid marine natural products, triene $\mathbf{1 1 1}$ was selectively epoxidized at two of its three carbon-carbon double bonds to give diepoxide $\mathbf{1 1 2}$ in good yield $(76 \%)$ and high diastereoselectivity of $>90 \%$ de when using ketone $\mathbf{1 0 6}$ as the organocatalyst. The allylic electronwithdrawing group proximal to the other carbon-carbon double bond prevented its epoxidation. ent-Nakorone, an oxidative degradation product of abudinols, was then obtained via TMSOTfpromoted cyclization with the propargylsilane nucleophile, followed by ozonolysis.

Conceptually similar chiral iminium salts/oxaziridinium salts systems have been introduced as epoxidizing systems since the late 


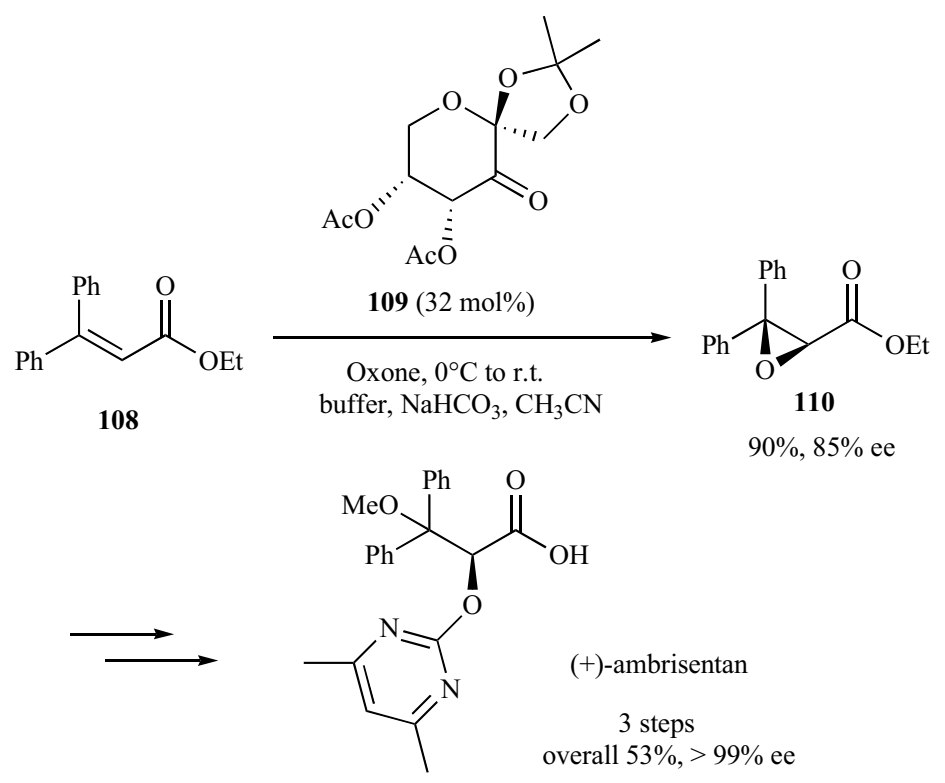

Scheme 44. Synthesis of (+)-ambrisentan through Shi’s epoxidation.
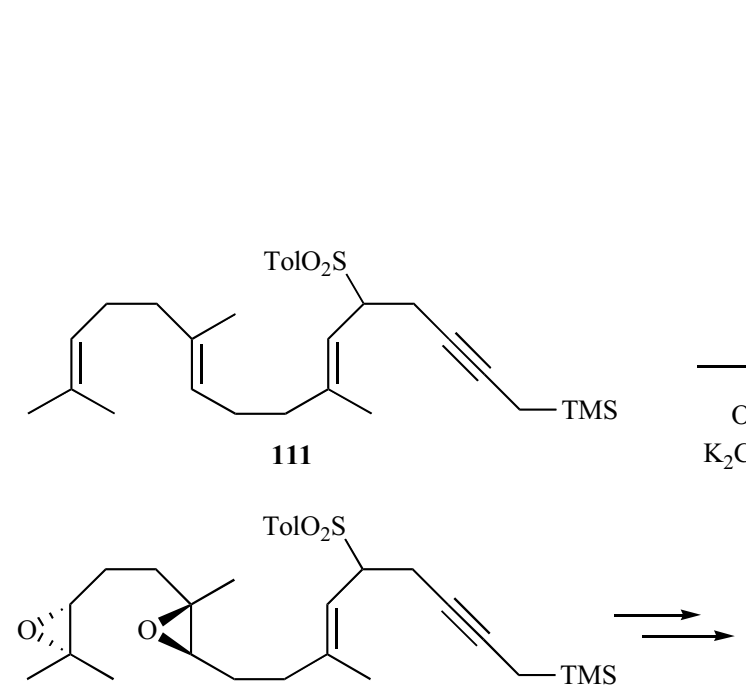

112

$76 \%,>90 \%$ de

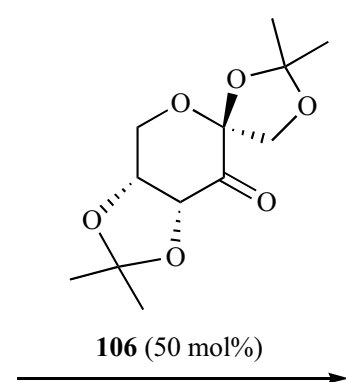

Oxone, $0^{\circ} \mathrm{C}$, buffer

$\mathrm{K}_{2} \mathrm{CO}_{3}, \mathrm{CH}_{3} \mathrm{CN} / \mathrm{DMM} / \mathrm{H}_{2} \mathrm{O}$

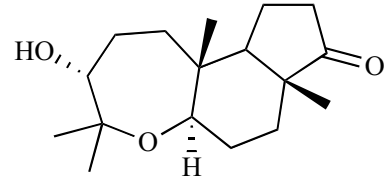

ent-nakorone

Scheme 45. Synthesis of ent-nakorone through Shi's epoxidation.

1980s [98]. A tetraphenylphosphonium monoperoxybisulfate (TPPP) [99] was employed as oxidant in combination with organocatalyst 113 in the asymmetric epoxidation of some $Z$-alkenes to the corresponding epoxides, which were isolated in good yields and good to high enantioselectivities of up to $97 \%$ ee (Scheme 46) [100]. In particular, the epoxidation of a benzopyran substrate into tricyclic epoxide 114 occurred with the highest efficiency, and was applied to synthesize the antihypertensive agent (-)-cromakalim with high stereoselectivity via ring-opening of the epoxide unit with pyrrolidone, as shown in Scheme 46. In addition, organocatalyst 113 was used in the key epoxidation step for a concise asymmetric synthesis of natural coumarin derivatives (-)-lomatin, and (+)-transkhellactone [101].

Page and co-authors reported the application of another chiral iminium salt-catalyzed epoxidation as key step in the first highly enantioselective synthesis of $(+)$-scuteflorin A, one of the numerous and pharmacological active compounds recently isolated from Scutellaria species (Scheme 47) [102]. A previously reported chiral iminium salt 115 [103] served as organocatalyst under non aqueous conditions, to epoxidize the starting $Z$-alkene 116 into the corresponding key enantiopure epoxide 117 in 97\% yield. Epoxide hydrolysis/oxidation and esterification completed the synthesis.

The combination of diaryl prolinol 118 as organocatalyst with an alkyl hydroperoxide, such as TBHP, as oxidant in asymmetric epoxidation system was investigated by Zhao et al., developing the first asymmetric epoxidation reactions of a variety of transdisubstituted electron-poor alkenes, such as 119, into the corresponding chiral epoxides, such as 120, in good yields, complete diastereocontrol, and good enantioselectivities [104]. As an application, the authors developed a short synthesis of natural products (-)$(5 R, 6 S)$-norbalasubramide and $(-)-(5 R, 6 S)$-balasubramide which is depicted in Scheme 48. 
<smiles></smiles><smiles>CC1(C)Oc2ccc(C#N)cc2[C@H](O)C1=O</smiles>

114 $59 \%, 97 \%$ ee
$76-85 \%, 61-93 \%$ ee<smiles>CC1(C)Oc2ccc(C#N)cc2[C@@H](N2CCCC2=O)[C@H]1O</smiles>

(-)-cromakalim $52 \%$<smiles>O=C(/C=C/c1ccccc1)C(Cl)(Cl)Cl</smiles>

119

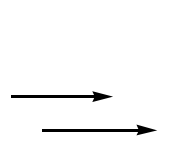<smiles>Cc1cc(C)cc(C(O)(c2cc(C)cc(C)c2)C2CCCN2)c1</smiles>

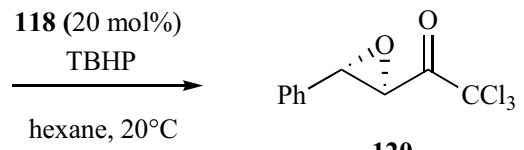

120

$77 \%, 86 \%$ ee

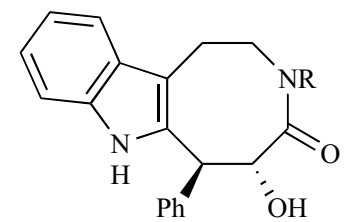

$\mathrm{R}=\mathrm{H}:(5 R, 6 S)$-norbalasubramide, $50 \%, 96 \%$ ee $\mathrm{R}=$ Me: $(5 R, 6 S)$-balasubramide, $76 \%, 86 \%$ ee

Scheme 48. Synthesis of $(5 R, 6 S)$-norbalasubramide and $(5 R, 6 S)$ balasubramide through epoxidation with L-prolinol/TBHP system.

Scheme 46. Synthesis of (-)-cromakalim through chiral iminium saltcatalyzed epoxidation.

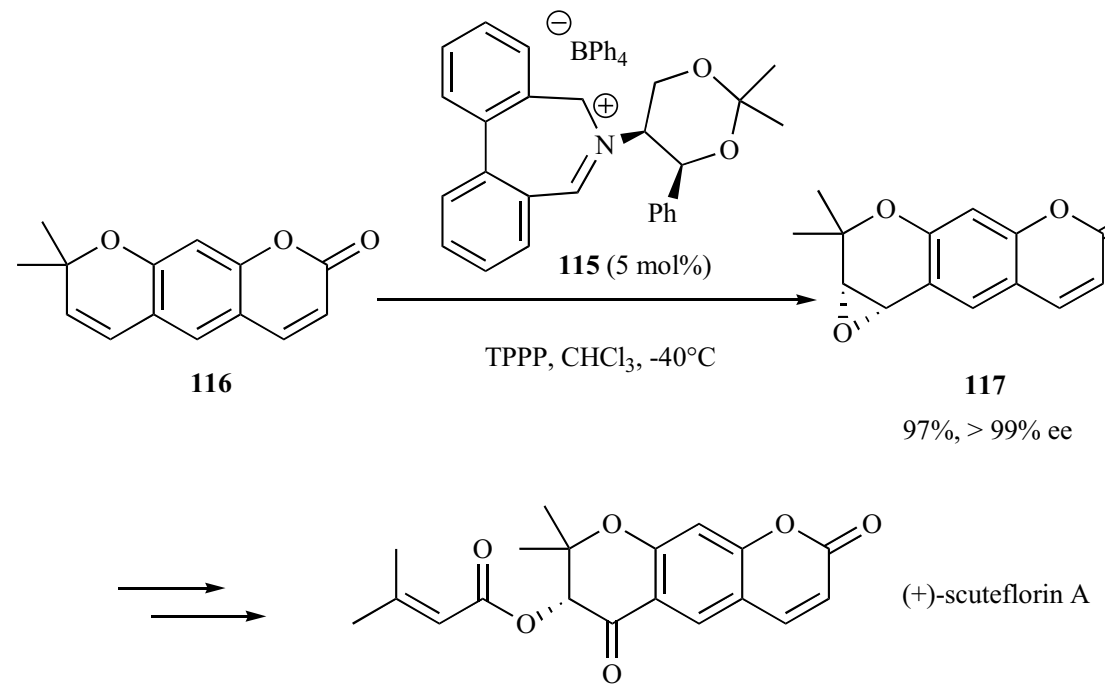

Scheme 47. Synthesis of $(+)$-scuteflorin A through chiral iminium salt-catalyzed epoxidation.

In 2010, Hayashi et al. reported a short synthesis of $(R)$-methyl palmoxirate, a potent oral hypoglycemic agent, based on the first successful asymmetric epoxidation of aliphatic $\alpha$-substituted acroleins, that was catalyzed by diphenylprolinol silyl ether $\mathbf{1 2 1}$ and $\mathrm{H}_{2} \mathrm{O}_{2}$ as oxidant [105]. Terminal epoxide 122, bearing a quaternary stereocenter, was obtained as key intermediate in good yield (78\%) and high enantioselectivity (up to $92 \%$ ee) starting from alkene 123, as shown in Scheme 49.

\subsubsection{Kinetic Resolutions of Racemic Epoxides as Key Steps}

Besides reactions mediated by metal complexes or organocatalysts, another important tool in asymmetric synthesis to obtain optically active products is the kinetic resolution of racemic molecules [106]. In 1990s, Jacobsen et al. demonstrated the exceptional catalytic performance of $\mathrm{Cr}(\mathrm{III})$-salen complexes in the kinetic resolu- tion of racemic terminal monosubstituted and 2,2-disubstituted epoxides by $\mathrm{TMSN}_{3}$, which occurred with complete regioselectivity for the terminal position and very high stereoselectivity factors of up to 280 [107]. Later, these authors reported enhanced reactivity by using dimeric catalyst $\mathbf{1 2 4}$ in hydrolytic kinetic resolution of terminal epoxides (Scheme 50) [108]. A recent synthetic application of kinetic resolution using primary alcohols was illustrated by the same authors in the total synthesis of (+)-reserpine via intermediate enone 125 [109]. The kinetic resolution of a racemic epoxide performed in acetonitrile with $4.5 \mathrm{~mol} \%$ of catalyst $\mathbf{1 2 8}$ and benzyl alcohol as the nucleophile, afforded the secondary alcohol $\mathbf{1 2 6}$ in $41 \%$ yield and $96 \%$ ee, which was further converted into enone 125. Then, this product was coupled with dihydro- $\beta$-carboline 127 to access antipsychotic and antihypertensive drug $(+)$-reserpine. 


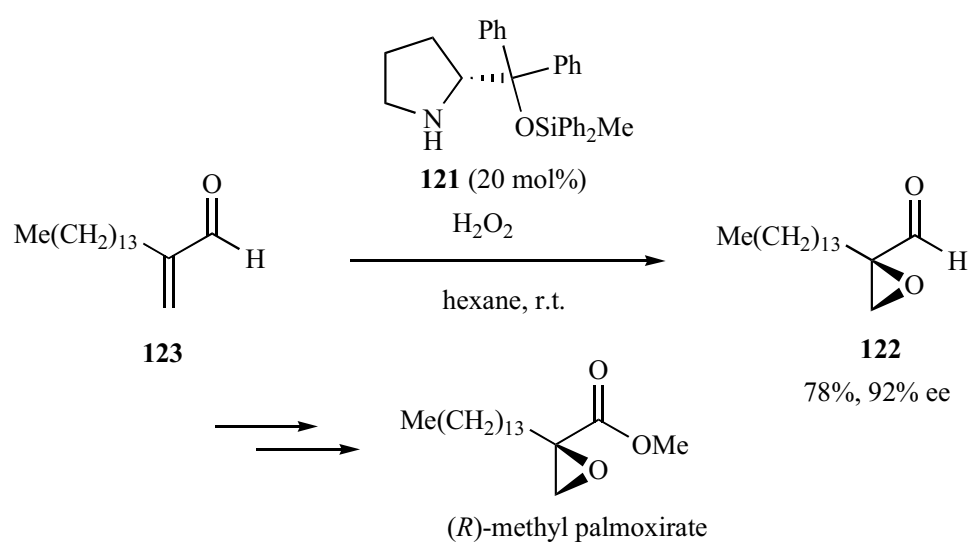

Scheme 49. Synthesis of $(R)$-methyl palmoxirate.

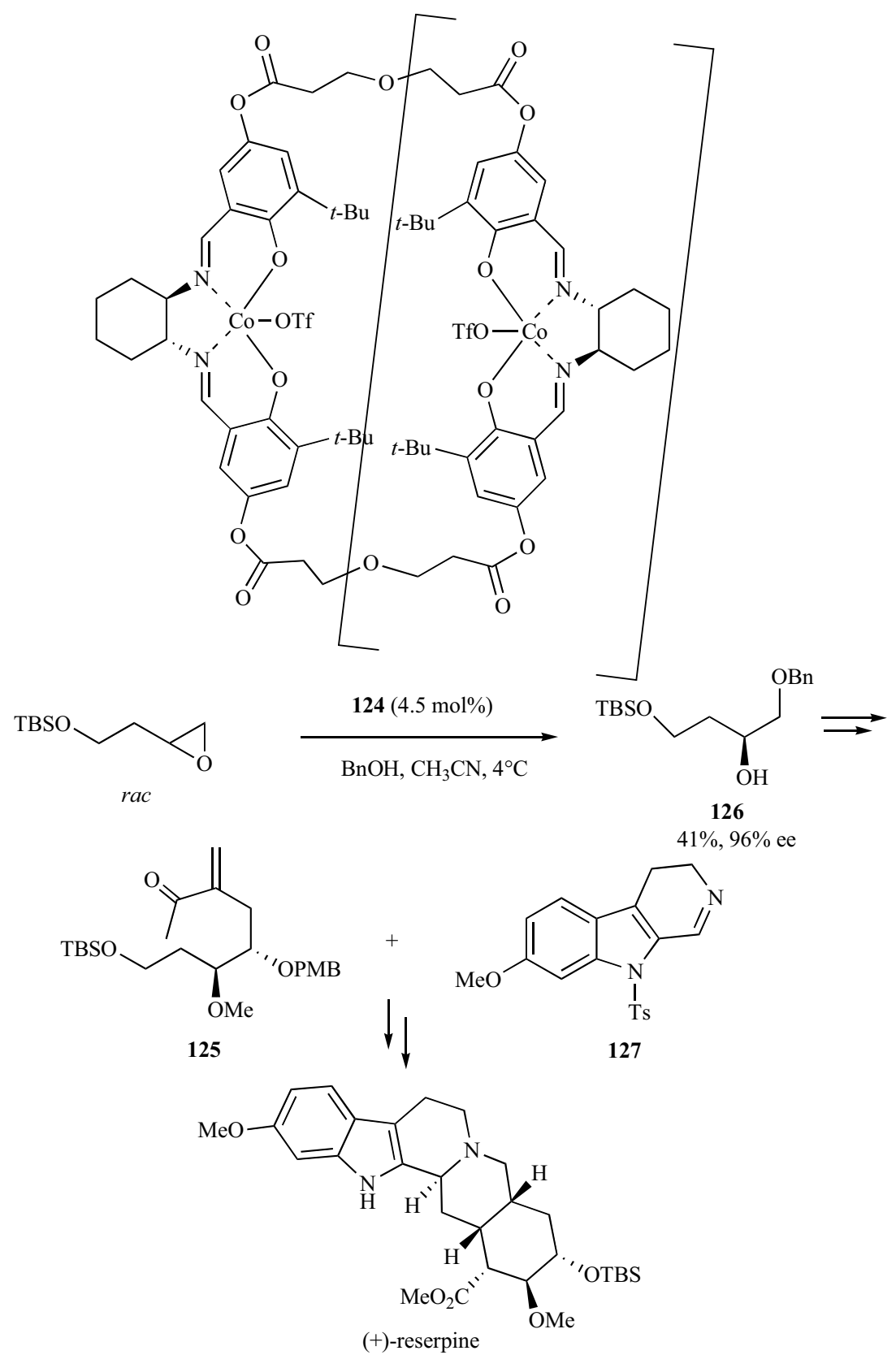

Scheme 50. Synthesis of (+)-reserpine. 


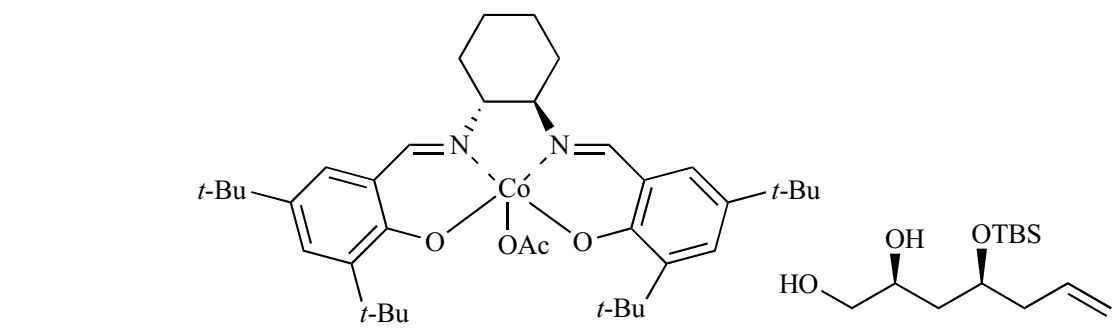<smiles>C=CC[C@H](CC1CO1)O[Na]</smiles>

$129(0.3-0.5 \mathrm{~mol} \%)$

rac-128
$\mathrm{H}_{2} \mathrm{O}$, r.t.

$+\quad 48 \%, 94 \%$ ee<smiles>C=CC[C@H](CC1CO1)O[Na]</smiles>

128

$48 \%, 98 \%$ ee<smiles>O=C(/C=C/c1ccccc1)C[C@@H](O)C[C@@H]1CC=CC(=O)O1</smiles>

$(5 S, 7 R)$-kurzilactone<smiles>COc1ccc(CC2CO2)cc1</smiles>

ent-129 $(0.5 \mathrm{~mol} \%)$ $\mathrm{H}_{2} \mathrm{O}$, r.t.<smiles>COc1ccc([C@@H]2NC(=O)O[C@H]2CO)cc1</smiles>

(+)-epi-cytoxazone<smiles>COc1ccc([C@@H](N)[C@H](O)CO)cc1</smiles>

$47 \%, 98 \%$ ee<smiles>COc1ccc(C([Al])C2CO2)cc1</smiles>

131

$48 \%, 98 \%$ ee

Scheme 51. Syntheses of $(5 S, 7 R)$-kurzilactone and (+)-epi-cytoxazone

Rare examples of hydrolytic kinetic resolution of functionalized racemic epoxides bearing two stereocenters have been reported. The groups of Tae and Sudalai independently investigated the hydrolytic kinetic resolution of racemic syn- and anti-2-hydroxy-1oxiranes in order to obtain both enantiomers of syn- and antiepoxides (Scheme 51) [110]. Racemic syn-O-protected terminal epoxide 128 underwent hydrolytic kinetic resolution with chiral cobalt catalyst 129 to give enantioenriched syn-epoxide 128 along with 1,2-diol 130 in excellent conversions and enantioselectivities of up to $98 \%$ ee. Epoxide 128 was employed as the starting reagent for the total synthesis of the opposite enantiomer of natural product $(5 S, 7 R)$-kurzilactone. Optically active trans-epoxide $\mathbf{1 3 1}$ was produced under comparable reaction conditions albeit using catalyst ent-129 and further employed in a concise total synthesis of the cytokine modulator (+)-epi-cytoxazone (Scheme 51).

The hydrolytic kinetic resolution methodology performed in the presence of cobalt catalyst ent-129 also constituted the key step of a total synthesis of natural product (+)-eldanolide, a long range sex attractant, which was reported by Sudalai et al., in 2013 [111]. As shown in Scheme 52, racemic anti-3-methyl epoxy ester $\mathbf{1 3 2}$ led to the corresponding trans-3,4-disubstituted-g-butyrolactone $\mathbf{1 3 3}$ along with unreacted chiral epoxide $\mathbf{1 3 2}$ both isolated in excellent enantioselectivities of $96-97 \%$ ee. Epoxide 132 was subsequently converted into expected natural product $(+)$-eldanolide. Another advantage of this methodology was the production of chiral 3,4disubstituted $\gamma$-butyrolactones, which constitute important scaffolds endowed with several biological activities.

The hydrolytic kinetic resolution of terminal epoxides was recently applied in the total synthesis of the anti-Parkinson agent safinamide, starting from commercially available benzyl glycidyl ether (Scheme 53) [112]. Enantiopure epoxide 134 was obtained in good conversion (46\%) via hydrolytic kinetic resolution of the corresponding racemic epoxide in the presence of ent-129 as catalyst, which secured a highly enantioselective approach to safinamide via simple elaboration steps. In addition, the hydrolytic kinetic resolution of racemic epoxides has also been used in the synthesis of other natural and bioactive compounds, such as $(S)$-timolol [113], decarestrictine D [114], (+)-isolaurepan [115], (R)-tuberculostearic 
<smiles>COC(=O)C[C@H](C)[C@H]1CO1</smiles>

rac-132<smiles>COC(=O)CC(C)C1CO1</smiles>

132

$48 \%, 96 \%$ ee

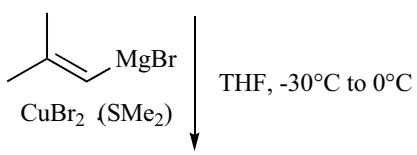

$\therefore$<smiles>CC(C)=CC[C@@H]1CCC(=O)O1</smiles>

(+)-eldanolide
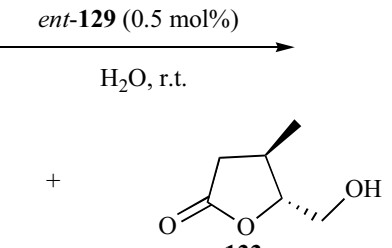

133

In 2004, Bartoli, Melchiorre et al. showed that the same cobalt catalyst ent-129 could also catalyze the highly regioselective kinetic resolution of epoxides with carbamates as nucleophiles in the presence of $p$-nitrobenzoic acid as an additive to provide the corresponding enantiopure chiral $\beta$-amino alcohols 135 (Scheme 54) [120]. The utility of this novel methodology was demonstrated in a total synthesis of the anti-hypertensive drug ( $\beta$-blocker) ( $S$ )propanolol.

\subsubsection{Asymmetric Sulfur Ylide-Mediated Epoxidations as Key Steps}

An alternative non-oxidative preparation of chiral epoxides relies on the use of chiral sulfur ylides and aldehydes as reactive partners [121]. This methodology has been the focus of significant interest to efficiently produce chiral epoxides in the last decade [87a, 122]. For example, Aggarwal et al. developed a total synthesis of SK\&F 104353, a leukotriene $\mathrm{D}_{4}$ inhibitor, that was based on the reaction of diastereoisomerically pure $O$-protected sulfonium salt 136 with aromatic hindered aldehyde 137, performed in the presence of $\mathrm{KOH}$ at low temperature, to afford the corresponding chiral key trans-epoxide 138 in $77 \%$ yield and high enantioselectivity $(90 \%$ ee) [123]. The latter was subsequently converted into expected SK\&F 104353 (Scheme 55).

acid [116], $(R)$-mexiletine [117], neocarazostatin B [118], and amprenavir [119].
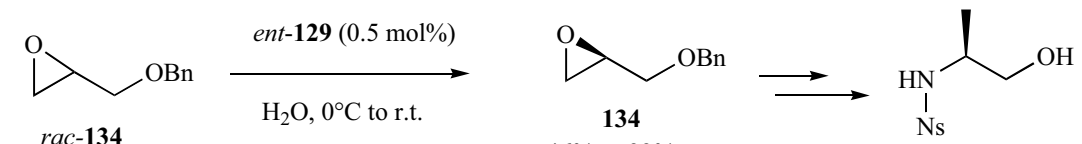

$\%,>99 \%$ ee

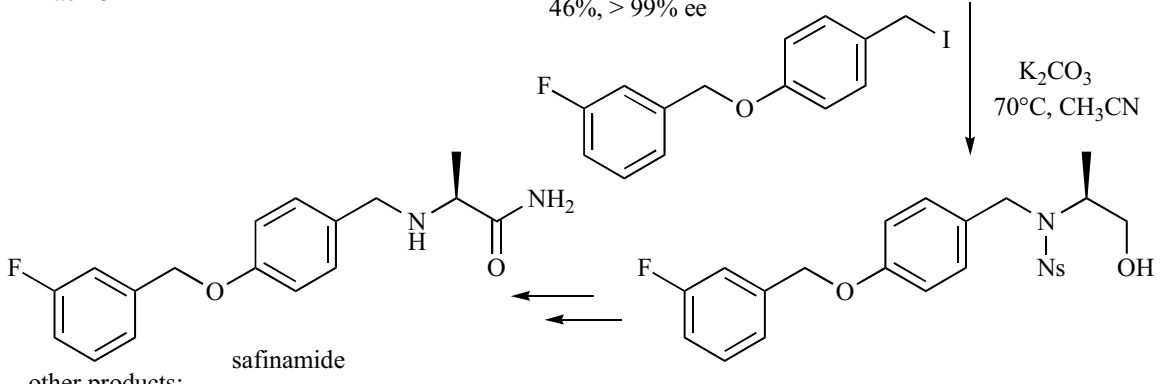<smiles>CC(C)CNC[C@H](O)COc1nscc1N1CCOCC1</smiles>

(S)-timolol<smiles>C[C@H]1C[C@H](O)/C=C\[C@@H](O)[C@@H](O)CC(=O)O1</smiles>

decarestrictine $\mathrm{D}$

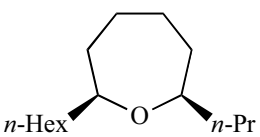

$(+)$-isolaurepan<smiles>CCCCCCCCCCCCC(=O)O</smiles>

$(R)$-tuberculostearic acid<smiles>COc1c(C)c(C[C@H](C)O)c2[nH]c3ccc(CC=C(C)C)cc3c2c1O</smiles>

neocarazostatin B<smiles>Cc1cccc(C)c1OC[C@H](C)N</smiles>

(R)-mexiletine<smiles>CC(C)CN(C[C@H](O)[C@H](Br)[18CH]Br)S(=O)(=O)c1ccc(N)cc1</smiles>

Scheme 53. Synthesis of safinamide and structures of other products. 

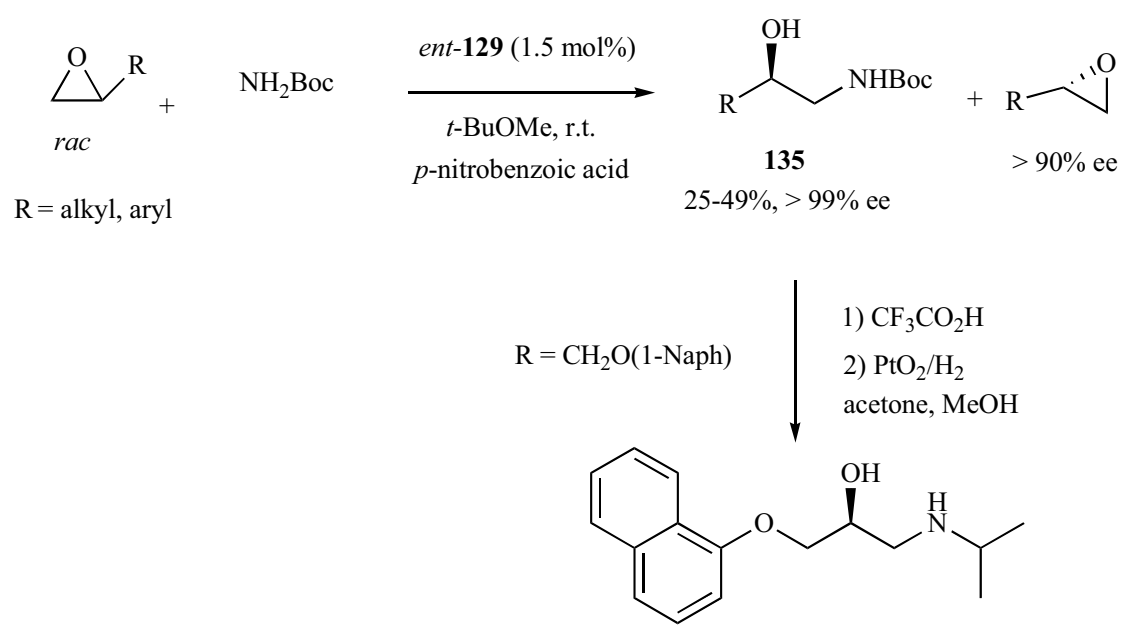

(S)-propanolol

$96 \%$

Scheme 54. Synthesis of (S)-propanolol.<smiles>O=Cc1ccccc1Cc1ccccc1</smiles>

137

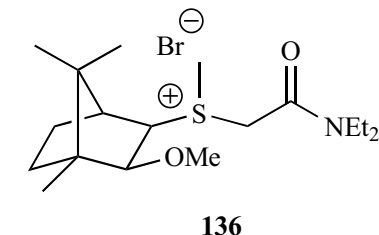

136<smiles>CCCCCCc1ccccc1[C@H]1O[C@H]1C(=O)N(CC)CCc1ccccc1</smiles>

138<smiles>O=C(O)CCSC(c1ccccc1Cl)C(C(=O)O)c1ccccc1</smiles>

SK\&F 104353

$77 \%, 90 \%$ ee

Scheme 55. Synthesis of SK\&F 104353.

The same group also developed asymmetric sulfur ylide epoxidations of readily available hemiaminals [124]. As shown in Scheme 56, the reaction of cyclic hemiaminal 139 with chiral sulfonium salt 140 at room temperature in dichloromethane in the presence of a base, such as phosphazene P2 $\left(N, N, N^{\prime}, N^{\prime}\right.$ tetramethyl- $N$ '-(tris(dimethylamino)phosphoranylidene) phosphoric triamide ethylimine), led to the corresponding chiral epoxide 141 in $54 \%$ yield. The latter was further successively submitted to TMSOTf and $\mathrm{Sc}(\mathrm{OTf})_{3}$ to afford the corresponding chiral piperidine 142 as the only detected diastereomer in $93 \%$ ee and with $90 \%$ yield. The synthetic utility of this novel methodology was demonstrated by its application in the synthesis of the potent neurokinin-1 (NK-1) receptor antagonist CP-122,721, as depicted in Scheme 56.

Most of the recent efforts in the asymmetric ylide-mediated epoxidation were focused on the synthesis of readily accessible optically pure sulfides able to improve and extend the scope of epoxidation in order to apply this methodology in total synthesis $[42,125]$. An innovative scaffold for the starting sulfide has been reported by Sarabia et al., based on the use of easily available amino acids Land D-methionines (Scheme 57) [126]. For example, sulfonium salt 143 was readily prepared in four steps and 70\% overall yield from L-methionine. The reactions of $\mathbf{1 4 3}$ with various aldehydes were performed under basic conditions to give exclusively the corresponding chiral trans-epoxides 144 in almost diastereoisomerically pure form. Employment of enantiopure aldehydes as reagents enabled the preparation of complex epoxy amides, such as 145, with an excellent control of the diastereoselectivity. This compound constituted a useful intermediate for the synthesis of macrolide-type natural products. The same group recently reported an in-depth study on the bicyclic core ring-size of sulfonium salts of type 143, demonstrating that it was possible to increase the scope of simple and chiral aldehydes employable in the epoxidation, for instance heteroaromatic, vinyl, and hemiacetal [127]. The versatility of this methodology was demonstrated in the total syntheses of bengamides analogues [128], a family of marine natural products isolated from sponges, exhibiting prominent antitumor, antihelmintic, and antibiotic activities as well as natural product (-)-depudecin [129], an antiangiogenic microbial polyketide (Scheme 57). Further applications include the synthesis of cyclodepsipeptides globomycin and SF-1902 A5 [130], and sphingoid-type bases [131].

\subsubsection{Catalytic Asymmetric Darzens Reactions as Key Steps}

An important transformation to obtain epoxides bearing an electron-withdrawing groups is the Darzens reaction [132]. Since the first asymmetric metal-catalyzed Darzens reaction reported by 


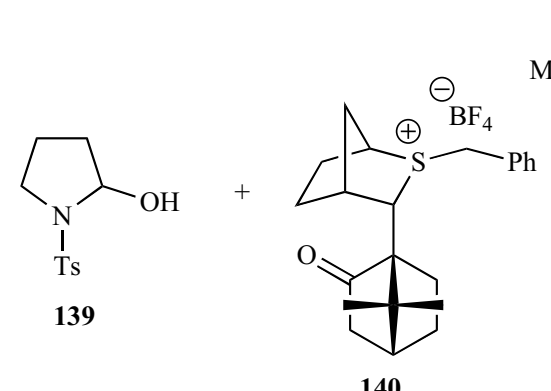

140
$\mathrm{Me}_{2} \mathrm{~N}-\underset{\mathrm{I}}{\mathrm{P}=\mathrm{N}} \mathrm{I}_{2}-\stackrel{\mathrm{NEt}}{\mathrm{I}}-\mathrm{NMe}_{2}$

phosphazene P2

$\mathrm{CH}_{2} \mathrm{Cl}_{2}$, r.t.

$54 \%$

141

1) $\mathrm{TMSOTf} / \mathrm{CH}_{2} \mathrm{Cl}_{2}$, r.t.

2) $\mathrm{Sc}(\mathrm{OTf})_{3} / \mathrm{CH}_{2} \mathrm{Cl}_{2}$, r.t.

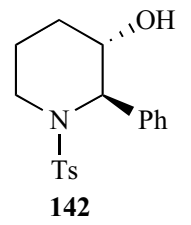

NHTs

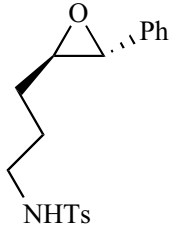

$90 \%,>99 \%$ de, $93 \%$ ee<smiles>COc1ccc(OC(F)(F)F)cc1CN[C@@H]1CCCN[C@H]1c1ccccc1</smiles>

CP-122,721

Scheme 56. Synthesis of CP-122,721<smiles>CC1(C)OC[C@@H]2CC[Si](C)(C(=O)[O-])CC(=O)N21</smiles>

143

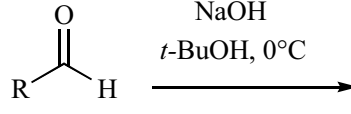

$\mathrm{R}$<smiles>CC1(C)CC1C=O</smiles>

144

$44-95 \%,>98 \%$ de<smiles>CSCCC1COC(C)(C)N1C(=O)CC(=O)[C@@H](C)[C@@H](C)[C@H]1COC(C)(C)O1</smiles>

145

$48 \%,>98 \%$ de<smiles>C=C[C@H](O)[C@H]1O[C@@H]1/C=C/[C@@H]1O[C@@H]1[C@@H](C)O</smiles>

(-)-depudecin

Scheme 57. Syntheses of bengamide E and (-)-depudecin.

North et al. in 2007 [133], successful examples of this type of methodology have been developed and applied in total synthesis. Therefore, Gong et al. have described an enantioselective titaniumcatalyzed Darzens reaction as key step in the total synthesis of protease inhibitor (-)-bestatin [134]. The reaction was catalyzed by an in situ generated complex from $\mathrm{Ti}(\mathrm{O} i \mathrm{Pr})_{4}$ and $(R)$-BINOL. It occurred between diazoacetamide 146 and aldehyde 147 in the presence of molecular sieves (Scheme 58). A complete control of the diastereoselectivity was observed, providing the corresponding cisglycidic amide 148 in good yield (88\%) and high enantioselectivity of $92 \%$ ee. This epoxide constituted a useful intermediate in the synthesis of (-)-bestatin.

\subsection{Chiral Thiiranes}

Sulfur-containing compounds are widespread among natural products and biologically active substances [135]. Consequently, great efforts have been devoted to develop stereocontrolled $\mathrm{C}-\mathrm{S}$ bond-forming procedures [136]. In particular, thiiranes are suitable precursors of numerous products, including biologically active compounds. Several methods for thiirane preparation [137] have 
<smiles>O=CC(=O)C=[N+]=Nc1ccccc1</smiles>

146

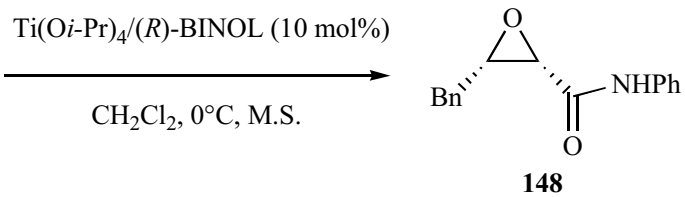

$88 \%, 92 \%$ ee<smiles>CCC[C@H](NC(=O)[C@@H](O)[C@H](N)Cc1ccccc1)C(=O)O</smiles>

(-)-bestatin

Scheme 58. Synthesis of (-)-bestatin.

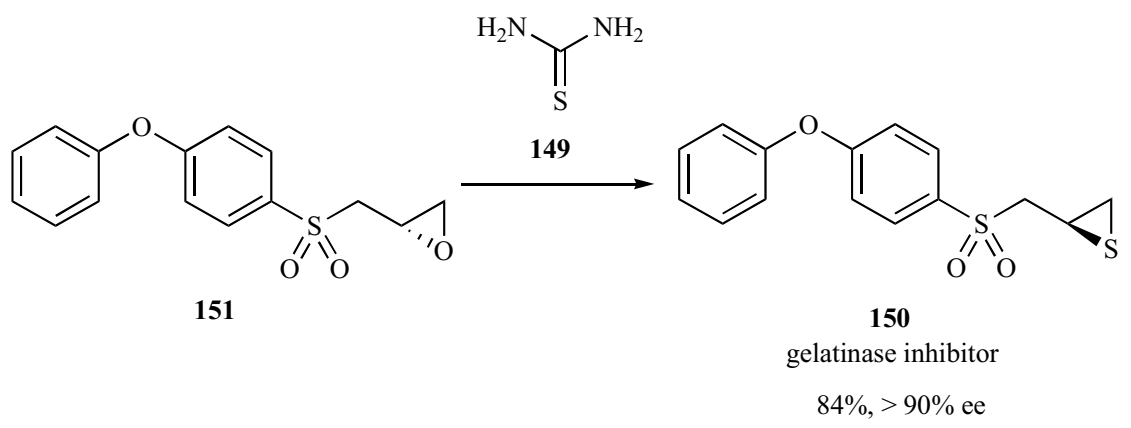

Scheme 59. Synthesis of a gelatinase inhibitor.

been reported, among which the most convenient one consists in the conversion of oxiranes into the corresponding thiiranes by an oxygen-sulfur exchange reaction. With this aim, various sulfur reagents have been investigated such as thiourea 149 [138]. In 2005, an asymmetric version of this methodology was applied by Mobashery et al. to the synthesis of chiral 1,2-(4-phenoxyphenylsulfonylmethyl)thiirane 150, which is a selective gelatinase inhibitor active for cancer metastasis [139]. The key step of the synthesis consisted in the reaction of the corresponding $(S)$-epoxide 151 with thiourea 149 to give the expected $(R)$-thiirane 151 in good yield $(84 \%)$ and high enantioselectivity $(>90 \%$ ee), as shown in Scheme 59.

\section{CHIRAL CYCLOPROPANES IN TOTAL SYNTHESIS}

The strained cyclopropane subunit $[2 \mathrm{a}, 140]$ is present in a range of biologically relevant products, such as terpenes, pheromones, fatty acid metabolites, and unusual amino acids [141], among others. These compounds exhibit a large spectrum of biological properties, including enzyme inhibition and insecticidal, antifungal, herbicidal, antimicrobial, antibiotic, antibacterial, antitumor, and antiviral activities [3,142]. This fact has inspired chemists to find novel approaches for their synthesis [143], and thousands of cyclopropane compounds have already been prepared [144]. In particular, the asymmetric synthesis of cyclopropanes has remained a challenge [2f, 145], since it was demonstrated that members of the pyrethroid class of compounds to be effective insecticides [146]. In the last decade, many important chiral cyclopropane derivatives have been synthesized according to three principal methodologies, including the Simmons-Smith reaction [147], the transition-metal-catalyzed decomposition of diazo compounds [2f, 148], and the Michael-initiated ring-closure (MIRC) [149]. In each case, the reactions can start from chiral substrates (or auxiliaries) or can be promoted by chiral catalysts.

\subsection{Asymmetric Simmons-Smith Cyclopropanations as Key Steps}

In 1950s, Simmons and Smith reported the reaction of alkenes with diiodomethane performed in the presence of activated zinc which afforded cyclopropanes in high yields [150]. The reactive intermediate is an organozinc species and the preparation of such species, including $\mathrm{RZnCH}_{2} \mathrm{I}$ or $\mathrm{IZnCH}_{2} \mathrm{I}$ compounds and samarium derivatives, was developed in the following years [151]. Ever since, asymmetric versions of the Simmons-Smith reaction [152] have been developed and applied to the synthesis of various biologically active products using either chiral substrates or chiral catalysts.

\subsubsection{Using Chiral Substrates}

Various asymmetric cyclopropanations of acyclic allylic alcohols have been reported, using the heteroatom as the directing group, through chelation with the zinc reagent. This SimmonsSmith reaction has distinct advantages over the reaction with a simple olefin in relation to the reaction rate and stereocontrol [153]. Many asymmetric cyclopropanations of chiral allylic alcohols have been used as key steps in total synthesis of natural products of biological interest. For instance, Takemoto et al. reported in 2000s an asymmetric total synthesis of natural product halicholactone, in which a regio- and stereoselective cyclopropanation of chiral diene 152 into epoxide 153 obtained as the only detected stereoisomer constituted the key step (Scheme 60) [154].

In 2006, Smith and Simov developed the total synthesis of the marine diolide (-)-clavosolide A on the basis of the direct Simmons-Smith cyclopropanation of chiral $\mathrm{N}$-methoxyamide 154, providing the corresponding key cyclopropane intermediate $\mathbf{1 5 5}$ in $74 \%$ yield and diastereoselectivity of $84 \%$ de, as shown in Scheme 61 [155].

In 2007 , a total synthesis of the two biologically active oxylipins solandelactones $\mathrm{E}$ and $\mathrm{F}$ was described by White et al. [156]. 


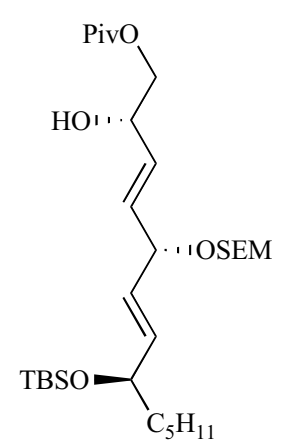

152

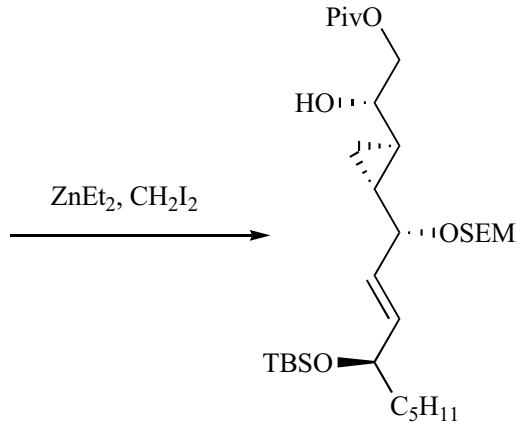

153
$66 \%,>99 \%$ de

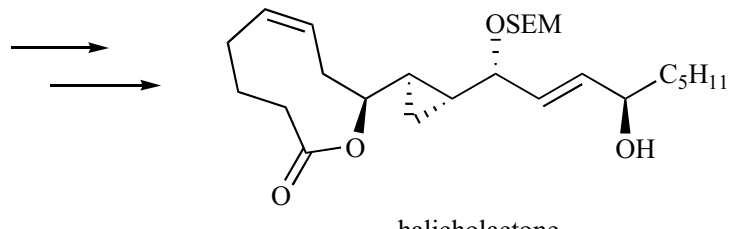

halicholactone

Scheme 60. Synthesis of halicholactone.

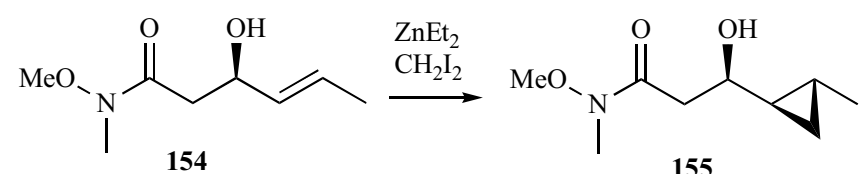

155

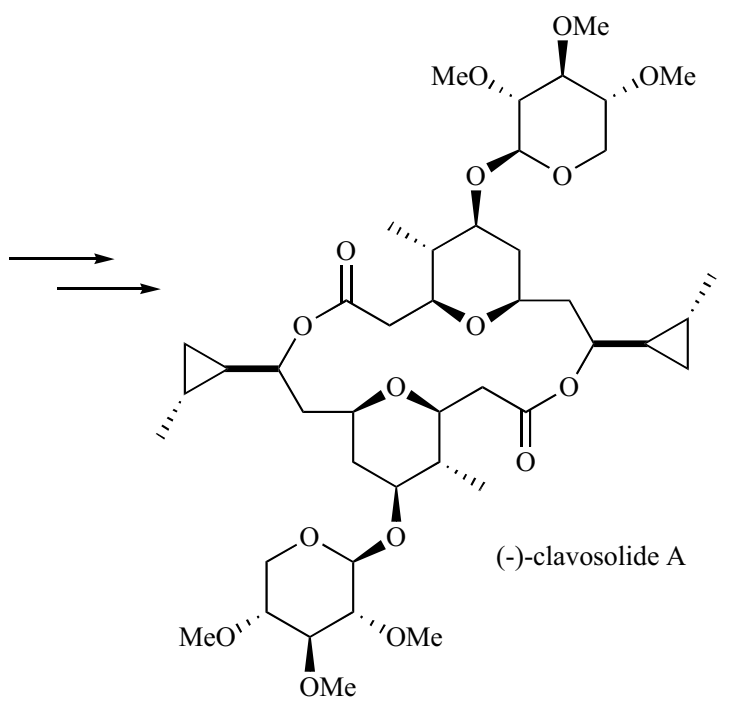

Scheme 61. Synthesis of (-)-clavosolide A.

The key step was a comparable Simmons-Smith cyclopropanation of chiral $\mathrm{N}$-methoxyamide $\mathbf{1 5 6}$ which provided the corresponding functionalized cyclopropane $\mathbf{1 5 7}$ as the only detected stereoisomer diastereomer in almost quantitative yield, as shown in Scheme 62. The authors confirmed that the structures of the two solandelactones were epimeric at $\mathrm{C} 11$.

Brevipolides are extracted from the invasive tropical plant of Hyptis brevipes, and exhibit interesting drug properties. Recently, Mohapatra et al. developed a highly diastereoselective synthesis of the $\mathrm{C} 1-\mathrm{C} 12$ fragment of brevipolide H (Scheme 63) [157]. The key

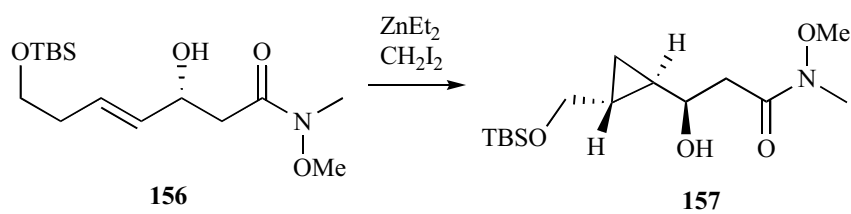

157 $97 \%,>99 \%$ de<smiles>CCCCC/C=C\C[C@H](O)/C=C/C(O)[C@@H]1C[C@H]1[C@H]1C/C=C\CCC(=O)O1</smiles>

(S)-C11: solandelactone E (R)-C11:solandelactone $\mathrm{F}$

Scheme 62. Synthesis of solandelactones E and F.

step was the cyclopropanation of chiral alkene $\mathbf{1 5 8}$ into $\mathbf{1 5 9}$ in excellent yield (up to 97\%) and diastereoselectivity (up to $98 \%$ de). A similar reaction was previously reported by Kumaraswamy et al., but with inferior results in the synthesis of another representative member of the brevipolide family [158].

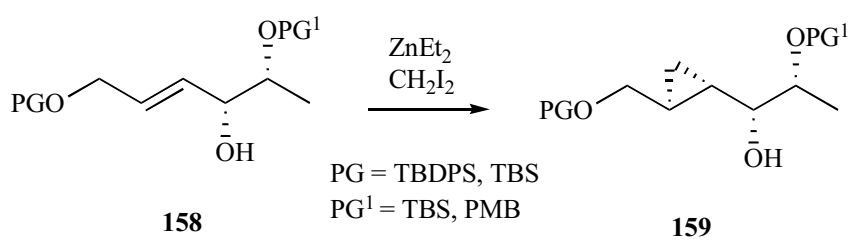

$90-97 \%, 90-98 \%$ de<smiles>COc1ccc(/C=C/C(=O)O[C@@H](C)C(=O)[C@@H]2C[C@@H]2[C@@H](O)[C@H]2CC=CC(=O)O2)cc1</smiles>

Scheme 63. Synthesis of the $\mathrm{C} 1-\mathrm{C} 12$ fragment of brevipolide $\mathrm{H}$.

In addition to chiral allylic alcohols, chiral acetals bearing an alkene function, such as $\mathbf{1 6 0}$ and $\mathbf{1 6 1}$, have been used in diastereoselective acetal-directed cyclopropanations as key steps of total syntheses of solandelactone E (Scheme 64a, structure in Scheme 62) [159], and a marine fatty acid metabolite exhibiting lipoxygenase-inhibiting activity (Scheme 64b) [160], both providing the corresponding cyclopropane derivatives 162 and $\mathbf{1 6 3}$, respectively, in good to excellent yields (72-95\%) and as the only detected stereoisomers.

In 2006, standard Simmons-Smith conditions were also applied by Abad et al. to the cyclopropanation of diterpene 164 [161]. The reaction occurred stereoselectively from the less hindered $b$-side of the double bond, affording the expected cyclopropane 165 in $94 \%$ yield and as the only detected stereoisomer (Scheme 65). This tricyclo[3.2.1.0] octane moiety constituted the key intermediate in the synthesis of biologically interesting trachylobane-, beyerane-, atisane-, and kaurane-type diterpenes.

In 2015, Tori et al. applied similar Simmons-Smith conditions to the last step of a total synthesis of natural product (+)crispatanolide starting from chiral alkene 166, as shown in Scheme 66 [162]. Surprisingly, the major product was not the expected (+)- 


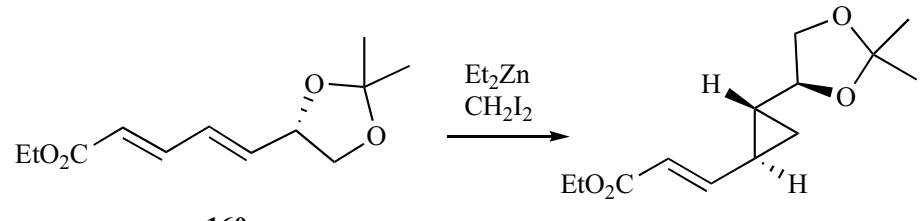

160

162

$\longrightarrow \quad$ solandelactone $\mathrm{E} \quad$ (64a)

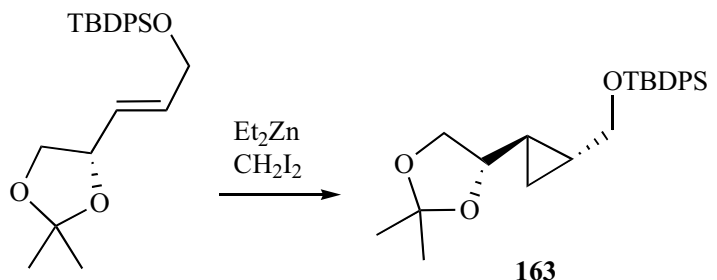

161

163<smiles>CCCCC/C=C\CC/C=C/C(=O)[C@@H]1C[C@@H]1[C@H]1CCCC(=O)O1</smiles>

metabolite

Scheme 64. Syntheses of solandelactone E and a marine fatty acid metabolite.

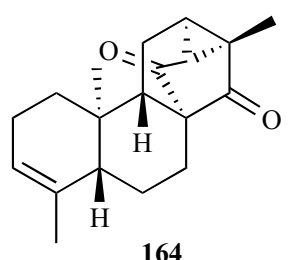

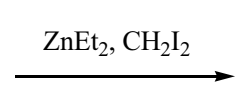

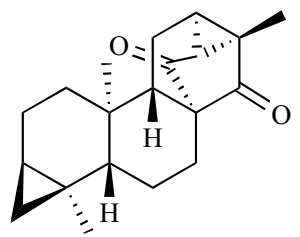

164

165

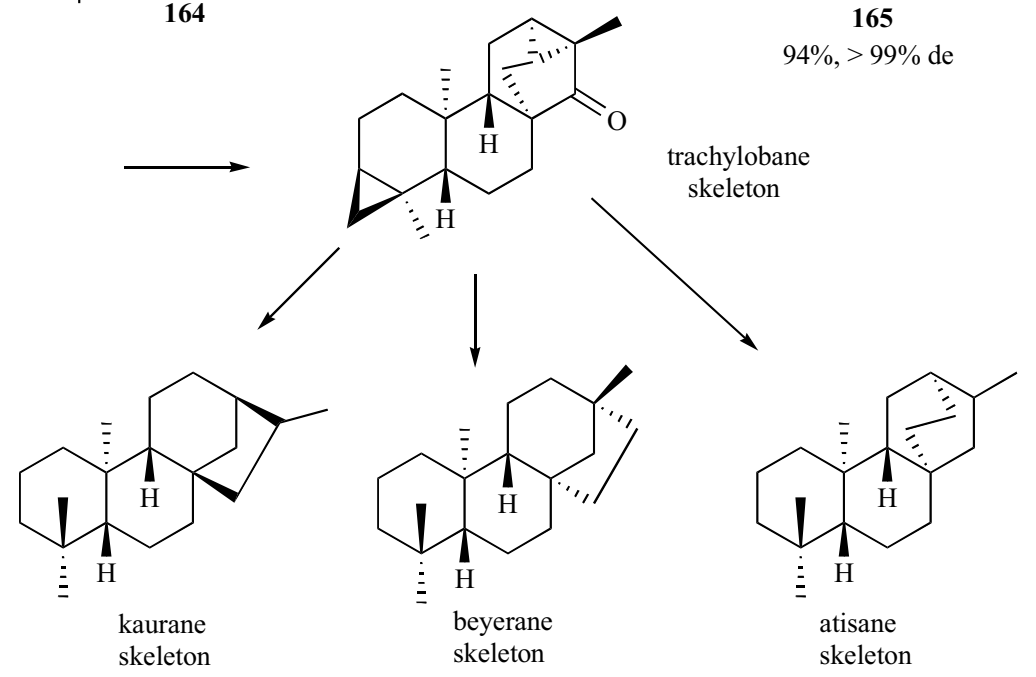

Scheme 65. Syntheses of trachylobane-, kaurane-, beyerane- and atisane-type diterpenes.

crispatanolide, but a diastereomer, very likely because of the directing effect of the lactone carbonyl group. However, this synthesis allowed likewise assigning the absolute configuration of the natural $(+)$-crispatanolide.

In addition, various types of recoverable chiral auxiliaries have been successfully employed in asymmetric Simmons-Smith cyclo- propanations as key steps of total syntheses of various natural products. For example, the asymmetric Simmons-Smith cyclopropanation of chiral allylic alcohol $\mathbf{1 6 7}$ led to the corresponding cyclopropanes 168 in high to quantitative yields and as almost single diastereomers $(>95 \%$ de) [163] to be used as key intermediates in several natural products, such as cascarillic acid [164], 


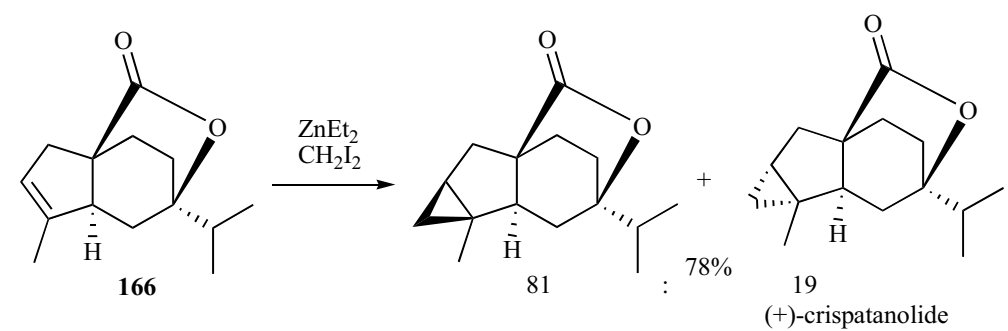

Scheme 66. Synthesis of (+)-crispatanolide and its diastereomer.

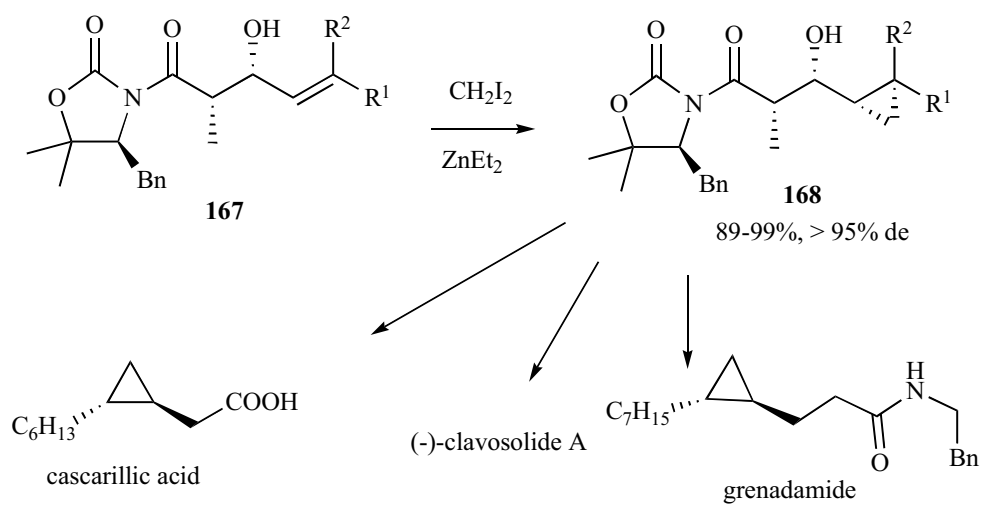

Scheme 67. Syntheses of cascarillic acid, (-)-clavosolide and grenadamide.

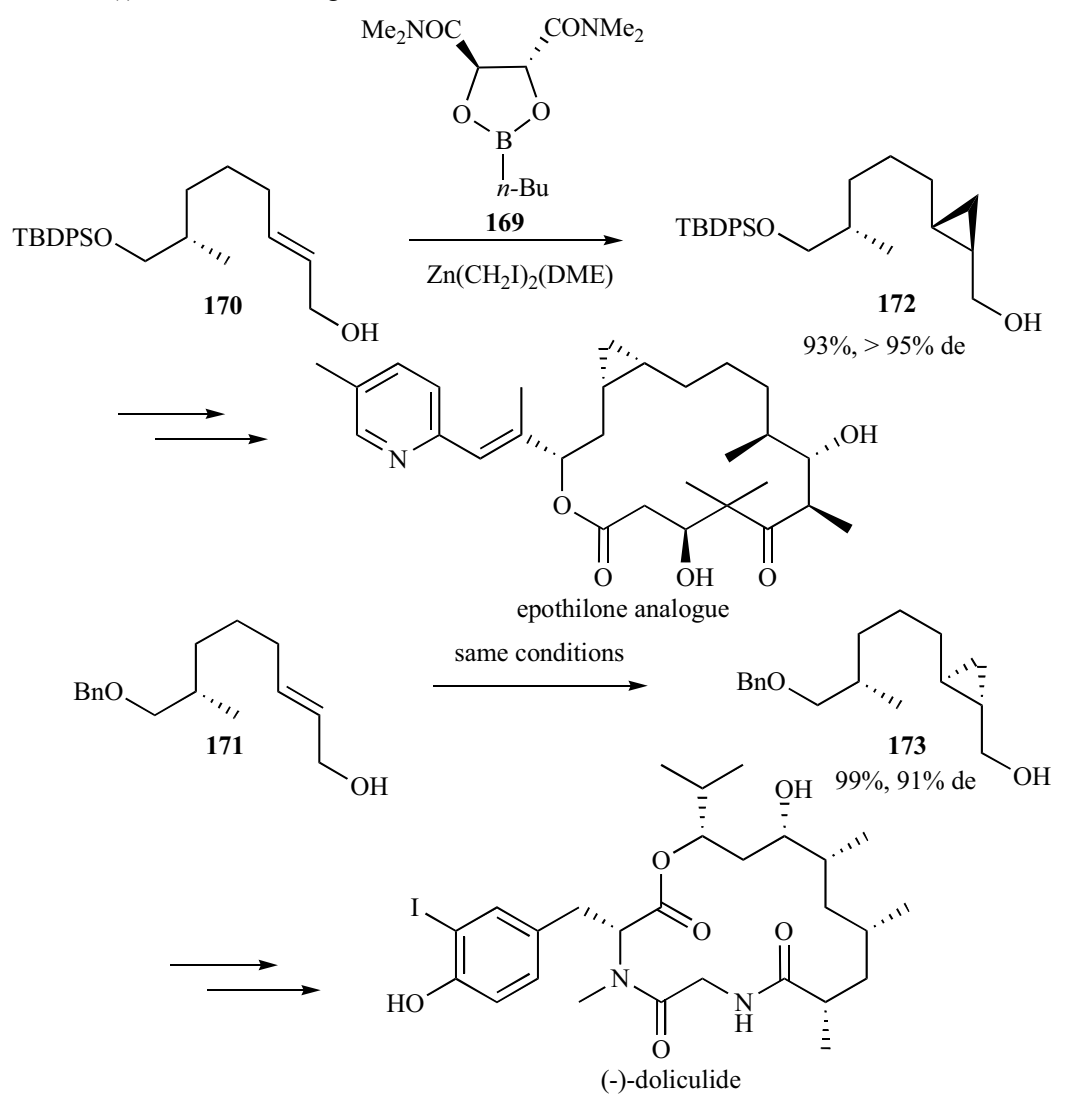

Scheme 68. Syntheses of an epothilone analogue and (-)-doliculide though Charette's cyclopropanations.

(-)-clavosolide A (structure in Scheme 61) [165], and grenadamide [166] (Scheme 67).

\subsubsection{Using Chiral Catalysts}

In 2001, Liu and Ghosh reported the cyclopropanation of cisand trans-disubstituted allylic alcohols, such as $\mathbf{1 7 0}$ and $\mathbf{1 7 1}$, per- formed in the presence of chiral dioxaborolane ligand 169, which led to the corresponding chiral cyclopropylmethanols $\mathbf{1 7 2}$ and $\mathbf{1 7 3}$, respectively, in diastereoselectivities of up to $>95 \%$ de. These reactions constituted the key steps for biologically active product synthesis, such as an epothilone analogue [167], and (-)-doliculide [168], as shown in Scheme 68. It must be noted that in fact these 


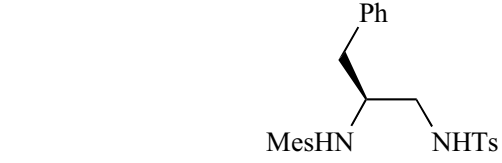

178<smiles>OCC=C(c1ccccc1)c1ccccc1</smiles>

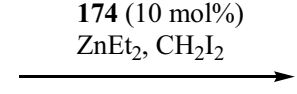<smiles>OC[C@@H]1CC1(c1ccccc1)c1ccccc1</smiles>

175

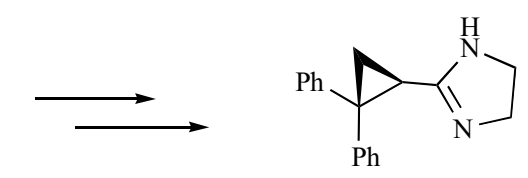

(+)-cibenzoline
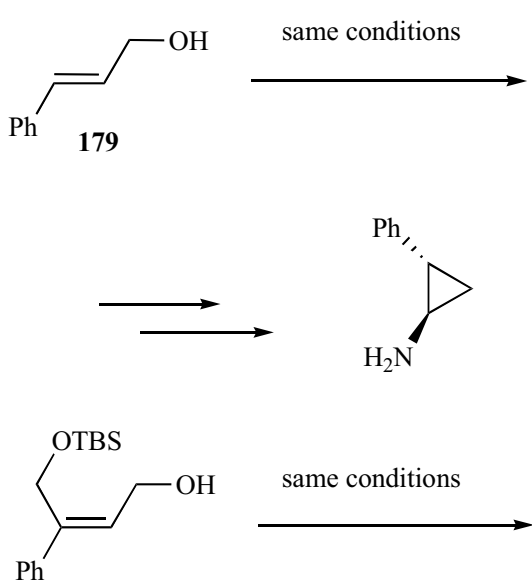

180

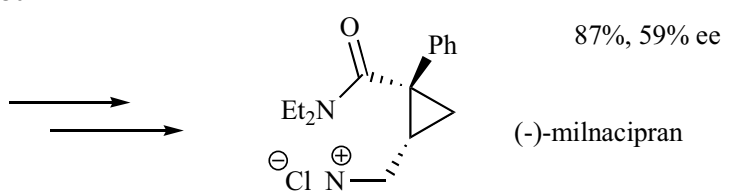

Scheme 69. Syntheses of (+)-cibenzoline, (+)-tranylcypromine and (-)milnacipran.

results arose from a double induction since the starting materials were also chiral.

In 2006, (S)-phenylalanine-derived disulfonamide 174 was applied as chiral ligand to promote the cyclopropanation of a range of 3,3-diaryl-2-propen-1-ols in the presence of $\mathrm{Et}_{2} \mathrm{Zn}$ and $\mathrm{CH}_{2} \mathrm{I}_{2}$, providing the corresponding cyclopropylmethanols with moderate to good enantioselectivities (59-84\% ee), as shown in Scheme 69 [169]. Chiral cyclopropanes 175, 176 and 177, derived from the corresponding allylic alcohols 178, 179, and 180, were further converted into (+)-cibenzoline, an antiarrhythmic agent [170], (+)tranylcypromine, a strong monoamineoxidase inhibitor, and (-)milnacipran, a serotonin-noradrenaline reuptake inhibitor, respectively [171].

\subsection{Asymmetric Transition-Metal Decomposition of Diazoal-} kanes as Key Steps

\subsubsection{Intermolecular Cyclopropanations}

\section{Chiral Substrates}

Since the pioneering work of Nozaki and Noyori reported in 1966 [172], the transition-metal-catalyzed cyclopropanation of
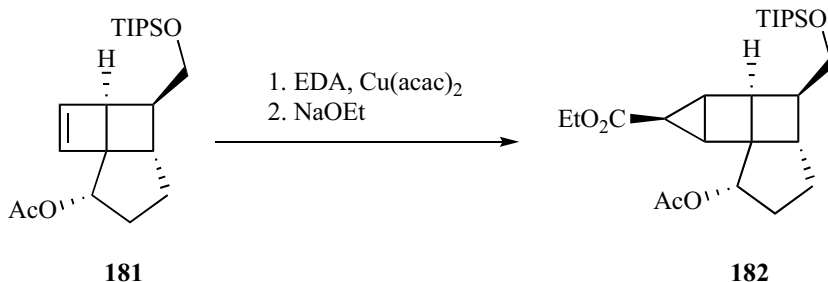

182

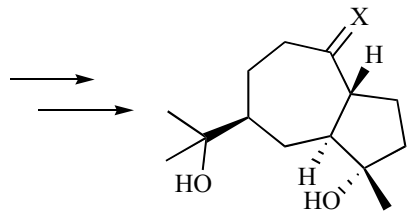

$93-95 \%,>90 \%$ de

$\mathrm{X}=\mathrm{CH}_{2}$ : pleocarpenene $\mathrm{X}=\mathrm{O}$ : pleocarpenone

Scheme 70. Synthesis of pleocarpenene and pleocarpenone.

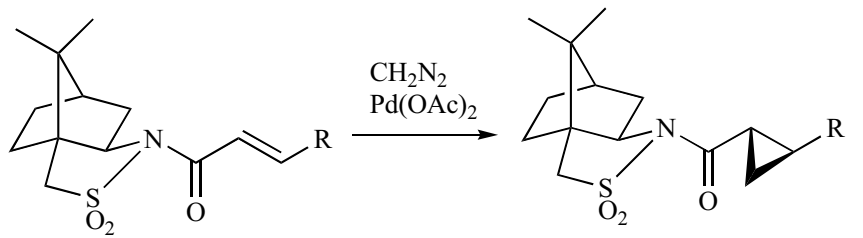<smiles>[R]C(=O)NC[C@@H]1C[C@H]1c1cccc2c1C[C@@H](CCCCc1ccccc1)O2</smiles>

$11-76 \%$ $80: 20$ to $96: 4 \mathrm{dr}$
Scheme 71. Synthesis of melatoninergic ligands.

alkenes with diazo compounds has emerged as one of the most highly efficient routes to functionalized cyclopropanes. These reactions have been applied in total synthesis, starting from chiral substrates, but also in the presence of chiral catalysts. As a rare example of reaction involving a chiral substrate, Snapper et al. developed the asymmetric cyclopropanation of chiral tricyclic alkene $\mathbf{1 8 1}$ as key step in total syntheses of natural products pleocarpenene and pleocarpenone [173]. The authors observed a high stereochemical control $(>90 \% \mathrm{de})$ in the cyclopropanation with ethyl diazoacetate (EDA) into compound $\mathbf{1 8 2}$ followed by deacetylation reaction using $\mathrm{Cu}(\mathrm{acac})_{2}$ as the catalyst (Scheme 70).

Moreover, Oppolzer's chiral sultam 183 was applied for the synthesis of novel melatoninergic agents, as shown in Scheme $\mathbf{7 1}$ [174].

\section{Chiral Catalysts}

Chiral copper catalysts are among the most effective catalysts for the preparation of the trans-isomer of cyclopropanes with the widest reaction scope. Among them, non-racemic $C_{2}$-symmetric bidentate bisoxazoline ligands [34] have been used in cyclopropanation reactions with copper for more than thirty years (see also subsection entitled "Copper-catalyzed nitrene transfer to alkenes") [175]. Some of these copper-catalyzed reactions have been included into multistep syntheses of natural products [176]. For example, carbohydrate-based bis(oxazoline) ligand $\mathbf{1 8 4}$ and copper(I) triflate were used in the reaction of non-1-ene 185 and EDA for the total synthesis of unnatural $(+)$-grenadamide [177] (Scheme 72).

In 2012, the cyclopropanation of $N$-Boc-3-methylindole $\mathbf{1 8 6}$, performed in the presence of bisoxazoline ligand 187 in combination with CuOTf, yielded a key building block $\mathbf{1 8 8}$ for the synthesis 


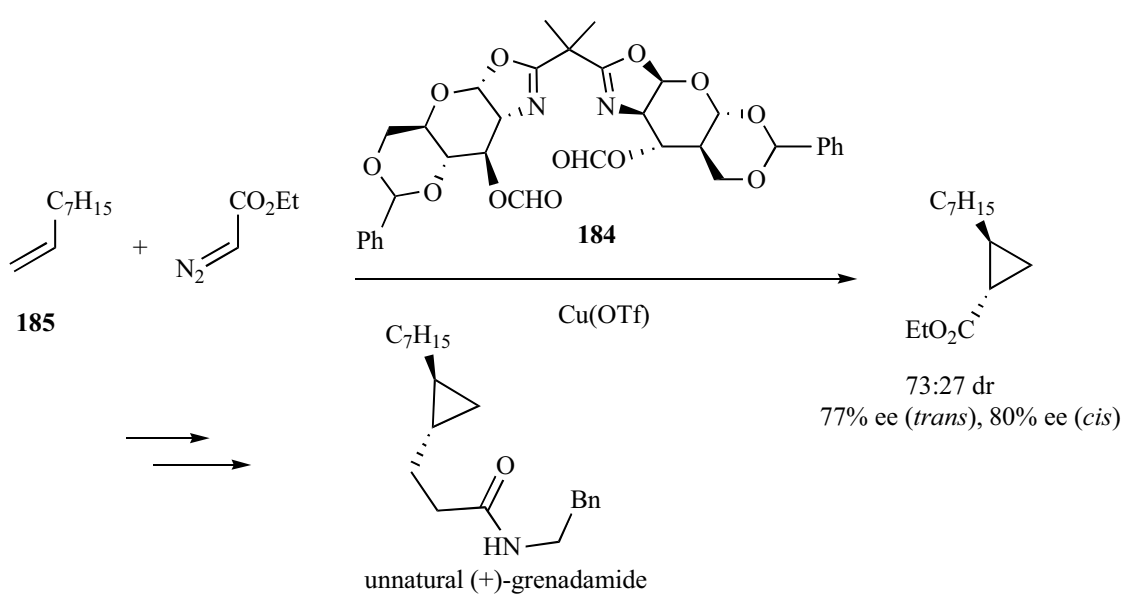

Scheme 72. Synthesis of unnatural (+)-grenadamide.<smiles>Cc1cn(C(C)(C)C)c2ccccc12</smiles>

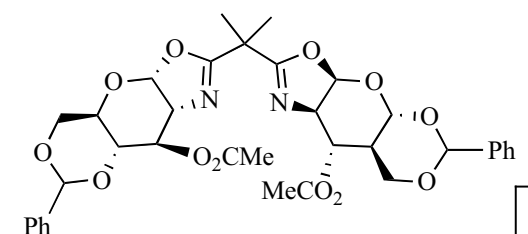

$+\mathrm{N}_{2} \mathrm{CHCO}_{2} \mathrm{Et}$

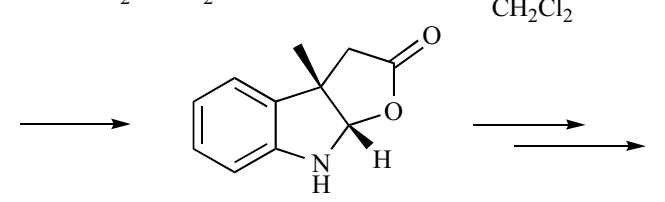

188 $71 \%, 96 \%$ ee

$187(3.3 \mathrm{~mol} \%)$

CuOTf $(3 \mathrm{~mol} \%)$<smiles>CCOC(=O)[C@H]1[C@H]2[C@H](C)[C@]1(C)c1ccccc1N2C(=O)OCc1ccccc1</smiles><smiles>CN1CC[C@]2(C)c3ccccc3N(C)[C@H]12</smiles>

(-)-desoxyeseroline $59 \%, 96 \%$ ee<smiles>COc1cc2c(cc1OC)[C@@]1(C=CCC1)C(OC)C2</smiles>

190

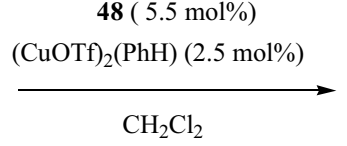<smiles>CCOC(=O)C1CC2[C@H](O)Cc3cc(OC)c(OC)cc3[C@@]12C</smiles>

189

$+\mathrm{N}_{2} \mathrm{CHCO}_{2} \mathrm{Et}$

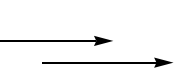

Scheme 73. Syntheses of (-)-desoxyeseroline and cryptotrione through copper-catalyzed cyclopropanations.

of the indole alkaloid (-)-desoxyeseroline that was isolated in 59\% overall yield and 96\% ee (Scheme 73) [178]. Moreover, the use of ligand $\mathbf{4 8}$ allowed the stereoselective preparation of the tetracyclic core and key intermediate $\mathbf{1 8 9}$ in a total synthesis of cryptotrione to be achieved (Scheme 73). The key cyclopropane intermediate $\mathbf{1 8 9}$ was obtained in $93 \%$ yield and $82 \%$ de starting from alkene $\mathbf{1 9 0}$ [179].

Copper-salen catalysts were found particularly efficient in the synthesis of chrysantemate esters, and $(1 R, 3 R)$-chrysanthemic acid ester 191 was prepared in the presence of $\mathrm{Cu}(\mathrm{I})$-salen complex 192 in $90 \%$ yield with $78: 22 \mathrm{dr}$ and enantioselectivities of $91 \%$ and $62 \%$ ee for the trans- and cis-diastereomers, respectively [180] (Scheme 74).

Chiral dirhodium carboxamide catalysts were originally developed by Doyle for enantioselective cyclopropanations [181]. In the presence of these catalysts, allylic substrates and in particular dihydronaphthalene have a potentially competing pathway to cyclopropanation, such as allylic $\mathrm{C}-\mathrm{H}$ insertion. An example was developed 


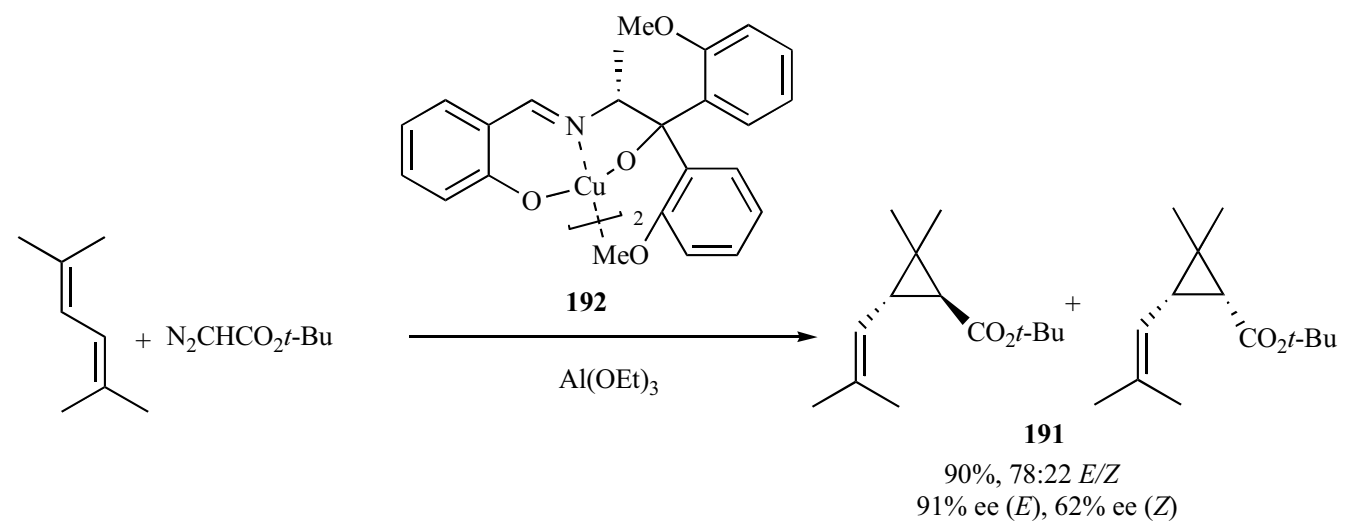

Scheme 74. Synthesis of chrysanthemic acid ester.

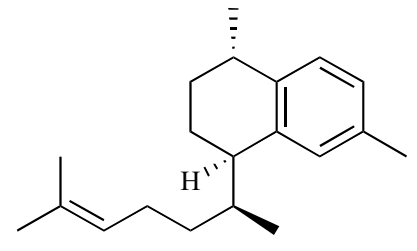

(+)-erogorgiaene

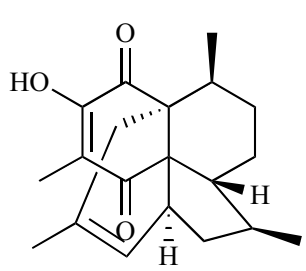

(-)-colombiasin A

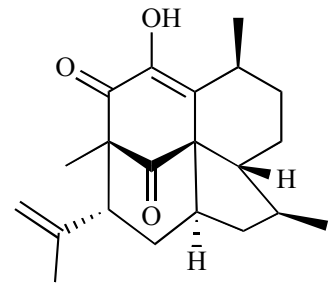

(-)-elisapterosin B

Scheme 75. Natural products synthesized through chiral dirhodium catalysis.<smiles></smiles>

193<smiles>CN(C)C[C@@H]1C[C@H]1c1cn(C)c2ccc(C#N)cc12</smiles>

BMS-505130

Scheme 76. Synthesis of BMS-505130 through ruthenium-catalyzed cyclopropanation.

by Davies et al. with the total synthesis under $\mathrm{Rh}_{2}(R \text {-DOSP })_{4}$ catalysis of the natural products (+)-erogorgiaene, and (-)colombiasin A, (-)-elisapterosin B through cyclopropanation and $\mathrm{C}-\mathrm{H}$ insertion, respectively, of the same dihydronaphthalene derivative [182] (Scheme 75).

Moreover, chiral ruthenium catalysts have also been applied to the field of catalytic enantioselective cyclopropanation. This approach was employed by Marcin et al. as key step in a total synthesis of BMS-505130, a selective serotonin reuptake inhibitor [183]. As shown in Scheme 76, 1-tosyl-3-vinylindole 193 was cyclopropanated by Nishiyama's catalyst 194 with ethyl diazoacetate to give the corresponding key cyclopropane 195 in $82 \%$ yield and $86 \%$ de. The latter was further converted into expected BMS-505130.

\subsubsection{Intramolecular Cyclopropanations}

\section{Chiral Substrates}

Initially, intramolecular cyclopropanation reactions were performed with appropriate chiral substrates, and generally occurred with complete stereocontrol, leading to the exclusive formation of one stereoisomeric product. Copper and rhodium complexes are the most popular catalysts for these reactions. For example, $\mathrm{Rh}_{2}(\mathrm{OAc})_{4}$ was shown to promote the last step in the synthesis of terpenes, such as dihydromayurone, as the only detected stereoisomer [184]. As shown in Scheme 77, this step evolved through the intramolecular cyclopropanation of chiral diazoketone 196 with complete diastereoselectivity and moderate yield (57\%). On the other hand, a 


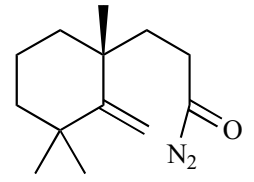

196

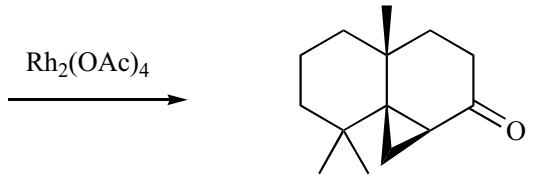

dihydromayurone $57 \%$, > 99\% de<smiles>C=C(CCC(N)=O)[C@]1(C)CCCC1(C)C</smiles>

197

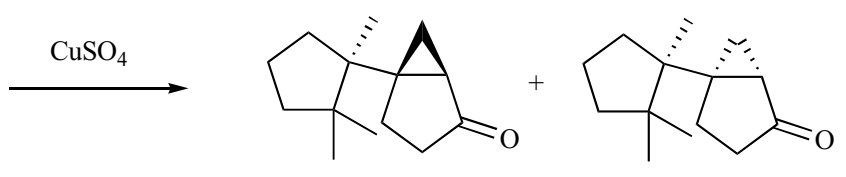

198

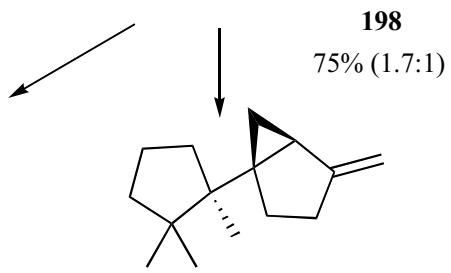

(+)- $\beta$-microbiotene (-)-microbiotol<smiles>C=C(C)[C@@H]1CC=C(C)[C@](C)(CC(=O)C(C)=N)[C@@H]1C</smiles>

199

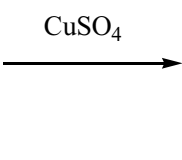<smiles>C=C[C@]1(O)CC[C@]2(C)[C@@H](C)CC[C@]2(C)[C@@H]1C</smiles>

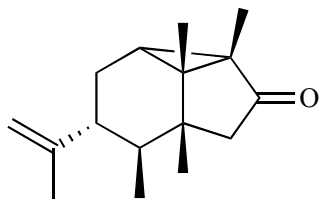

200

(+)-pinguisenol

Scheme 77. Syntheses of dihydromayurone, (-)-microbiotol, (+)- $\beta$-microbiotene and (+)-pinguisenol.

copper-catalyzed intramolecular cyclopropanation, occurring with low diastereoselectivity of $26 \%$ de, constituted the key step in the synthesis of sesquiterpenes (-)-microbiotol and ( + )- $\beta$-microbiotene starting from chiral diazoketone 197 derived from cyclogeraniol (Scheme 77) [185]. The key cyclopropane intermediate 198 was obtained in good yield $(75 \%)$. In addition, the key step to construct the bicyclic system of another sesquiterpene $(+)$-pinguisenol was based on the diastereoselective copper-catalyzed intramolecular cyclopropanation of chiral diazoketone 199 into cyclopropane 200 obtained as the only detected stereoisomer with moderate yield $(52 \%)$, followed by regioselective cyclopropane cleavage (Scheme 77) $[186]$.

\section{Chiral Catalysts}

A number of chiral catalysts have been successfully applied to the enantioselective intramolecular cyclopropanation of unsaturated diazoketones as key steps in total synthesis. For example, Nakada et $a l$. investigated the enantioselective copper-catalyzed intramolecular cyclopropanation of $\alpha$-diazo- $\beta$-keto sulfones (Scheme 78) [187]. The success of this methodology was illustrated by its application to the total syntheses of several biologically active products, such as (-)-allocyathin $\mathrm{B}_{2}$ [188], (-)-malyngolide [189], and, (-)-methyl jasmonate, as illustrated in Scheme 78 [190]. Key intermediates 202a-c of these syntheses were produced with up to $97 \%$ ee and $93 \%$ yield through intramolecular cyclopropanation of the corresponding unsaturated diazoketones 201a-c catalyzed with a combination of CuOTf with a chiral bisoxazoline ligand among 203-205.

The same group also developed the enantioselective preparation of tricyclo[4.4.0.0]dec-2-ene derivatives [191] and tricyclo[4.3.0.0]nonenones 206 by using CuOTf combined with chiral ligand 205 [192]. The resulting chiral cyclopropanes 207 were employed as key intermediates in the (formal) total syntheses of natural and biologically active products, such as (+)-busidarasin $\mathrm{C}$ and acetoxytubipofuran [191], (+)-digitoxigenin [193], (-)-platensimycin and (-)-platencin [192], as well as nemorosone, garsubellin A, clusianone, and hyperforin [194] (Scheme 79).

A related methodology was also applied to the intramolecular cyclopropanation of various $\alpha$-diazo- $\beta$-oxo-5-hexenyl phosphonates 208 [195]. In the presence of a combination of $\mathrm{CuBF}_{4}$ and bisoxazoline ligand $\mathbf{2 0 3}$ (structure in Scheme 78), (1R,5S)bicyclo[3.1.0] hexane 209 was obtained in good yield (79\%) and high enantioselectivity of $91 \%$ ee and was futher converted into natural and bioactive product $(+)$-colletoic acid (Scheme 80).

Moreover, asymmetric $\mathrm{Rh}_{2}(S \text {-MEPY })_{4}$-catalyzed cyclization of allylic diazoacetates led to chiral 1,2,3-trisubstituted cyclopropanes, 


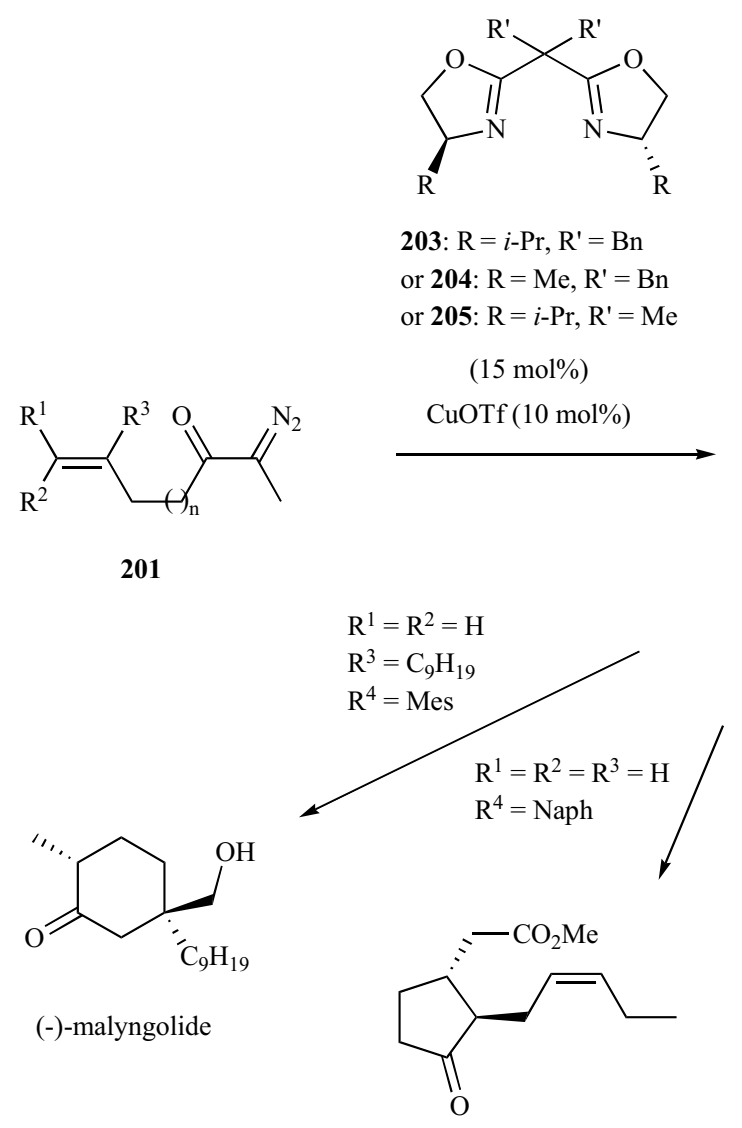

(-)-methyl jasmonate

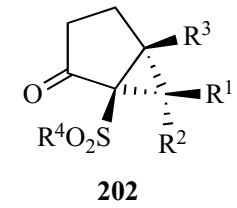

$92-93 \%, 83-97 \%$ ee

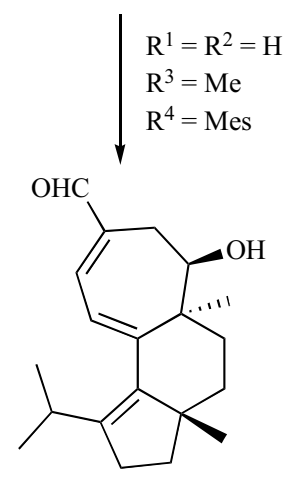

(-)-allocyathin B2

Scheme 78. Syntheses of (-)-malyngolide, (-)-methyl jasmonate and (-)-allocyathin $\mathrm{B}_{2}$ through copper-catalyzed cyclopropanations.

as rigid replacements of dipeptide arrays in several biological systems, with excellent enantioenantioselectivities [196]. For example, Martin et al. reported that allylic diazoacetate $\mathbf{2 1 0}$ underwent rhodium-catalyzed cyclopropanation with high diastereo- and enantiocontrol $(100 \%$ de, $92 \%$ ee) since the corresponding cyclopropane 211 was obtained in $80 \%$ yield as almost single stereoisomer (Scheme 81). The latter constituted a key intermediate in a total synthesis of natural biologically active product ambruticin S [197]. Furthermore, the reaction of secondary divinyldiazoacetate $\mathbf{2 1 2}$ led to the corresponding cyclopropane derivative $\mathbf{2 1 3}$ as a 50:50 mixture of two diastereomers each obtained in $94 \%$ ee and quantitative yield (Scheme 81) [198]. This mixture was further employed as key intermediate in the total synthesis of natural products, tremulenediol A and tremulenolide A [199], and to that of various cyclopropanederived peptidomimetics [200].

In 2015, Chanthamath and Iwasa reported the enantioselective intramolecular cyclopropanation of electron-deficient allylic diazoacetate 214, performed in the presence of ruthenium catalyst 215 that provided the corresponding diastereo- and enantiopure cyclopropane-fused g-lactone $\mathbf{2 1 6}$ in high yield $(90 \%)$ [201]. The latter was employed as building block in the total syntheses of drug DCG-IV and natural product dysibetaine $\mathrm{CPa}$ (Scheme 82).

\subsection{Asymmetric Michael-Initiated Ring Closures as Key Steps}

Michael-initiated ring-closing (MIRC) reactions also constitute highly efficient routes to cyclopropanes. These reactions involve a conjugate addition to an electrophilic alkene generally to produce an enolate, which then undergoes an intramolecular ring closure. A range of asymmetric Michael-initiated ring-closing reactions based on the use of chiral substrates have been applied to the synthesis of important products. As a recent example, Marek et al. have developed the MIRC reaction of chiral alkylidene bis( $p$-tolylsulfoxides) 217 with trimethylsulfoxonium ylide $\mathbf{2 1 8}$, leading to the corresponding chiral bis(p-tolylsulfinyl) cyclopropane 219 with a moderate diastereoselectivity of $72 \%$ de, which was further used to prepare enantiomerically enriched polyalkylated cyclopropane derivatives [202]. As illustrated in Scheme 83, this methodology was applied to the synthesis of $(9 R, 10 S)$-dihydrosterculic acid, a natural fatty acid [203].

\subsection{Miscellaneous Asymmetric Cyclopropanations as Key Steps}

Enantioenriched cyclopropane derivatives, such as 220, can also be efficiently prepared from the addition of the dianion of (-)dimenthylsuccinate 221 to bromochloromethane 222 (Scheme 84) [204]. This method, providing up to $98 \%$ de and $87 \%$ yield, was used in the total synthesis of natural bioactive callipeltoside [205], and to that of the first peptide nucleic acid (PNA) bearing a cyclopropane, $(S, S)$-tcprPNA [206].

LTMP-induced intramolecular cyclopropanation of unsaturated terminal epoxides provided an efficient and completely stereoselective entry to bicyclo[3.1.0]hexan-2-ols and bicyclo[4.1.0]heptan-2ols. This methodology was applied to a total synthesis of natural product $(+)$-cuparenone, starting from chiral chlorohydrin $\mathbf{2 2 3}$ that was converted into the corresponding bicyclohexanol 224 as almost single stereoisomer (>99\% de, 97\% ee) in 59\% yield (Scheme 85) [207]. 


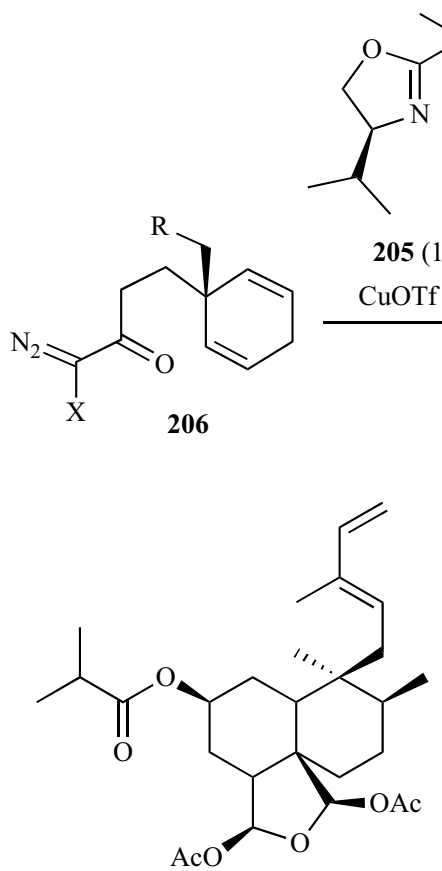

(+)-busidarasin C

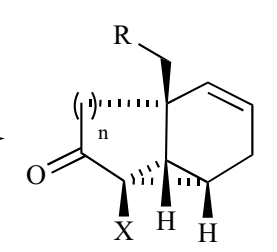

207
$\mathrm{R}=\mathrm{H}$, TBSO,

$\mathrm{X}=\mathrm{CO}_{2} t-\mathrm{Bu}, \mathrm{n}=2$

$\mathrm{R}=\mathrm{H}, \mathrm{X}=\mathrm{SO}_{2} \mathrm{Ph}, \mathrm{n}=2$

$\mathrm{R}=\mathrm{TBDPSOCH}_{2}$,

$\mathrm{X}=\mathrm{SO}_{2} \mathrm{Ph}, \mathrm{n}=1,2$

$78-91 \%, 92-95 \%$ ee<smiles>CC(=O)OCC1=CC=C[C@H]2Cc3occ(C)c3C[C@H]12</smiles>

acetoxytubipofuran

(+)-digitoxigenin<smiles>C=C1C(=O)C2(CCC(=O)Nc3c(O)ccc(C(=O)O)c3O)CC3CC(CC1C3)C2</smiles>

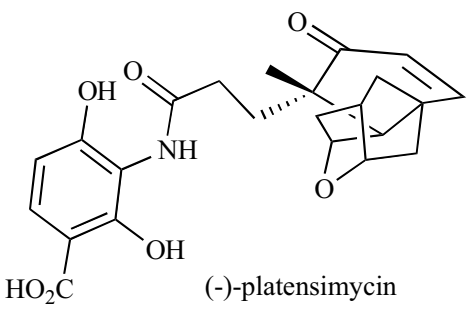

(-)-platencin

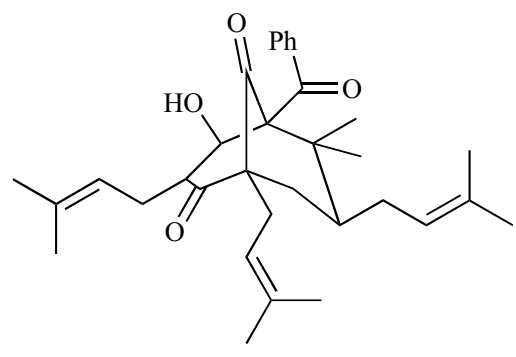

nemorosone

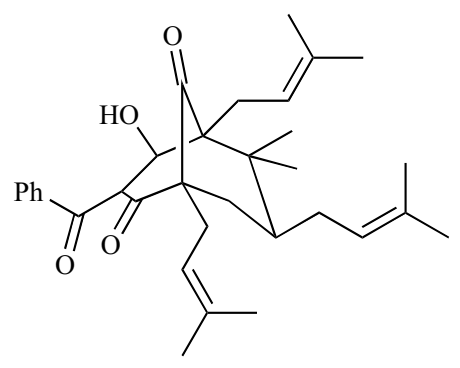

clusianone

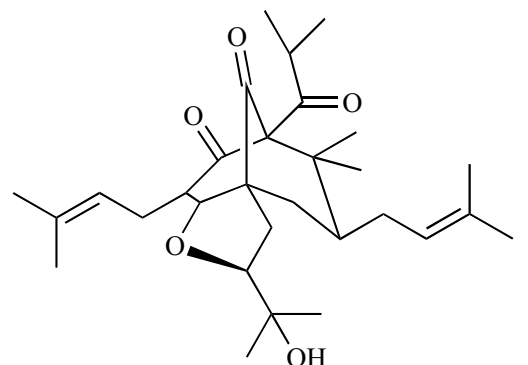

garsubellin A

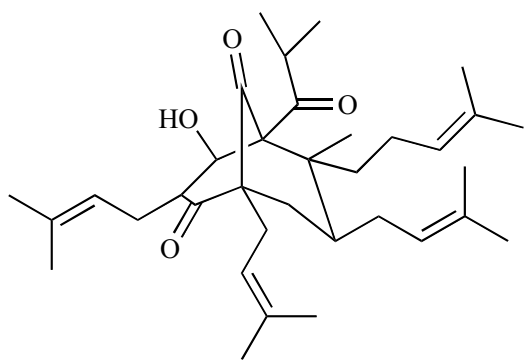

hyperforin

Scheme 79. (Formal) syntheses of (+)-busidarasin C, acetoxytubipofuran, (+)-digitoxigenin, (-)-platencin, (-)-platensimycin, nemorosone, garsubellin A, clusianone, and hyperforin though copper-catalyzed cyclopropanations. 


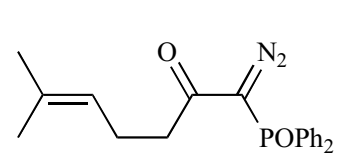

208
203 (15 mol\%)

$\mathrm{CuBF}_{4}(10 \mathrm{~mol} \%)$
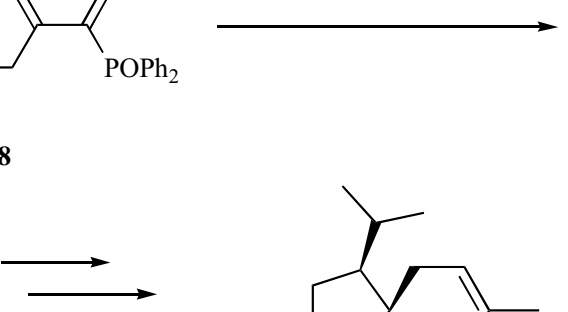

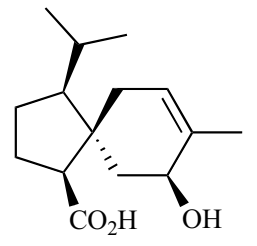

$(+)$-colletoic acid

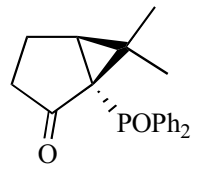

209<smiles>C/C=C\COC(=O)C=[W]</smiles>

210

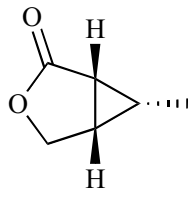

211<smiles>CC[C@H]1O[C@@H](/C(C)=C/[C@@H](C)/C=C/[C@@H]2[C@@H](/C=C/[C@@H]3O[C@H](CC(=O)O)C[C@H](O)[C@H]3O)[C@@H]2C)CC=C1C</smiles>

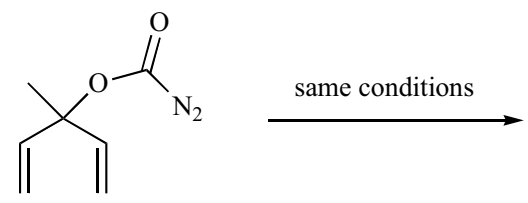

212

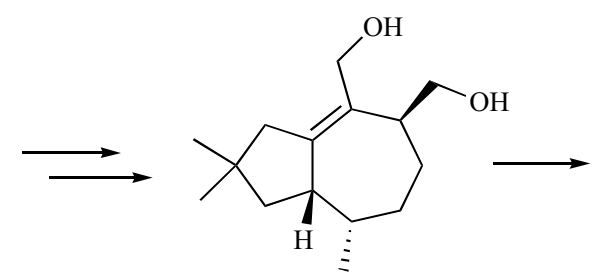

tremulenediol A

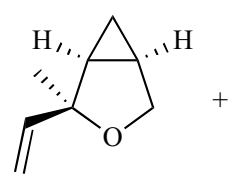

213

$99 \%, 0 \%$ de, $94 \%$ ee

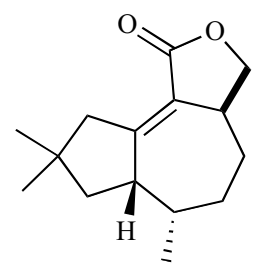

tremulenolide A

Scheme 81. Syntheses of ambruticin S, tremulenediol A and tremulenolide A through rhodium-catalyzed cyclopropanations. 


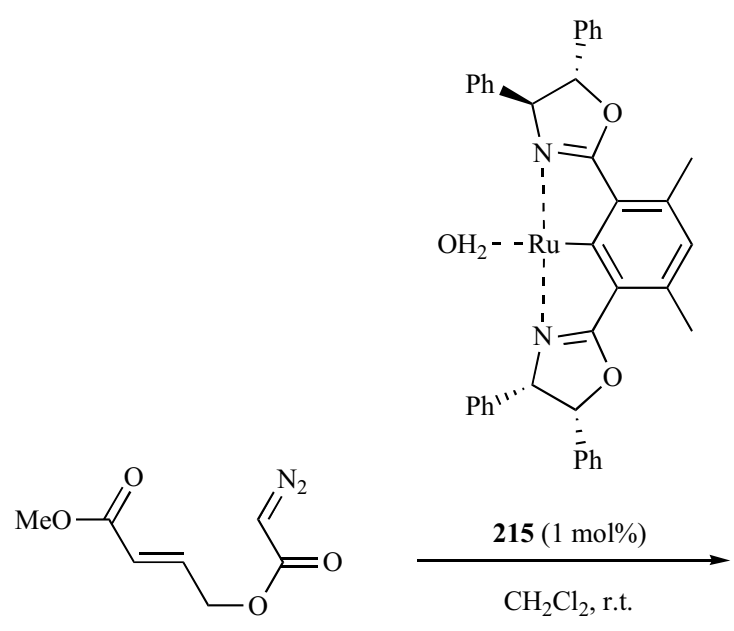

214

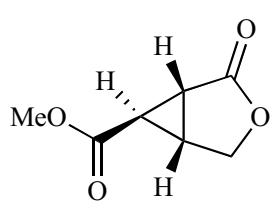

216

$90 \%,>99 \%$ de, $99 \%$ ee
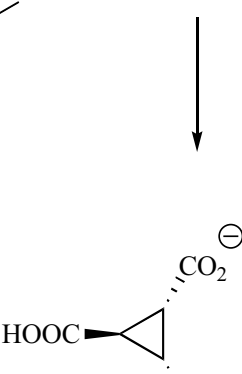

$\oplus \bar{\prime}$

dysibetaine $\mathrm{CPa}$

Scheme 82. Syntheses of DCG-IV and dysibetaine CPa through ruthenium-catalyzed cyclopropanation.

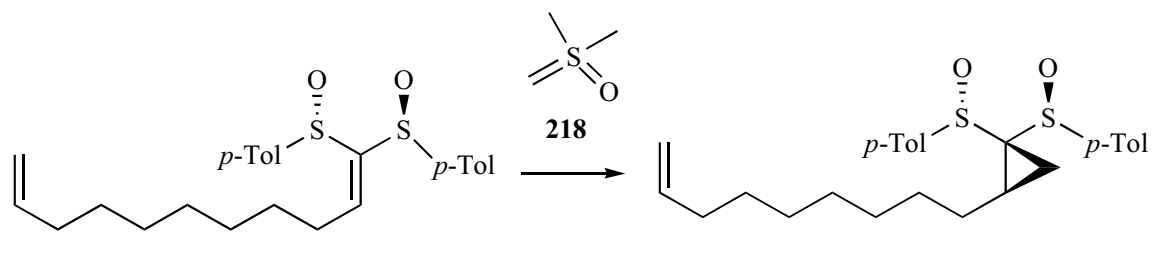

217

219

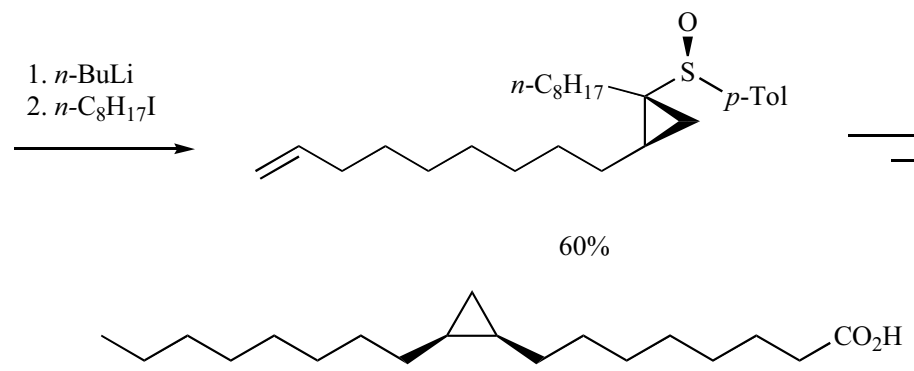

(9R,10S)-dihydrosterculic acid

Scheme 83. Synthesis of $(9 R, 10 S)$-dihydrosterculic acid. 
<smiles>[R]C(=O)CCC(=O)O</smiles>

221

$\mathrm{R}^{*}=(-)$-menthyl

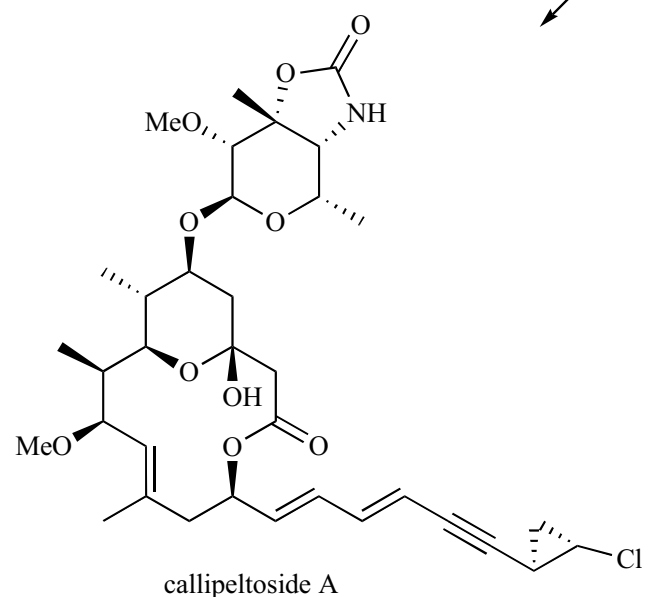<smiles>[R]OC(=O)CC1CC1C(=O)OC</smiles>

220

$87 \%,>98 \%$ de

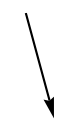<smiles>Cc1cn(CC(=O)N(CC(=O)O)[C@@H]2C[C@H]2NC(C)(C)C)c(=O)[nH]c1=O</smiles>

$(S, S)$-tcprPNA

Scheme 84. Syntheses of callipeltoside A and $(S, S)$-tcprPNA.<smiles>C=C(c1ccc(C)cc1)C(C)(C)C[C@H](O)CCl</smiles>

223

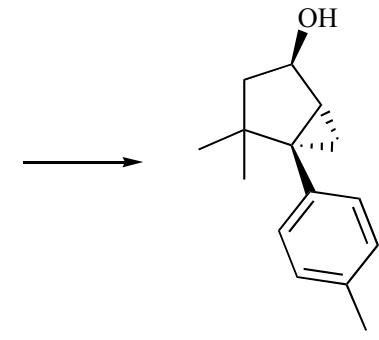

224

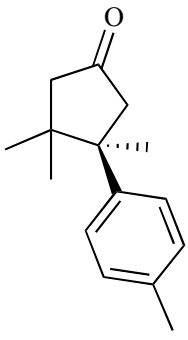

$(+)$-cuparenone

$59 \%, 100 \%$ de, $97 \%$ ee

Scheme 85. Synthesis of (+)-cuparenone.

In 2015, Cramer et al. reported an efficient access to the sevenmembered ring of the cyclopropylindolobenzazepine core of antiviral agent beclabuvir [208]. As shown in Scheme 86, a TADDOLbased phosphoramidite palladium(0) complex 225 enabled the enantioselective Friedel-Crafts reaction by $\mathrm{C}-\mathrm{H}$ insertion on cyclopropane $\mathbf{2 2 6}$ to give pentacyclic chiral product 227 with $80 \%$ yield and $89 \%$ ee. This method provided efficient access to the construction of the seven-membered ring of the cyclopropylindolobenzazepine core of beclabuvir.

In 1989, the group of Kulinkovich showed that the reaction of esters with a mixture of $\mathrm{Ti}(\mathrm{O}-i-\mathrm{Pr})_{4}$ and an excess of a Grignard reagent led to the corresponding substituted cyclopropanols [209]. Later, asymmetric versions of this methodology have been devel- oped by using either chiral substrates or chiral titanium catalysts. For example, Singh et al. demonstrated that, under Kulinkovich reaction conditions, chiral b-alkoxy ester $\mathbf{2 2 8}$ afforded the corresponding cyclopropanol $\mathbf{2 2 9}$ as the only detected stereoisomer in high yield $(87 \%)$, that constituted the key intermediate for the synthesis of all the stereoisomers of tarchonanthuslactone, a naturally occurring biologically active product (Scheme 87) [210].

In 2006, a total synthesis of antitumor agent (-)-irofulven was developed on the basis of the reaction between strained ketene hemithioacetal 230 and methyl pyruvate 231 performed in the presence of chiral bisoxazoline copper catalyst 232 [211]. The reaction afforded the corresponding functionalized chiral cyclopropane $\mathbf{2 3 3}$ in both high yield (95\%) and enantioselectivity (92\% ee) that was 

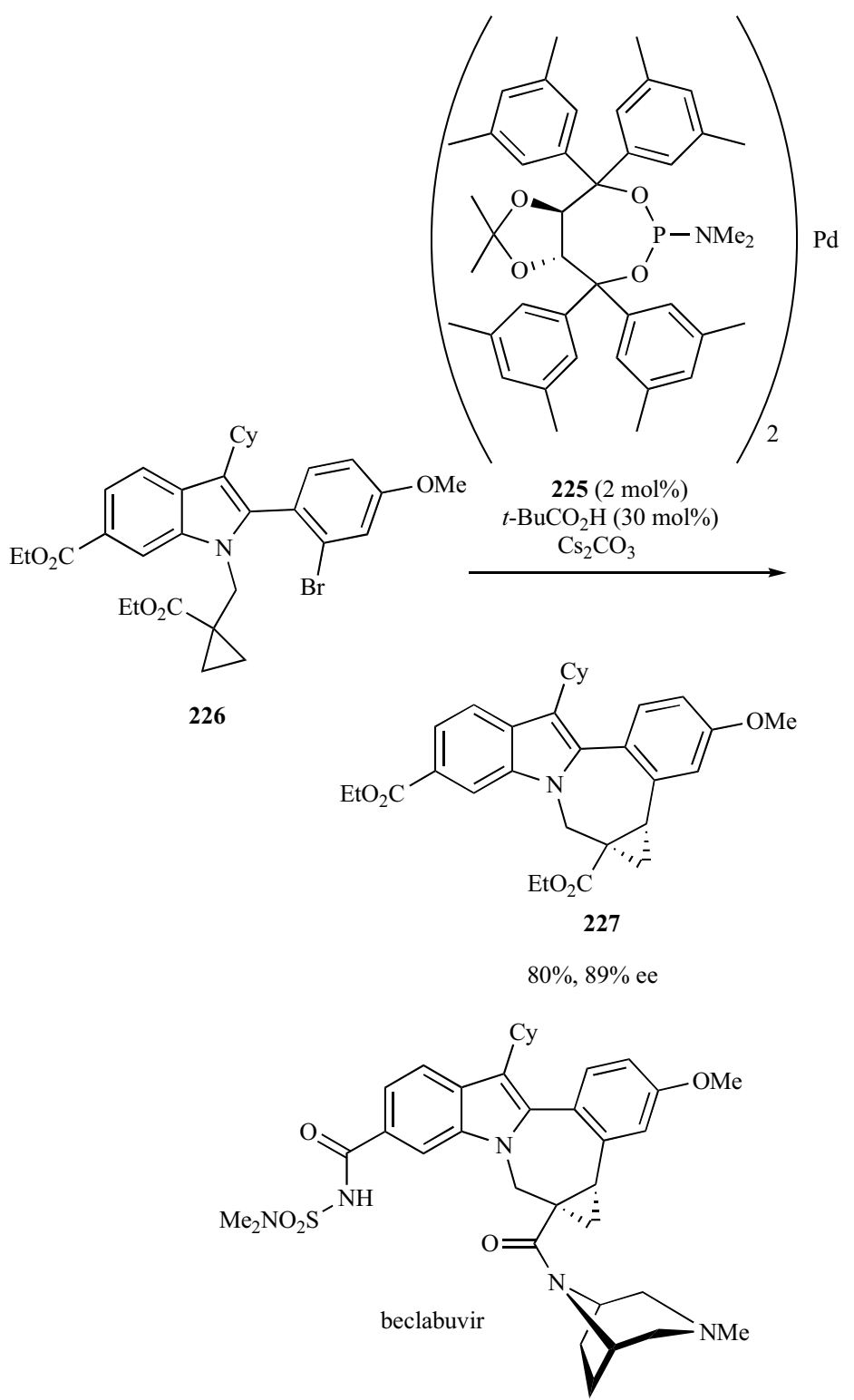

Scheme 86. Synthesis of the cyclopropylindolobenzazepine core of beclabuvir.

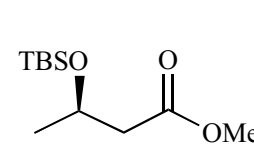

228

$$
\begin{gathered}
\mathrm{Ti}(\mathrm{O}-i-\mathrm{Pr})_{4} \\
\mathrm{EtMgBr}
\end{gathered}
$$
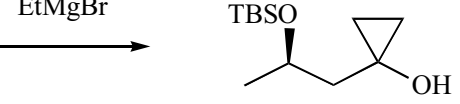

229
$87 \%,>99 \%$ ee

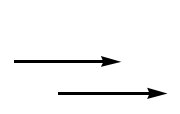<smiles>C[C@@H](C[C@H]1CC=CC(=O)O1)OC(=O)CCc1ccc(O)c(O)c1</smiles>

tarchonanthuslactone

Scheme 87. Synthesis of tarchonanthuslactone.

further converted into expected (-)-irofulven, as shown in Scheme 88

\section{CONCLUSION}

This review highlighted major total syntheses of biologically active compounds, including natural products, using chiral threemembered rings as key intermediates. The interest towards synthetic methodologies for their preparation has increased in the last decades, dictated either by the biological activities that display many naturally occurring products bearing a three-membered unit or by their ring strain making them useful precursors of more complex interesting molecules. Classic as well as modern protocols, such as organocatalyzed reactions, have been applied to make asymmetric aziridination, azirination, epoxidation, thiirination, and cyclopropanation key steps of a wide number of syntheses of important products. The use of classical methods which employ chiral substrates and auxiliaries is still highly frequent particularly for asymmetric aziridination and cyclopropanation. On the other hand, the development of enantioselective catalytic methodologies has witnessed exponential growth during the last decade, in particular, in the area of asymmetric organocatalytic epoxidations. The development of new catalytic systems including organocatalysts or chiral 


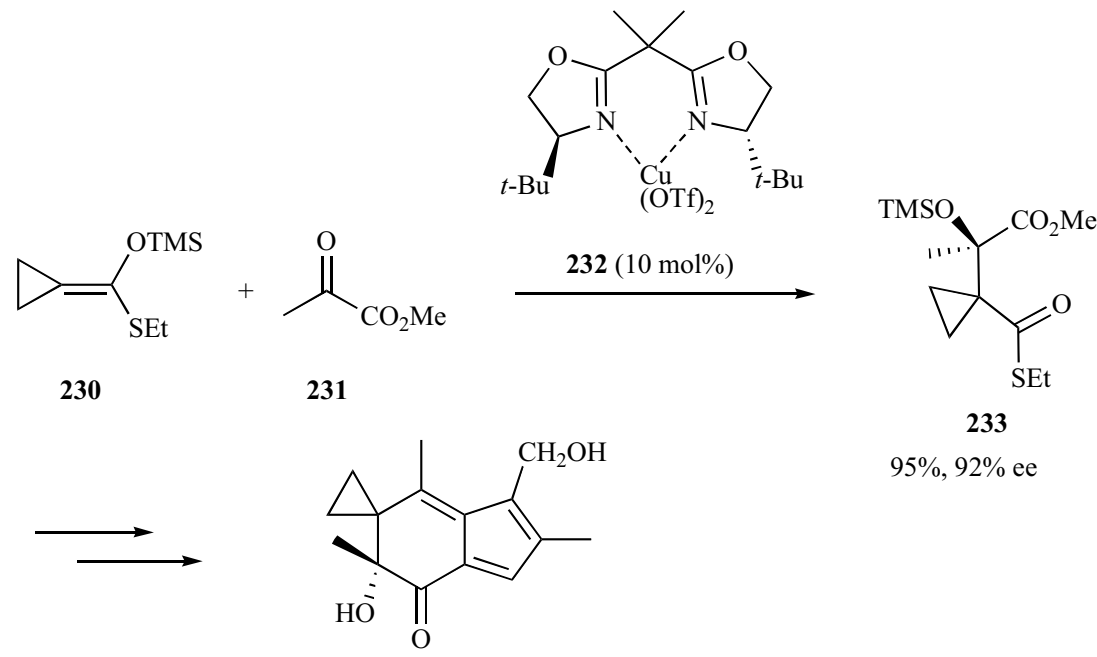

(-)-irofulven

Scheme 88. Synthesis of (-)-irofulven.

ligands for metal catalysts for the synthesis of the other threemembered rings is still in its infancy, However, their expansion is awaited in the coming few years, opening the way to the synthesis of other biologically important products. Undoubtedly, the chemistry of three-membered rings will continue to play a dominant role in the history of total synthesis for many years.

\section{REFERENCES}

[1] Salaun, J. Cyclopropane derivatives and their diverse biological activities. Top. Curr. Chem., 2000, 207, 1-67. (b) Faust, R. Fascinating natural and artificial cyclopropane architectures. Angew. Chem. Int. Ed., 2001, 40, 22512253.

[2] (a) De Meijere, A.; Kozhushkov, S.I; Kokin, A.A.; Emme, I. Redlich, S ; Schreiner, P.R. New structurally interesting cyclopropane derivatives. A world of wonders and surprises. Pure Appl. Chem., 2003, 75, 549-562. (b) Rubin, M.; Rubina, M.; Gevorgyan, V. Transition metal chemistry of cyclopropenes and cyclopropanes. Chem. Rev., 2007, 107, 3117-3179. (c) Classics in Stereoselective Synthesis; Carreira, E.M.; Kvaerno, L., Eds.; Wiley: Weinheim, 2009; chap. 15, pp. 483-514. (d) El-Deftar, M.; Adly, F.G.; Gardiner, M.G.; Ghanem, A. Chiral dirhodium catalysts: A new era for asymmetric catalysis. Curr. Org. Chem., 2012, 16, 1808-1836. (e) Chen, D.Y.K.; Pouwer, R.H; Richard, J.A. Recent advances in the total synthesis of cyclopropanecontaining natural products. Chem. Soc. Rev., 2012, 41, 4631-4642. (f) Adly, F.G.; Ghanem, A. Chiral dirhodium(II) carboxylates and carboxamidates as effective chemzymes in asymmetric synthesis of three-membered carbocycles. Chirality, 2014, 26, 692-711.

[3] De Meijere, A. Topics in Current Chemistry; Springer: Berlin, 2000

[4] Andrei, Y. Introduction: Small heterocycles in synthesis. Chem. Rev., 2014, 114(16), 7783-7783.

[5] Murphree, S.S. Three-Membered Heterocycles. Structure and Reactivity. In: Modern Heterocyclic Chemistry; Alvarez, J.; Vaquero, J.J.; Barluenga, J. Eds.; Wiley: Weinheim, 2011; pp. 11-162.

[6] (a) For reviews concentrating on not especially asymmetric aziridination (and epoxidation), see: (a) Aggarwal, V.K.; McGarrigle, E.M.; Shaw, M.A. Science of Synthesis, 2010, 37, 311-347. (b) Muchalski, H.; Johnston, J.N. Science of Synthesis, 2011, 1, 155-184. (c) Karila, D.; Dodd, R.H. Recent progress in iminoiodane-mediated aziridination of olefins. Curr. Org. Chem., 2011, 15, 1507-1538. (d) Chang, J.W.W.; Ton, T.M.U.; Chan, P.W.H. Transition-metal-catalyzed aminations and aziridinations of $\mathrm{C}-\mathrm{H}$ and $\mathrm{C}=\mathrm{C}$ bonds with iminoiodinanes. Chem. Rec., 2011, 11, 331-357. (e) Jung, N.; Bräse, S. New catalysts for the transition-metal-catalyzed synthesis of aziridines.
Angew. Chem., Int. Ed., 2012, 51, 5538-5540. (f) Chawla, R.; Singh, A.K.; Yadav, L.D.S. Organocatalysis in synthesis and reactions of epoxides and aziridines. $R S C A d v$., 2013, 3, 11385-11403. (g) Wang, P.A. Organocatalyzed enantioselective desymmetrization of aziridines and epoxides. Beilstein $J$. Org. Chem., 2013, 9, 1677-1695. (h) Charette, A.B.; Lebel, H.; Roy, M.N Asymmetric Cyclopropanation and Aziridination Reactions. In: CopperCalalyzed Asymmetric Synthesis; Alexakis, A.; Krause, N.; Woodward, S., Eds.; Wiley-VCH: Weinheim, 2014; pp.203-258. (i) Pellissier, H. Recent develoments in asymmetric aziridination. Adv. Synth Catal, 2014, 356, 1899 1935. (j) Degennaro, L.; Trinchera, P.; Luisi, R. Recent advances in the stereoselective synthesis of aziridines. Chem. Rev., 2014, 114, 7881-7929. (k) Callebaut, G.; Meiresonne, T.; De Kimpe, N.; Mangelinckx, S. Synthesis and reactivity of 2-(Carboxymethyl)aziridine derivatives. Chem. Rev., 2014, $114,7954-8015$

[7] (a) Pellissier, H. Recent developments in asymmetric aziridination. Tetrahedron, 2010, 66, 1509-1555. (b) Padwa, A. Aziridines and Azirines: Monocyclic. In: Comprehensive Heterocyclic Chemistry III; Ramsden, A.; Scriven, E.F.V.; Taylor, R.J.K., Eds.; Elsevier: Oxford, 2008; vol. 1, pp. 1-104. (c) Bisol, B.T.; Mandolesi Sà, M. Recentes avanços na preparação de aziridinas. Aplicações sintéticas e implicações mecanísticas. Quim. Nova, 2007, 30, 106-115. (d) Singh, G.S.; D'hooghe, M.; De Kimpe, N. Synthesis and reactivity of $c$-heteroatom-substituted aziridines. Chem. Rev., 2007, 107, 20802135. (e) Sweeney, J.B. Synthesis of Aziridines. In: Aziridines and Epoxides in Organic Synthesis; Yudin, A., Ed.; Wiley-VCH: Weinheim, 2006; chap. 4, pp. 117-144. (f) Aggarwal, V.K.; Badine, M.; Moorthie, V. Asymmetric Synthesis of Epoxides and Aziridines from Aldehydes and Imines. In: Aziridines and Epoxides in Organic Synthesis; Yudin, V., Ed.; Wiley-VCH: Weinheim, 2006; chap. 1, pp. 1-35. (g) Zhou, P.; Chen, B.C.; Davis, F.A. Asymmetric Syntheses with Aziridinecarboxylate and Aziridinephosphonate Building Blocks. In: Aziridines and Epoxides in Organic Synthesis; Yudin, A., Ed.; Wiley-VCH: Weinheim, 2006; chap. 3, pp. 73-115. (h) Padwa, A.; Murphree, S.S. Epoxides and aziridines - A mini review. Arkivoc, 2006, III, 6-33. (i) Mößner, C.; Bolm, C. Catalyzed Asymmetric Aziridinations. In: Transition Metals for Organic Synthesis, $2^{\text {nd }}$ ed.; Wiley-VCH: Weinheim, 2004; pp. 389-402. (j) Cardillo, G.; Gentilucci, L.; Tolomelli, A. Aziridines and oxazolines: Valuable intermediates in the synthesis of unusual amino acids. Aldrichim. Acta, 2003, 36, 39-50. (k) Lee, W.K.; Ha, H.J. Highlights of the chemistry of enantiomerically pure aziridine-2-carboxylates. Aldrichim. Acta, 2003, 36, 57-63. (1) Padwa, A.; Murphree, C. Three-membered Ring Systems. In: Progress in Heterocyclic Chemistry; Gribble, G.W.; Joule, J.A., Eds.; Pergamon: Oxford, 2003; vol. 15, pp. 75-99. (m) Müller, P.; Fruit, C. Enantioselective catalytic aziridinations and asymmetric nitrene insertions into CH bonds. Chem. Rev., 2003, 103, 2905-2919. (n) Padwa, A.; Murphree, S.S. Three-membered Ring Systems. In: Progress in Heterocyclic Chemistry; Gribble, G.W.; Gilchrist, T.L., Eds.; Elsevier Science: Oxford, 2000; vol. 12 , pp. 57-76. (o) Osborn, H.M.I.; Sweeney, J.B. The asymmetric synthesis of aziridines. Tetrahedron: Asymmetry, 1997, 8, 1693-1715. (p) Pearson, W.H.; Lian, B.W.; Bergmeier, S.C. Aziridines and Azirines: Monocyclic. In: Comprehensive Heterocyclic Chemistry II; Padwa, A., Ed; Pergamon: Oxford, 1996; vol. $1 A$, pp. 1. (q) Kemp, J.E.G. Addition Reactions with Formation of Carbon-Nitrogen Bonds. In: Comprehensive Organic Synthesis; Pergamon: Oxford, 1991; vol. 7, pp. 469-513. (r) Padwa, A.; Woolhouse, A.D. Aziridines, Azirines and Fused-ring Derivatives. In: Comprehensive Heterocyclic Chemistry; Lwowski, W., Ed.; Pergamon Press: Oxford, 1984; vol. 7, pp. 4793. 
(a) Padwa, A. Intermolecular 1,3-Dipolar Cycloadditions. In: Comprehensive Organic Synthesis; Pergamon: Oxford, 1991; vol. 4, pp. 1069-1109. (b) Tanner, D. Stereocontrolled synthesis via chiral aziridines. Pure Appl. Chem., 1993, 65, 1319-1328. (c) Tanner, D. A highly efficient aminohydroxylation process. Angew. Chem. Int. Ed. Engl., 1994, 33, 599-619. (d) Atkinson, R.S. 3-Acetoxyaminoquinazolinones (QNHOAc) as aziridinating agents: Ringopening of N-(Q)-substituted aziridines. Tetrahedron, 1999, 55, 1519-1559. (e) Stamm, H. Nucleophilic ring opening of aziridines. J. Prakt. Chem., 1999, 341, 319-331. (f) McCoull, W.; Davis, F.A. Recent synthetic applications of chiral aziridines. Synthesis, 2000, (10), 1347-1365. (g) Righi, G.; Bonini, C. In: Targets Heterocycl. Systems: Chemistry and Properties; Attanasi, O.A.; Spinelli, D., Eds.; Italian Society of Chemistry: Rome, 2000; vol. 4, pp. 139-165. (h) Zwanenburg, B.; Holte, T.P. The Synthetic Potential of Three-Membered Ring Aza-Heterocycles. In: Stereoselective Heterocyclic Synthesis III, Metz, P., Ed.; Springer: Berlin, 2001; vol. 216, pp. 93-124. (i) Sweeney, J.B. Aziridines: Epoxides' ugly cousins? Chem. Soc. Rev., 2002 31, 247-258. (j) Aires-De-Sousa, J.; Prabhakar, S.; Lobo, A.M.; Rosa, A.M.; Goes, M.J.S.; Corvo, M.C.; Williams, D.J.; White, A.J.P. Asymmetric synthesis of $N$-aryl aziridines. Tetrahedron: Asymmetry, 2002, 12, 3349-3365. (k) $\mathrm{Hu}$, X.E. Nucleophilic ring opening of aziridines. Tetrahedron, 2004, 60 2701-2743. (1) Pineschi, M. Asymmetric ring-opening of epoxides and aziridines with carbon nucleophiles. Eur. J. Org. Chem., 2006, (22), 49794988. (m) Yudin, A, Ed. Aziridines and Epoxides in Organic Synthesis; Wiley-VCH: Weinheim, 2006. (n) Florio, S.; Luisi, R. Aziridinyl anions: Generation, reactivity, and use in modern synthetic chemistry. Chem. Rev., 2010, 110, 5128-5157. (o) Lu, P. Recent developments in regioselective ring opening of aziridines. Tetrahedron, 2010, 66, 2549-2560.

[9] Zalialov, I.A.; Dahanubar, V.H. Aziridines and aziridinium ions in the practical synthesis of pharmaceutical intermediates-a perspective. Curr. Opin. Drug Discov. Devel., 2002, 5, 918-927.

[10] Dauban, P.; Dodd, R.H. Iminoiodanes and C-N bond formation in organic synthesis. Synlett, 2003, 11, 1571-1586.

[11] Trost, B.M.; Dong, G. New class of nucleophiles for palladium-catalyzed asymmetric allylic alkylation. total synthesis of agelastatin A. J. Am. Chem. Soc., 2006, 128, 6054-6055.

[12] Di Chenna, P.H.; Dauban, P.; Ghini, A.; Baggio, R.; Garland, M.T.; Burton, G.; Dodd, R.H. PhI=NSes mediated aziridination of 11-pregnane derivatives: Synthesis of an 11,12-aziridino analogue of neuroactive steroids. Tetrahedron, 2003, 59, 1009-1014.

[13] Keaney, G.F.; Wood, J.L. Rhodium perfluorobutyramide $\left(\mathrm{Rh}_{2}(\mathrm{pfm})_{4}\right): \mathrm{A}$ synthetically useful catalyst for olefin aziridinations. Tetrahedron Lett., 2005, 46, 4031-4034.

[14] (a) Trost, B.M.; Zhang, T. A concise synthesis of (-)-oseltamivir. Angew. Chem. Int. Ed. Engl., 2008, 47, 3759-3761. (b) Trost, B.M.; Zhang, T. Development of a concise synthesis of (-)-oseltamivir (tamiflu). Chem. Eur. J., 2011, 17, 3630-3643

[15] Diaper, C.M.; Sutherland, A.; Pillai, B.; James, M.N.G.; Semchuk, P.; Blanchard, J.S.; Vederas, J.C. The stereoselective synthesis of aziridine analogues of diaminopimelic acid (DAP) and their interaction with dap epimerase. Org. Biomol. Chem., 2005, 3, 4402-4411.

[16] Katsuki, T. Azide compounds: Nitrogen sources for atom-efficient and ecologically benign nitrogen-atom-transfer reactions. Chem. Lett., 2005, 34 , 1304-1309.

[17] Yoshimisu, T.; Ino, T.; Tanaka, T. Total synthesis of (-)-agelastatin A. Org. Lett., 2008, 10, 5457-5460

[18] Mendlik, M.T.; Tao, P.; Hadad, C.M.; Coleman, R.S.; Lowary, T.L. Synthesis of L-Daunosamine and L-ristosamine glycosides via photoinduced aziridination. Conversion to thioglycosides for use in glycosylation reactions. $J$. Org. Chem., 2006, 71, 8059-8070

[19] Barros, M.T.; Matias, P.M.; Maycock, C.D.; Ventura, R.M. Aziridines as a protecting and directing group. Stereoselective synthesis of $(+)$-Bromoxone. Org. Lett., 2003, 5, 4321-4323.

[20] Tarrade, A.; Dauban, P.; Dodd, R.H. Enantiospecific total synthesis of (-)Polyoxamic acid using 2,3-aziridino- $\gamma$-lactone methodology. J. Org. Chem., 2003, 68, 9521-9524

[21] Unthank, M.G.; Hussain, N.; Aggarwal, V.K. The use of vinyl sulfonium salts in the stereocontrolled asymmetric synthesis of epoxide- and aziridinefused heterocycles: Application to the synthesis of (-)-balanol. Angew. Chem. Int. Ed. Engl, 2006, 45, 7066-7069.

[22] Paleo, M.R.; Aurrecoechea, N.; Jung, K.Y.; Rapoport, H. Formal enantiospecific synthesis of (+)-FR900482. J. Org. Chem., 2003, 68, 130-138.

Trost, B.M.; O'Boyle, B.M. Synthesis of 7-Epi (+)-FR900482: An epimer of comparable anti-cancer activity. Org. Lett., 2008, 10, 1369-1372.

[24] Hashimoto, M.; Matsumoto, M.; Terashima, S. Synthetic studies of carzinophilin. Part 2: Synthesis of 3,4-dibenzyloxy-2-methylidene-1azabicyclo[3.1.0]hexane systems corresponding to the $\mathrm{C} 1-\mathrm{C} 17$ fragment of carzinophilin. Tetrahedron, 2003, 59, 3041-3062.

[25] (a) Bobeck, D.R.; Warner, D.L.; Vedejs, E. Internal azomethine ylide cycloaddition methodology for access to the substitution pattern of aziridinomitosene A. J. Org. Chem., 2007, 72, 8506-8518. (b) Vedejs, E.; Naidu, B.N.; Klapars, A.; Warner, D.L.; Li, V.S.; Na, Y.; Kohn, H. Synthetic enantiopure aziridinomitosenes: Preparation, reactivity, and DNA alkylation studies. $J$. Am. Chem. Soc., 2003, 125, 15796-15806.
[26] Kongkathip, B.; Akkarasamiyo, S.; Kongkathip, N. A new and efficien asymmetric synthesis of oseltamivir phosphate (Tamiflu) from D-glucose. Tetrahedron, 2015, 71, 2393-2399.

[27] Papaioannou, N.; Blank, J.T.; Miller, S.J. Enantioselective synthesis of an aziridinomitosane and selective functionalizations of a key intermediate. $J$. Org. Chem., 2003, 68, 2728-2734

[28] Fürmeier, S.; Metzger, J.O. Fat-Derived aziridines and their $\boldsymbol{n}$-substituted derivatives: Biologically active compounds based on renewable raw materials. Eur. J. Org. Chem., 2003, (4), 649-659.

[29] Koohang, A.; Bailey, J.L. Coates, R.M; Erickson, H.K.; Owen, D.; Poulter, C.D. Enantioselective inhibition of squalene synthase by aziridine analogues of presqualene diphosphate. J. Org. Chem., 2010, 75, 4769-4777.

[30] Khantikaew, I.; Takahashi, M.; Kumamoto, T.; Suzuki, N.; Ishikawa, T. Synthesis of (-)-benzolactam-V8 by application of asymmetric aziridination. Tetrahedron, 2012, 68, 878-882

[31] (a) Satoh, N.; Akiba, T.; Yokoshima, S.; Fukuyama, T. A practical synthesis of (-)-oseltamivir. Angew. Chem. Int. Ed. Engl., 2007, 46, 5734-5736. (b) Satoh, N.; Akiba, T.; Yokoshima, S.; Fukuyama, T. A practical synthesis of (-)-oseltamivir. Tetrahedron, 2009, 65, 3239-3245.

[32] Feng, X.; Duesler, E.N.; Mariano, P.S. Pyridinium Salt photochemistry in concise route for synthesis of the trehazolin aminocyclitol, trehazolamine. $J$ Org. Chem., 2005, 70, 5618-5623

[33] Fruit, C.; Robert-Paillard, F.; Bernardinelli, G.; Mueller, P.; Dodd, R.H.; Dauban, P. Diastereoselective rhodium-catalyzed nitrene transfer starting from chiral sulfonimidamide-derived iminoiodanes. Tetrahedron: Asymmetry, 2005, 16, 3484-3487.

[34] Evans, D.A.; Woerpel, K.A.; Hinman, M.M.; Faul, M.M. Bis(oxazolines) as chiral ligands in metal-catalyzed asymmetric reactions. Catalytic, asymmetric cyclopropanation of olefins. J. Am. Chem. Soc., 1991, 113, 726-728.

[35] Cranfill, D.C.; Lipton, M.A. Enantio- and diastereoselective synthesis of $(R, R)$-B-Methoxytyrosine. Org. Lett., 2007, 9, 3511-3513.

[36] Nemoto, T.; Hayashi, M.; Xu, D.; Hamajima, A.; Hamada, Y. Enantioselective synthesis of $(R)$-Sumanirole using organocatalytic asymmetric aziridination of an $\alpha, \beta$-unsaturated aldehyde. Tetrahedron: Asymmetry, 2014, 25, 1133-1137.

[37] Arai, H.; Sugaya, N.; Sasaki, N.; Makino, K.; Lectard, S.; Hamada, Y. Enantioselective aziridination reaction of $\alpha \beta$-unsaturated aldehydes using an organocatalyst and tert-butyl $N$-arenesulfonyloxycarbamates. Tetrahedron Lett., 2009, 50, 3329-3332.

[38] (a) Jacobsen, E.N. Aziridination. In: Comprehensive Asymmetric Catalysis II; Jacobsen, E.N.; Pfaltz, A.; Yamamoto, H., Eds; Springer: Berlin, 1999; pp. 607. (b) Katsuki, T. Metal Complexes as Catalysts for Oxygen, Nitrogen, and Carbon-atom Transfer Reactions. In: Comprehensive Coordination Chemistry II; McCleverty, J., Ed; Elsevier Science Ltd.: Oxford, 2003; vol. 9, pp. 207-264.

[39] Patwardhan, A.P.; Pulgam, V.R.; Zhang, Y.; Wulff, W.D. Highly diastereoselective alkylation of aziridine-2-carboxylate esters: Enantioselective synthesis of LFA-1 antagonist BIRT-377. Angew. Chem. Int. Ed. Engl., 2005 , 44, 6169-6172.

[40] Wang, Z.; Li, F.; Zhao, L.; He, Q.; Chen, F.; Zheng, C. An efficient enantioselective synthesis of florfenicol via asymmetric aziridination. Tetrahedron, 2011, 67, 9199-9203.

[41] Mukherjee, M.; Zhou, Y.; Gupta, A.K.; Guan, Y.; Wulff, W.D. A genera synthesis of sphinganines through multicomponent catalytic asymmetric aziridination. Eur. J. Org. Chem., 2014, 7, 1386-1390.

[42] Aggarwal, V.K.; Winn, C.L. Catalytic, asymmetric sulfur ylide-mediated epoxidation of carbonyl compounds: Scope, selectivity, and applications in synthesis. Acc. Chem. Res., 2004, 37, 611-620.

[43] Aggarwal, V.K.; Vasse, J.L. Asymmetric sulfur ylide mediated aziridination: Application in the synthesis of the side chain of taxol. Org. Lett., 2003, 5, 3987-3990

[44] (a) Heimgartner, H. 3-Amino-2H-Azirines. Synthons for $\alpha, \alpha$-Disubstituted $\alpha$ Amino acids in heterocycle and peptide synthesis [New analytical methods (43)]. Angew. Chem. Int. Ed. Engl., 1991, 30, 238-264. (b) Würthwein, E.U.; Hergenröther, T.; Quast, H. Exolendo preferences of double bonds in threemembered ring compounds - The bias toward endocyclic unsaturation in 3 Alkyl- and 3-Amino- $2 \mathrm{H}$-azirines: A theoretical and experimental study. Eur. J. Org. Chem., 2002, (11), 1750-1755.

[45] (a) Padwa, A. Chapter 1 - Cycloaddition and cyclization chemistry of $2 \mathrm{H}$ Azirines. Adv. Heterocycl. Chem., 2010, 99, 1-31. (b) Lemos, A. Addition and cycloaddition reactions of phosphinyl- and phosphonyl-2H-Azirines, nitrosoalkenes and azoalkenes. Molecules, 2009, 14, 4098-4119. (c) Padwa, A. Aziridines and Azirines: Monocyclic. In: Comprehensive Heterocyclic Chemistry III; Ramsden, A.; Scriven, E.F.V.; Taylor, R.J.K., Eds.; Elsevier: Oxford, 2008; vol. 1, pp. 1-104. (d) Pinho-E-Melo, T.M.V.D.; D’A. Rocha Gonsalves, A.M. Exploiting 2-Halo-2H-Azirine chemistry. Curr. Org. Synth., 2004, 1, 275-292. (e) Palacios, F.; Ochoa De Retana, A.M.; De Marigorta, E.M.; De los Santo, J.M. Preparation, properties and synthetic applications of 2H-Azirines a review. Org. Prep. Proc. Int., 2002, 34, 219-269. (f) Palacios, F.; Ochoa De Retana, A.M.; De Marigorta, E.M.; De los Santos, J.M. $2 \mathrm{H}$-Azirines as synthetic tools in organic chemistry. Eur. J. Org. Chem., 2001, (13), 2401-2414. (g) Pearson, W.H.; Lian, B.W.; Bergmeier, S.C. Aziridines and Azirines: Monocyclic. In: Comprehensive Heterocyclic Chemistry II; Katritzky, A.R.; Rees, C.W.; Scriven, E.F.V., Eds.; Elsevier: Oxford, 
1996; vol. 1A, pp. 1-60. (h) Nair, V. Azirines. In : Small Ring HeterocyclesPart 1, Aziridines, Azirines, Thiiranes, Thiirenes; Hassner, A., Ed.; Wiley: New York, 1983; pp. 215-332.

[46] Palacios, F.; Ochoa De Retana, A.M.; Gil, J.I.; Ezpeleta, J.M. Simple asymmetric synthesis of $2 \mathrm{H}$-Azirines derived from phosphine oxides. J. Org. Chem., 2000, 65, 3213-3217.

[47] Palacios, F.; Ochoa De Renata, A.M.; Gil, J.I. Easy and efficient synthesis of enantiomerically enriched $2 \mathrm{H}$-azirines derived from phosphonates. Tetrahedron Lett., 2000, 41, 5363-5366.

[48] Palacios, F. Aparicio, D.; Ochoa De Renata, A.M ; De los Santos, J.M. Gil, J.I.; Lopez De Munain, R. Asymmetric synthesis of $2 \mathrm{H}$-aziridine phosphonates, and $\alpha$ - or $\beta$-aminophosphonates from enantiomerically enriched $2 \mathrm{H}$ azirines. Tetrahedron: Asymmetry, 2003, 14, 689-700.

[49] Skepper, C.K.; Dalisay, D.S.; Molinski, T.F. Synthesis and antifungal activity of (-)-(Z)-Dysidazirine. Org. Lett., 2008, 10, 5269-5271.

[50] Skepper, C.K.; Dalisay, D.S.; Molinski, T.F. Synthesis and chain-dependent antifungal activity of long-chain $2 H$-azirine-carboxylate esters related to dysidazirine. Bioorg. Med. Chem. Lett., 2010, 20, 2029-2032.

[51] Sakamoto, S.; Inokuma, T.; Takemoto, Y. Organocatalytic asymmetric neber reaction for the synthesis of $2 H$-Azirine carboxylic esters. Org. Lett., 2011, 13, 6374-6377.

[52] (a) Aziridines and Epoxides in Organic Synthesis; Yudin, A., Ed.; WileyVCH: Weinheim, 2006. (b) Johnson, J.B. Ring Opening of Epoxides, Aziridines, and Cyclic Anhydrides. In: Science of Synthesis, Stereoselective Synthesis; De Vries, J.G.; Molander, G.A.; Evans, P.A., Eds., Georg Thieme: Stuttgart, 2011; vol. 3, pp. 759-827.

[53] Heravi, M.M.; Lashaki, T.B.; Poorahmad, N. Applications of sharpless asymmetric epoxidation in total synthesis. Tetrahedron: Asymmetry, 2015, 26, 405-495. (b) Vilotijevic, I.; Jamison, T.F. Biomimetic Organic Synthesis; $I^{s t}$ ed.; Poupon, E.; Nay, B., Eds.; Wiley-VCH: Weinheim, 2011; pp. 537 590. (c) Heterocycles in Natural Product Synthesis, $1^{\text {st }}$ ed; Majumdar, K.C. Chattopadhyay, S.K., Eds.; Wiley-VCH: Weinheim, 2011; chap. 1 and 3. (d) Vilotijevic, I.; Jamison, T.F. Epoxide-opening cascades in the synthesis of polycyclic polyether natural products. Angew. Chem., Int. Ed., 2009, 48, 5250-5281. (e) Martín, T.; Padrón, J.I.; Martín, V.S. Strategies for the synthesis of cyclic ethers of marine natural products. Synlett, 2014, 25(1), 12-32.

[54] Sonawane, S.P.; Patil, G.D.; Gurjar, M.K. Concise synthesis of two $\beta$ adrenergic blocking agents in high stereoselectivity using the readily available chiral building block ( $2 S, 2$ 'S,2" $S$ )-tris-(2,3-epoxypropyl)-isocyanurate. Org. Process Res. Dev., 2011, 15, 1365-1370.

[55] Wei, S.; Messerer, R.; Tsogoeva, S.B. Asymmetric synthesis of $\beta$-adrenergic blockers through multistep one-pot transformations involving in situ chira organocatalyst formation. Chem. Eur. J., 2011, 17, 14380-14384.

[56] (a) Ryu, S.E.; Choi, H.J.; Kim, D.H. Stereochemistry in inactivation of carboxypeptidase A.structural analysis of the inactivated carboxypeptidase A by an enantiomeric pair of 2-benzyl-3,4-epoxybutanoic acids. J. Am. Chem. Soc., 1997, 119, 38-41. (b) Lee, M.; Kim, D.H. Syntheses and kinetic evaluation of racemic and optically active 2-benzyl-2-methyl-3,4-epoxybutanoic acids as irreversible inactivators for carboxypeptidase A. Bioorg. Med.Chem., 2002, 10, 913-922.

[57] Chen, W.L.; Fu, X.; Lin, L.L.; Yuan, X.; Luo, W.W.; Feng, J.H.; Liu, X.H.; Feng, X.M. An asymmetric [3+2] cycloaddition of alkynes with oxiranes by selective $\mathrm{C}-\mathrm{C}$ bond cleavage of epoxides: Highly efficient synthesis of chiral furan derivatives. Chem. Commun., 2014, 50, 11480-11483. (b) Chen, W.L.; Xia, Y.; Lin, L.L.; Yuan, X.; Guo, S.S.; Liu, X.H.; Feng, X.M. Asymmetric synthesis of furo[3,4-b]indoles by catalytic [3+2] cycloaddition of indoles with epoxides Chem Eur. J, 2015, 21, 15104-15107. (c) D'Elia, V.; Pelletier, J.D.A.; Basset, J.M. Cycloadditions to epoxides catalyzed by group IIIV transition-metal complexes. ChemCatChem, 2015, 7, 1906-1917. (d) Yuan, X.; Lin, L.; Chen, W.; Wu, W.; Liu, X.; Feng, X. Synthesis of chiral tetrahydrofurans via catalytic asymmetric [3 + 2] cycloaddition of heterosubstituted alkenes with oxiranes. J. Org. Chem., 2016, 81, 1237-1243.

[58] (a) Bierl, B.A.; Beroza, M.; Collier, C.W. Potent sex attractant of the gypsy moth: Its isolation, identification, and synthesis. Science, 1970, 170, 87-89. (b) Prasad, K.R.; Anbarasan, P. Enantiodivergent synthesis of both enantiomers of gypsy moth pheromone disparlure. J. Org. Chem., 2007, 72, 31553157.

[59] Ayer, W.A.; Lee, S.P.; Tsuneda, A.; Hiratsuka, Y. The isolation, identification, and bioassay of the antifungal metabolites produced by Monocillium nordinii. Can. J. Microbiol., 1980, 26, 766-773. (b) Garbaccio, R.M.; Stachel, S.J.; Baeschlin, D.K.; Danishefsky, S.J. Concise asymmetric syntheses of radicicol and monocillin. I. J. Am. Chem. Soc., 2001, 123, $10903-$ 10908.

[60] Ruano, G.J.L.; Castro, M.A.M.; Rodríguez, J.H. A new general method to obtain chiral 2-alkylglycidic acid derivatives: Synthesis of methyl (R)-(+)palmoxirate. J. Org. Chem., 1994, 59, 533-536. (b) Jiménez, O.; Bosch, M.P.; Guerrero, A. Lipase-catalyzed enantioselective synthesis of methyl $(R)$ - and $(S)$-2-tetradecyloxiranecarboxylate through sequential kinetic resolution. J. Org. Chem., 1997, 62, 3496-3499.

[61] (a) Yamaguchi, J.; Hayashi, Y. Syntheses of fumagillin and ovalicin. Chem. Eur. J., 2011, 16, 3884-3901. (b) Nicolaou, K.C.; Roschangar, F.; Vourloumis, D. Chemical biology of epothilones. Angew. Chem. Int. Ed., 1998, 37, 2014-2045.
[62] (a) Modern Oxidation Methods; Bäckvall, J.-E., Ed.; Wiley-VCH: Weinheim, 2010; Chap 2-4, 6, 7, 9, 11. (b) Müller, C. Grover, N; Cokoja, M. Kühn, F.E. Homogeneous Catalytic Olefin Epoxidation with Molybdenum Complexes. In: Advances in Inorganic Chemistry; Van Eldik, R.; Hubbard C.D., Eds.; Elsevier: Oxford, 2013; vol. 65, pp. 33-83. (c) Amini, M.; Haghdoost, M.M.; Bagherzadeh, M. Monomeric and dimeric oxido-peroxido tungsten(VI) complexes in catalytic and stoichiometric epoxidation. Coord. Chem. Rev., 2014, 268, 83-100. (d) Huber, S.; Cokoja, M.; Kühn, F.E. Historical landmarks of the application of molecular transition metal catalysts for olefin epoxidation. J. Organomet. Chem., 2014, 751, 25-32. (e) Kück, J.W.; Reich, R.M.; Kühn, F.E. Molecular epoxidation reactions catalyzed by rhenium, molybdenum, and iron complexes. Chem. Rec., 2016, 16, 349-364. (f) Saisaha, P.; De Boer, J.W.; Browne, W.R. Mechanisms in manganese catalysed oxidation of alkenes with $\mathrm{H}_{2} \mathrm{O}_{2}$. Chem. Soc. Rev., 2013, 42, 20592074.

[63] For reviews, see: (a) Jacobsen, E.N.; Wu, M.N. Comprehensive Asymmetric Catalysis I-III; Jacobsen, E.N.; Pfaltz, A.; Yamamoto, H., Eds.; Springer: Berlin, 1999; vol. 2, pp. 649-677. (b) Modern Oxidation Methods, Bäckvall, E.J., Ed.; Wiley-VCH: Weinheim, 2004; chap. 2, 3, 10. (c) Matsumoto, K.; Katsuki, T. In: Asymmetric Synthesis, $2^{\text {nd }}$ ed. Christmann, M. Brase, S. Eds.; Wiley-VCH: Weinheim, 2009; pp. 123-127. (d) Burke, A.J.; Carreiro, E.P. In: Comprehensive Inorganic Chemistry II; Reedijk, J.; Poeppelmeier, K., Eds.; Elsevier: Amsterdam, 2013; pp. 309-382.

[64] Carreras, J.; Livendahl, M.; McGonigal, P.R.; Echavarren, A.M. Gold(I) as an artificial cyclase: Short stereodivergent syntheses of (-)-epiglobulol and $(-)-4 \beta, 7 \alpha-$ and $(-)-4 \alpha, 7 \alpha$-aromadendranediols. Angew. Chem., Int. Ed., 2013, $53,4896-4899$.

[65] (a) Moreira, I.C.; Lago, J.H.G.; Young, N.C.M.; Roque, N.F. Antifungal aromadendrane sesquiterpenoids from the leaves of Xylopia brasiliensis. $J$. Braz. Chem. Soc., 2003, 14, 828-831. (b) Gaspar-Marques, C.; Simões, M.F.; Rodríguez, B. Further labdane and kaurane diterpenoids and other constituents from Plectranthus fruticosus. J. Nat. Prod., 2004, 67, 614-621.

[66] Viswanadh, N.; Mujumdar, P. Sasikumar, M.; Kunte, S.S ; Muthukrishnan, M. An alternate synthesis of appetite suppressant $(R)$-2-benzylmorpholine employing Sharpless asymmetric epoxidation strategy. Tetrahedron Lett., 2016, 57, 861-863.

[67] Voight, E.A.; Yin, H.; Downing, S.V.; Calad, S.A.; Matsuhashi, H.; Giordano, I.; Hennessy, A.J.; Goodman, R.M.; Wood, J.L. Target-directed synthesis of antibacterial drug candidate GSK966587. Org. Lett., 2010, 12, $3422-3425$

[68] Kohyama, A.; Kanoh, N.; Kwon, E.; Iwabuchi, Y. An enantiocontrolled entry to the tricyclic polar segment of (+)-fusarisetin A. Tetrahedron Lett. 2016, 57, 517-519.

[69] Jang, J.H.; Asami, Y.; Jang, J.P.; Kim, S.O.; Moon, D.O.; Shin, K.S.; Hashizume, D.; Muroi, M.; Saito, T.; Oh, H.; Kim, B.Y.; Osada, H.; Ahn, J.S. Fusarisetin A, an acinar morphogenesis inhibitor from a soil fungus, Fusarium sp. FN080326. J. Am. Chem. Soc., 2011, 133, 6865-6867.

[70] Makita, N.; Hoshino, Y.; Yamamoto, H. Asymmetric epoxidation of homoallylic alcohols and application in a concise total synthesis of (-)- $\alpha$-bisabolo and (-)-8-epi- $\alpha$-bisabolol. Angew. Chem., Int. Ed., 2003, 42, 941-943.

[71] Li, F.; Wang, Z.H.; Zhao, L.; Xiong, F.J.; He, Q.Q.; Chen, F.E. An efficient enantioselective synthesis of florfenicol via a vanadium-catalyzed asymmetric epoxidation. Tetrahedron: Asymmetry, 2011, 22, 1337-1341.

[72] Zhang, W.; Loebach, J.L.; Wilson, S.R.; Jacobsen, E.N. Enantioselective epoxidation of unfunctionalized olefins catalyzed by (Salen)manganese complexes. J. Am. Chem. Soc., 1990, 112, 2801-2803.

[73] Irie, R.; Noda, K.; Ito, Y.; Matsumoto, N.; Katsuki, T. Catalytic asymmetric epoxidation of unfunctionalized olefins. Tetrahedron Lett., 1990, 31, 7345 7348.

[74] For a recent review, see: Krishnan, K.K.; Thomas, A.M.; Sindhu, K.S. Anilkumar, G. Recent advances and perspectives in the manganese-catalysed epoxidation reactions. Tetrahedron, 2016, 72, 1-16

[75] Federsel, H.J. In: Stereoselective Synthesis of Drugs - An Industrial Perspective. In: Chirality in Drug Research; Francotte, E.; Lindner, W., Eds.; WileyVCH: Weinheim, 2006; vol. 33, pp. 29-65.

[76] Gerlach, U.; Brendel, J.; Lang, H.J.; Paulus, E.F.; Weidmann, K.; Brüggemann, A.; Busch, A.; Suessbrich, H.; Bleich, M.; Greger, R. Synthesis and activity of novel and selective $\mathrm{I}_{\mathrm{Ks}}$-channel blockers. J. Med. Chem., 2001, 44, 3831-3837.

[77] For selected examples. See: (a) Chen, Y.; Evarts, J.B.; Torres, E.; Fuchs, P.L. Synthesis of termini-differentiated 6-carbon stereotetrads: An alkylative oxidation strategy for preparation of the $\mathrm{C} 21-\mathrm{C} 26$ segment of apoptolidin. $\mathrm{Org}$. Lett., 2002, 4, 3571-3574. (b) El-Awa, A.; Du Jourdin, X.M.; Fuchs, P.L. Asymmetric synthesis of all eight seven-carbon dipropionate stereotetrads. $J$. Am. Chem. Soc., 2007, 129, 9086-9093. (c) Sikervar, V.; Fleet, J.C.; Fuchs, P.L. A general approach to the synthesis of enantiopure 19-nor-vitamin D3 and its C-2 phosphate analogs prepared from cyclohexadienyl sulfone. Chem. Commun., 2012, 48, 9077-9079.

[78] (a) Dai, W.; Li, J.; Li, G.; Yang, H.; Wang, L.; Gao, S. Asymmetric epoxidation of alkenes catalyzed by a porphyrin-inspired manganese complex. $\mathrm{Org}$ Lett., 2013, 15, 4138-4141. (b) Dai, W.; Shang, S.; Chen, B.; Li, G.; Wang, L.; Ren, L.; Gao, S. Asymmetric epoxidation of olefins with hydrogen peroxide by an in situ-formed manganese complex. J. Org. Chem., 2014, 79, 66886694 . 
[79] Bian, Z.; Marvin, C.C.; Pettersson, M.; Martin, S.F. Enantioselective tota syntheses of citrinadins A and B. Stereochemical revision of their assigned structures. J. Am. Chem. Soc., 2014, 136, 14184-14192.

[80] Kakei, H.; Tsuji, R.; Ohshima, T.; Shibasaki, M. Catalytic asymmetric epoxidation of $\alpha, \beta$-unsaturated esters using an yttrium-biphenyldiol complex. $J$. Am. Chem. Soc., 2005, 127, 8962-8963.

[81] Nemoto, T.; Kakei, H.; Gnanadesikan, V.; Tosaki, S.Y.; Ohshima, T.; Shibasaki, M. Catalytic asymmetric epoxidation of $\alpha, \beta$-unsaturated amides: Efficient synthesis of $\beta$-aryl $\alpha$-hydroxy amides using a one-pot tandem catalytic asymmetric epoxidation-Pd-catalyzed epoxide opening process. $J$. Am. Chem. Soc., 2002, 124, 14544-14545.

[82] Nemoto, T.; Ohshima, T.; Shibasaki, M. Catalytic asymmetric synthesis of $\alpha, \beta$-epoxy esters, aldehydes, amides, and $\gamma, \delta$-epoxy $\beta$-keto esters: Unique reactivity of $\alpha, \beta$-unsaturated carboxylic acid imidazolides. J. Am. Chem. Soc., 2001, 123, 9474-9475.

[83] Nemoto, T.; Ohshima, T.; Shibasaki, M. Enantioselective total syntheses of novel PKC activator $(+)$-decursin and its derivatives using catalytic asymmetric epoxidation of an enone. Tetrahedron Lett., 2000, 41, 9569-9574.

[84] Hara, K.; Park, S.Y.; Yamagiwa, N.; Matsunaga, S.; Shibasaki, M. Catalytic asymmetric epoxidation of $\alpha, \beta$-unsaturated phosphane oxides with a $\mathrm{Y}(\mathrm{O}-$ iPr) $)_{3}$ /biphenyldiol complex. Chem. Asian J., 2008, 3, 1500-1504.

[85] Tosaki, S.; Nemoto, T.; Ohshima, T.; Shibasaki, M. Catalytic asymmetric synthesis of both syn- and anti-3,5-dihydroxy esters: Application to 1,3polyol $/ \alpha$-pyrone natural product synthesis. Org. Lett., 2003, 5, 495-498.

[86] Kakei, H.; Nemoto, T.; Ohshima, T.; Shibasaki, M. Efficient synthesis of chiral $\alpha$ - and $\beta$-hydroxy amides: Application to the synthesis of $(\boldsymbol{R})$ fluoxetine. Angew. Chem. Int. Ed., 2004, 43, 317-320.

[87] (a) Hydrogen Bonding in Organic Synthesis; Pihko, P.M., Ed.; Wiley-VCH: Weinheim, 2009. (b) Comprehensive Enantioselective Organocatalysis: Catalysts, Reactions and Applications; Dalko, P.I., Ed.; Wiley-VCH: Weinheim, 2013. (c) Atodiresei, I.; Vila, C.; Rueping, M. Asymmetric organocatalysis in continuous flow: Opportunities for impacting industrial catalysis. ACS Catal., 2015, 5, 1972-1985.

[88] Zhu, Y.; Wang, Q.; Cornwall, R.G.; Shi, Y. Organocatalytic asymmetric epoxidation and aziridination of olefins and their synthetic applications Chem. Rev., 2014, 114, 8199-8256.

[89] For selected recent reviews, see: (a) Jew, S.S.; Park, H.G. Cinchona-based phase-transfer catalysts for asymmetric synthesis. Chem. Commun., 2009, (46), 7090-7103. (b) Shirakawa, S.; Maruoka, K. Recent developments in asymmetric phase-transfer reactions. Angew. Chem. Int. Ed., 2013, 52, 43124348 .

[90] Albanese, D.C.M.; Foschi, F.; Penso, M. Sustainable oxidations under phasetransfer catalysis conditions. Org. Process Res. Dev., 2016, 20, 129-139.

[91] Lygo, B.;. Gardiner, S.D.; To, D.C.M. Stereoselective synthesis of the epoxysuccinyl peptide E-64c. Synlett, 2006, (13), 2063-2066.

[92] Curci, R; D'Accolti, L.; Fusco, C. A novel approach to the efficient oxygenation of hydrocarbons under mild conditions. Superior oxo transfer selectivity using dioxiranes. Acc. Chem. Res., 2006, 39, 1-9.

[93] For a recent review, see: Wong, O.A.; Shi, Y.; Ramirez, T.; Shi, Y. Oxidation: Organocatalyzed Asymmetric Epoxidation of Alkenes. In: Comprehensive Chirality; Carreira, E.M.; Yamamoto, H., Eds.; Elsevier: Amsterdam, 2012; pp. 528-553

[94] (a) Wang, Z.X.; Shi, Y. A new type of ketone catalyst for asymmetric epoxidation. J. Org. Chem 1997, 62, 8622-8623, (b) Wang, Z X: Miller, S.M. Anderson, O.P.; Shi, Y. A class of $C_{2}$ and pseudo $C_{2}$ symmetric ketone catalysts for asymmetric epoxidation. Conformational effect on catalysis. J. Org. Chem., 1999, 64, 6443-6458.

[95] Kumar, V.P.; Chandrasekhar, S. Enantioselective synthesis of pladienolide B and truncated analogues as new anticancer agents. Org. Lett., 2013, 15 , 3610-3613.

[96] Peng, X.; Li, P.; Shi, Y. Synthesis of (+)-Ambrisentan via chiral ketonecatalyzed asymmetric epoxidation. J. Org. Chem., 2012, 77, 701-703.

[97] Tong, R.; Valentine, J.C.; McDonald, F.E.; Cao, R.; Fang, X.; Hardcastle, K.I. Total syntheses of durgamone, nakorone, and abudinol B via biomimetic oxa- and carbacyclizations. J. Am. Chem. Soc., 2007, 129, 1050-1051.

[98] For a review, see: Page, P.C.B.; Buckley, B.R. Oxaziridinium Salt-Mediated Catalytic Asymmetric Epoxidation. In: Mechanisms in Homogeneous and Heterogeneous Epoxidation Catalysis; Oyama, S.T., Ed.; Elsevier: Oxford, 2008; pp. 177-216

[99] Page, P.C.B.; Barros, D.; Buckley, B.R.; Ardakani, A.; Marples, B.A. Organocatalysis of asymmetric epoxidation mediated by iminium salts under nonaqueous conditions. J. Org. Chem., 2004, 69, 3595-3597.

[100] Page, P.C.B.; Buckley, B.R.; Heaney, H.; Blacker, A.J. Asymmetric epoxidation of cis-alkenes mediated by iminium salts: Highly enantioselective synthesis of Levcromakalim. Org. Lett., 2005, 7, 375-377.

[101] Page, P.C.B.; Appleby, L.F.; Day, D.P.; Chan, Y.; Buckley, B.R.; Allin, S.M.; McKenzie, M.J. Highly enantioselective total synthesis of (-)-(3'S)lomatin and (+)-(3'S,4'R)-trans-khellactone. Org. Lett., 2009, 11, 1991-1993.

[102] Bartlett, C.J.; Day, D.P.; Chan, Y.; Allin, S.M.; McKenzie, M.J.; Slawin, A.M.Z.; Page, P.C.B. Enantioselective total synthesis of (+)-scuteflorin a using organocatalytic asymmetric epoxidation. J. Org. Chem., 2012, 77, 772774 .
[103] Page, P.C.B.; Rassias, G.A.; Barros, D.; Ardakani, A.; Bethell, D.; Merifield, E. New organocatalysts for the asymmetric catalytic epoxidation of alkenes mediated by chiral iminium salts. Synlett, 2002, (4), 580-582

[104] Zheng, C.; Li, Y.; Yang, Y.; Wang, H.; Cui, H.; Zhang, J.; Zhao, G. Highly efficient asymmetric epoxidation of electron-deficient $\alpha, \beta$-enones and related applications to organic synthesis. Adv. Synth. Catal., 2009, 351, 1685-1691.

[105] Bondzic, B.P.; Urushima, T.; Ishikawa, H.; Hayashi, Y. Asymmetric epoxidation of $\alpha$-substituted acroleins catalyzed by diphenylprolinol silyl ether. Org. Lett., 2010, 12, 5434-5437.

[106] For a recent review, see: Pellissier, H. Catalytic non-enzymatic kinetic resolution. Avd. Synth. Catal., 2011, 353, 1613-1666.

[107] (a) Larrow, J.F.; Schaus, S.E.; Jacobsen, E.N. Kinetic resolution of terminal epoxides via highly regioselective and enantioselective ring opening with $\mathrm{TMSN}_{3}$. An efficient, catalytic route to 1,2-amino alcohols. J. Am. Chem. Soc., 1996, 118, 7420-7421. (b) Lebel, H.; Jacobsen, E.N. Chromiuncatalysed kinetic resolution of 2,2-disubstituted epoxides. Tetrahedron Lett., 1999, 40, 7303-7306.

[108] White, D.E.; Jacobsen, E.N. New oligomeric catalyst for the hydrolytic kinetic resolution of terminal epoxides under solvent-free conditions. Tetrahedron: Asymmetry, 2003, 14, 3633-3638. (b) White, D.E.; Tadross, P.M.; Lu, Z.; Jacobsen, E.N. A broadly applicable and practical oligomeric (salen)Co catalyst for enantioselective epoxide ring-opening reactions. Tetrahedron, 2014, 70, 4165-4180.

[109] Rajapaksa, N.S.; McGowan, M.A.; Rienzo, M.; Jacobsen, E.N. Enantioselective total synthesis of (+)-Reserpine. Org. Lett., 2013, 15, 706-709.

[110] (a) Kim, Y.J.; Tae, J. Resolution of 2-silyloxy-1-oxiranyl-4-pentenes by HKR: Total synthesis of $(5 S, 7 R)$-Kurzilactone. Synlett, 2006, 37(21), 61-64 (b) Santhosh, R.; Chouthaiwale, P.V.; Suryavanshi, G.; Chavan, V.B.; Sudalai, A. Co(III)(salen)-catalyzed HKR of two stereocentered alkoxy- and azido epoxides: A concise enantioselective synthesis of $(S, S)$-reboxetine and $(+)$ epi-cytoxazone. Chem. Commun., 2010, 46, 5012-5014.

[111] Devalankar, D.A.; Karabal, P.U.; Sudalai, A. Optically pure $\gamma$-butyrolactones and epoxy esters via two stereocentered HKR of 3-substituted epoxy esters: A formal synthesis of (-)-paroxetine, Ro 67-8867 and (+)-eldanolide. Org. Biomol. Chem., 2013, 11, 1280-1285.

[112] Reddy, A.; Mujahid, M.; Sasikumar, M.; Muthukrishnan, M. A new enantioselective synthesis of the anti-Parkinson agent safinamide. Synthesis, 2014, 46(13), 1751-1756.

[113] Narina, S.V.; Sudalai, A. Enantioselective synthesis of (S)-timolol via kinetic resolution of terminal epoxides and dihydroxylation of allylamines. Tetrahedron, 2007, 63, 3026-3030

[114] Gupta, P.; Kumar, P. An efficient total synthesis of decarestrictine D. Eur. J. Org. Chem., 2008, (7), 1195-1202.

[115] Tripathi, D.; Pandey, S.K.; Kumar, P. A general approach to medium-sized ring ethers via hydrolytic and oxidative kinetic resolutions: Stereoselective syntheses of (-)-cis-lauthisan and (+)-isolaurepan. Tetrahedron, 2009, 65, 2226-2231.

[116] Dyer, B.S ; Jones, J.D; Ainge, G.D ; Denis, M ; Larsen, D. S ; Painter, G.F. Synthesis and structure of phosphatidylinositol dimannoside. J. Org. Chem., 2007, 72, 3282-3288.

[117] Sasikumar, M.; Nikalje, M.D.; Muthukrisnan, M. A convenient synthesis of enantiomerically pure $(R)$-mexiletine using hydrolytic kinetic resolution method. Tetrahedron: Asymmetry, 2009, 20, 2814-2817.

[118] Czerwonka, R.; Reddy, K.R.; Baum, E.; Knölker, H.J. First enantioselective total synthesis of neocarazostatin $\mathrm{B}$, determination of its absolute configuration and transformation into carquinostatin A. Chem. Commun., 2006, (7), $711-713$

[119] Gadakh, S.K.; Reddy, S.R.; Sudalai, A. Enantioselective synthesis of HIV protease inhibitor amprenavir via Co-catalyzed HKR of 2-(1-azido-2phenylethyl)oxirane. Tetrahedron: Asymmetry, 2012, 23, 898-903.

[120] Bartoli, G.; Bosco, M.; Carlone, A.; Locatelli, M.; Melchiorre, P.; Sambri, L. Asymmetric catalytic synthesis of enantiopure $N$-protected 1,2-amino alcohols. Org. Lett., 2004, 6, 3973-3975.

[121] Gnas, Y.; Glorius, F. Chiral auxiliaries - principles and recent applications. Synthesis, 2006, (12), 1899-1930.

[122] For reviews, see: (a) Li, A.H.; Dai, L.X.; Aggarwal, V.K. Asymmetric ylide reactions: Epoxidation, cyclopropanation, aziridination, olefination, and rearrangement. Chem. Rev., 1997, 97, 2341-2372. (b) McGarrigle, E.M.; Myers, E.L.; Illa, O.; Shaw, M.A.; Riches, S.L.; Aggarwal, V.K. Chalcogenides as organocatalysts. Chem. Rev., 2007, 107, 5841-5883.

[123] (a) Aggarwal, V.K.; Hynd, G.; Picoul, W.; Vasse, J.L. Highly enantioselective Darzens reaction of a camphor-derived sulfonium amide to give glycidic amides and their applications in synthesis. J. Am. Chem. Soc., 2002, 124 9964-9965. (b) Aggarwal, V.K.; Charmant, J.P.H.; Fuentes, D.; Harvey, J.N.; Hynd, G.; Ohara, D.; Picoul, W.; Robiette, R.; Smith, C.; Vasse, J.L.; Winn, C.L. Highly enantioselective synthesis of glycidic amides using camphorderived sulfonium salts. Mechanism and applications synthesis. J. Am. Chem Soc., 2006, 124, 2105-2114

[124] Kokotos, C.G.; Aggarwal, V.K. Hemiaminals as substrates for sulfur ylides: Direct asymmetric syntheses of functionalized pyrrolidines and piperidines. Chem. Commun., 2006, 13(20), 2156-2158. 
[125] Aggarwal, V.K.; Richardson, J. The complexity of catalysis: Origins of enantio- and diastereocontrol in sulfur ylide mediated epoxidation reactions. Chem. Commun., 2003, 21, 2644-2651.

[126] Sarabia, F.; Chammaa, S.; García-Castro, M.; Martín-Gálvez, F. A highly efficient methodology of asymmetric epoxidation based on a novel chiral sulfur ylide. Chem. Commun., 2009, (38), 5763-5765.

[127] Sarabia, F.; Vivar-García, C.; García-Castro, M.; García-Ruiz, C.; MartínGálvez, F.; Sánchez-Ruiz, A.; Chammaa, S. A highly stereoselective synthesis of glycidic amides based on a new class of chiral sulfonium salts: Applications in asymmetric synthesis. Chem. Eur. J., 2012, 18, 15190-15201.

[128] Sarabia, F.; Martín-Gálvez, F.; García-Ruiz, C.; Sánchez-Ruiz, A.; VivarGarcía, C. Epi-, epoxy-, and C2-modified Bengamides: Synthesis and biological evaluation. J. Org. Chem., 2013, 78, 5239-5253.

[129] García-Ruiz, C.; Cheng-Sánchez, I.; Sarabia, F. Stereoselective total synthesis of (-)-Depudecin. Org. Lett., 2015, 17, 5558-5561.

[130] Sarabia, F.; Chammaa, S.; García-Ruiz, C. Solid phase synthesis of globomycin and SF-1902 A 5 . J. Org. Chem., 2011, 76, 2132-2144.

[131] Sarabia, F.; Vivar-García, C.; García-Ruiz, C.; Sánchez-Ruiz, A.; PinoGonzález, M.S.; García-Castro, M.; Chammaa, S. Exploring the reactivity of chiral glycidic amides for their applications in synthesis of bioactive compounds. Eur. J. Org. Chem., 2014, (18), 3847-3867.

[132] (a) Ballester, M. Mechanisms of the Darzens and related condensations. Chem. Rev., 1955, 55, 283-300. (b) Rosen, T. Darzens Glycidic Ester Condensation. In: Comprehensive Organic Synthesis; Trost, B.M.; Fleming, I.; Heathcock, C.H., Eds.; Pergamon: Oxford, UK, 1991; vol. 2, pp. 409-439.

[133] Achard, T.J.R.; Belokon, Y.N.; Ilyin, M.; Moskalenko, M.; North, M.; Pizzato, F. Enantio- and diastereoselective Darzens condensations. Tetrahedron Lett., 2007, 48, 2965-2969.

[134] Liu, W.J.; Lv, B.D.; Gong, L.Z. An asymmetric catalytic Darzens reaction between diazoacetamides and aldehydes generates cis-glycidic amides with high enantiomeric purity. Angew. Chem. Int. Ed., 2009, 48, 6503-6506.

[135] (a) Pellissier, H. Chiral Sulfur Ligands, Asymmetric Catalysis; Royal Society of Chemistry: Cambridge, 2009. (b) Toru, T.; Bolm, C. Organosulfur Chemistry in Asymmetric Synthesis; Wiley-VCH: Weinheim, 2008. (c) Mellah, M.; Voituriez, A.; Schulz, E. Chiral sulfur ligands for asymmetric catalysis. Chem. Rev., 2007, 107, 5133-5209.

[136] (a) Clayden, J.; MacLellan, P Asymmetric synthesis of tertiary thiols and thioethers. Belstein J. Org. Chem., 2011, 7, 582-595. (b) Zhang, Y.; Wang, J. Catalytic $[2,3]$-sigmatropic rearrangement of sulfur ylide derived from metal carbene. Coord. Chem. Rev., 2010, 254, 941-953.

[137] Sander, M. Thiiranes. Chem. Rev., 1966, 66, 297-339. (b) Vedejs, E.; Krafft, G.A. Cyclic sulfides in organic synthesis. Tetrahedron, 1982, 38, 2857-2881.

[138] Ketcham, R.; Shah, V.P. Cis- and trans-Stilbene Sulfides. J. Org. Chem., 1963, 28, 229-230.

[139] Lee, M.; Bernardo, M.M.; Meroueh, S.O.; Brown, S.; Fridman, R.; Mobashery, S. 1,4-Di(1,2,3-triazol-1-yl)butane as building block for the preparation of the iron(II) Spin-Crossover 2D coordination polymer. Org. Lett., 2005, 7, 4463-4465.

[140] For reviews see: (a) De Meijere, A. Bonding properties of cyclopropane and their chemical consequences. Angew. Chem. Int. Ed., 1979, 18, 809-826. (b) Wiberg, K.B. Structures, Energies and Spectra of Cyclopropanes in Cyclopropyl Group; John Wiley \& Sons, Ltd: New York, 1987. (c) Wong, H.N.C.; Hon, M.Y.; Tse, C.W.; Yip, Y.C.; Tanko, J.; Hudlicky, T. Use of cyclopropanes and their derivatives in organic synthesis. Chem. Rev., 1989, 89, 165198.

[141] For reviews see: (a) Salaun, J.; Baird, M.S. Biologicaliy active cyclopropanes and cyclopropenes. Curr. Med. Chem., 1995, 2, 511-542. (b) Gnad, F.; Reiser, O. Synthesis and applications of $\beta$-aminocarboxylic acids containing a cyclopropane ring. Chem. Rev., 2003, 103, 1603-1624. (c) Wessjohann, L.A.; Brandt, W.; Thiemann, T. Biosynthesis and metabolism of cyclopropane rings in natural compounds. Chem. Rev., 2003, 103, 1625-1648. (d) Brackmann, F.; De Meijere, A. Natural occurrence, syntheses, and applications of cyclopropyl-group-containing $\alpha$-amino acids. 1. 1Aminocyclopropanecarboxylic acid and other 2,3-methanoamino acids. Chem. Rev., 2007, 107, 4493-4537. (e) Brackmann, F.; De Meijere, A. Natural occurrence, syntheses, and applications of cyclopropyl-group-containing $\alpha$-amino acids. 2. 3,4- and 4,5-methanoamino acids. Chem. Rev., 2007, 107 , 4538-4583. (f) Kulinkovich, O.G. Cyclopropanes in Organic Synthesis; John Wiley \& Sons Ltd: New York, 2015.

[142] For reviews see: (a) Liu, H.W.; Walsh, C.T. Biochemistry of the Cyclopropyl Group in Cyclopropyl Group; John Wiley \& Sons, Ltd: New York, 1987. (b) Gagnon, A.; Duplessis, M.; Fader, L. Arylcyclopropanes: Properties, synthesis and use in medicinal chemistry. Org. Prep. Proc. Int., 2010, 42, 1-69.

[143] For reviews see: (a) Topics in Current Chemistry; De Meijere, A., Ed.; Heidelberg: Springer, 1986; vol. 133. (b) Topics in Current Chemistry; De Meijere, A., Ed.; Heidelberg: Springer, 1987; vol. 135. (c) The Chemistry of the Cyclopropyl Group; Rappoport, Z.; Patai, S., Eds.; John Wiley \& Sons Ltd: New York, 1987; vol. 1. (d) Topics in Current Chemistry; De Meijere, A., Ed.; Heidelberg: Springer, 1988; vol. 144. (e) Topics in Current Chemistry; Meijere, A., Ed.; Heidelberg: Springer, 1990; vol. 155. (f) The Chemistry of the Cyclopropyl Group; Rappoport, Z.; Patai, S., Eds.; John Wiley \& Sons Ltd: New York, 1995; vol. 2. (g) Topics in Current Chemistry; De Meijere, A., Ed.; Springer: Heidelberg, 1996; vol. 178. (h) Houben-Weyl: Carbocyclic Three and Four-Membered Ring Compounds; De Meijere, A., Ed.; Thieme:
Stuttgart, 1997; vol. E17a-c. (i) Goudreau, S.R.; Charette, A.B. Defying ring strain: New approaches to cyclopropanes. Angew. Chem. Int. Ed., 2010, 49, 486-488

[144] For reviews see: (a) Charette, A.B.; Lebel, H.; Roy, M.N. Copper-Catalyzed Asymmetric Synthesis; Wiley-VCH: Verlag, 2014. (b) Wang, H.; Zhou, X.; Mao, Y. Asymmetric synthesis of cyclopropylamine derivatives. Heterocycles, 2014, 89, 1767-1800. (c) Qian, D.; Zhang, J. Gold-catalyzed cyclopropanation reactions using a carbenoid precursor toolbox. Chem. Soc. Rev., 2015, 44, 677-698

[145] For reviews see: (a) Lebel, H.; Marcoux, J.F.; Molinaro, C.; Charette, A.B. Stereoselective cyclopropanation reactions. Chem. Rev, 2003, 103, 9771050. (b) Pellissier, H. Recent developments in asymmetric cyclopropanation. Tetrahedron, 2008, 64, 7041-7095. (c) Bartoli, G.; Bencivenni, G.; Dalpozzo, R. Asymmetric cyclopropanation reactions. Synthesis, 2014, 46(08), 979-1029.

[146] Arlt, D.; Jautelat, M.; Lantzsch, R. Syntheses of pyrethroid acids. Angew. Chem. Int. Ed. Engl., 1981, 20, 703-722.

[147] Charette, A.B.; Beauchemin, A. Simmons-Smith Cyclopropanation Reaction in Organic Reactions; John Wiley \& Sons: Weinheim, 2001.

[148] Davies, H.M.L.; Antoulinakis, E.G. Intermolecular Metal-Catalyzed Carbenoid Cyclopropanations. In: Organic Reactions; John Wiley \& Sons: Weinheim, 2001; vol 57, pp. 1-326.

[149] (a) Little, R.D.; Dawson, J.R. MIRC (Michael_Initiated_Ring_Closure) reactions formation of three, five, six and seven membered rings. Tetrahedron Lett., 1980, 21, 2609-2612. (b) Sun, X.L.; Tang, Y. Ylide-Initiated Michael Addition-Cyclization reactions beyond cyclopropanes. Acc. Chem. Res., 2008, 41, 937-948.

[150] Simmons, H.E.; Smith, R.D. A new synthesis of cyclopropanes from olefins. J. Am. Chem. Soc., 1958, 80, 5323-5324. (b) Simmons, H.E.; Smith, R.D. A new synthesis of cyclopropanes. J. Am. Chem. Soc., 1959, 81, 4256-4264.

[151] Chan, J.H.H.; Rickborn, B. Relative rates and stereochemistry of the iodomethylzinc iodide methylenation of some hydroxy- and methoxysubstituted cyclic olefins. J. Am. Chem. Soc., 1968, 90, 6406-6411.

[152] (a) Boche, G.; Lohrenz, J.C.W. The electrophilic nature of carbenoids, nitrenoids, and oxenoids. Chem. Rev., 2001, 101, 697-756. (b) Cornwall, R.G.; Wong, O.A.; Du, H.; Ramirez, T.A.; Shi, Y. A novel class of tunable cyclopropanation reagents $\left(\mathrm{RXZnCH}_{2} \mathrm{Y}\right)$ and their synthetic applications. Org. Biomol. Chem., 2012, 10, 5498-5513.

[153] Hoveyda, A.H.; Evans, D.A.; Fu, G.C. Substrate-directable chemical reactions. Chem. Rev., 1993, 93, 1307-1370. (b) Charette, A.B.; Marcoux, J.F. The asymmetric cyclopropanation of acyclic allylic alcohols: Efficient stereocontrol with iodomethylzinc reagents. Synlett, 1995, (12), 1197-1207. (c) Hermann, H.; Lohrenz, J.C.W.; Kühn, A.; Boche, G. The influence of the leaving group $\mathrm{X}(\mathrm{X}=\mathrm{F}, \mathrm{Cl}, \mathrm{Br}, \mathrm{I}, \mathrm{OH})$ on the carbenoid nature of the carbenoids $\mathrm{LiCH}_{2} \mathrm{X}$ and $\mathrm{XZnCH}_{2} \mathrm{X}-\mathrm{A}$ theoretical study. Tetrahedron, 2000, 56, 4109-4115. (d) Fang, W.H.; Phillips, D.L.; Wang, D.Q.; Li, Y.L. A density functional theory investigation of the Simmons-Smith cyclopropanation reaction: Examination of the insertion reaction of zinc into the C-I bond of $\mathrm{CH}_{2} \mathrm{I}_{2}$ and subsequent cyclopropanation reactions. J. Org. Chem., 2002, 67, 154160 .

[154] Takemoto, Y.; Baba, Y.; Saha, G.; Nakao, S.; Iwata, C.; Tanaka, T.; Ibuka, T. Asymmetric total synthesis of halicholactone. Tetrahedron Lett., 2000, 41, 3653-3656. (b) Baba, Y.; Saha, G.; Nakao, S.; Iwata, C.; Tanaka, T.; Ibuka, T.; Ohishi, H.; Takemoto, Y. Asymmetric total synthesis of halicholactone. J. Org. Chem., 2001, 66, 81-88.

[155] Smith, A.B.; Simov, V. Total synthesis of the marine natural product (-)Clavosolide A. A show case for the Petasis-Ferrier Union/Rearrangement tactic. Org. Lett., 2006, 8, 3315-3318.

[156] White, J.D.; Martin, W.H.C.; Lincoln, C.; Yang, J. Total synthesis of solandelactones E and F, homoeicosanoids from the hydroid Solanderia secunda. Org. Lett., 2007, 9, 3481-3483.

[157] Mohapatra, D.K.; Kanikarapu, S.; Naidu, P.R.; Yadav, J.S. Toward the synthesis of brevipolide H. Tetrahedron Lett., 2015, 56, 1041-1044.

[158] Kumaraswamy, G.; Jayaprakash, N.; Rambabu, D.; Gangulyb, A.; Banerjeeb, R. Towards the diastereoselective synthesis of derivative of 11'-epibrevipolide H. Org. Biomol. Chem., 2014, 12, 1793-1803.

[159] Davoren, J.E.; Martin, S.F. Enantioselective synthesis and structure revision of solandelactone E. J. Am. Chem. Soc., 2007, 129, 510-511.

[160] Mohapatra, D.K.; Yellol, G.S. Asymmetric total synthesis of eicosanoid. Arkivoc, 2005, III, 144-155.

[161] Abad, A.; Agullo, C.; Cunat, A.C.; De Alfonso Marzal, I.; Navarro, I.; Gris, A. A unified synthetic approach to trachylobane-, beyerane-, atisane- and kaurane-type diterpenes. Tetrahedron, 2006, 62, 3266-3283.

[162] Nakashima, K.; Kawano, H.; Kumano, M.; Kodama, H.; Kameoka, M. Yamamoto, A.; Mizutani, R.; Sono, M.; Tori, M. What is the absolute configuration of (+)-crispatanolide isolated from Makinoa crispate_(liverwort)? Tetrahedron Lett., 2015, 56, 4912-4915.

[163] Cheeseman, M.; Feuillet, F.J.P.; Johnson, A.L.; Bull, S.D. A novel strategy for the asymmetric synthesis of chiral cyclopropane carboxaldehydes. Chem. Commun., 2005, (18), 2372-2374.

[164] Cheeseman, M.; Davies, I.R.; Axe, P.; Johnson, A.L.; Bull, S.D. A temporary stereocentre approach for the asymmetric synthesis of chiral cyclopropanecarboxaldehydes. Org. Biomol. Chem., 2009, 7, 3537-3548.

[165] Son, J.B.; Hwang, M.H.; Lee, W.; Lee, D.H. Enantioselective total synthesis of (-)-Clavosolide B. Org. Lett., 2007, 9, 3897-3900. 
[166] Green, R.; Cheeseman, M.S.; Merritt, D.A.; Bull, S.D. An efficient asymmetric synthesis of grenadamide. Tetrahedron Lett., 2005, 46, 7931-7934.

[167] Nicolaou, K.C.; Namoto, K.; Ritzén, A.; Ulven, T.; Shoji, M.; Li, J.; D’Amico, G.; Liotta, D.; French, C.T.; Wartmann, M.; Altmann, K.H.; Giannakakou, P. Chemical synthesis and biological evaluation of cis- and trans12,13-cyclopropyl and 12,13-cyclobutyl epothilones and related pyridine side chain analogues. J. Am. Chem. Soc., 2001, 123, 9313-9323.

[168] Ghosh, A.K.; Liu, C. Total synthesis of antitumor depsipeptide (-)-doliculide. Org. Lett., 2001, 3, 635-638.

[169] Miura, T.; Murakami, Y.; Imai, N. Syntheses of $(R)-(+)$-cibenzoline and analogues via catalytic enantioselective cyclopropanation using $(S)$ phenylalanine-derived disulfonamide. Tetrahedron: Asymmetry, 2006, 17, 3067-3069.

[170] Koyata, N.; Miura, T.; Akaiwa, Y.; Sasaki, H.; Sato, R.; Nagai, T.; Fujimori, H.; Noguchi, T.; Kirihara, M.; Imai, N. Convenient preparation of optically active cibenzoline and analogues from 3,3-diaryl-2-propen-1-ols. Tetrahedron: Asymmetry, 2009, 20, 2065-2071.

[171] Ishizuka, Y.; Fujimori, H.; Noguchi, T.; Kawasaki, M.; Kishida, M.; Nagai, T.; Imai, N.; Kirihara, M. Asymmetric syntheses of pharmaceuticals containing a cyclopropane moiety using catalytic asymmetric Simmons-Smith reactions of allylalcohols: Syntheses of optically active tranylcypromine and milnacipran. Chem. Lett., 2013, 42, 1311-1313.

[172] Nozaki, H.; Moriuti, S.; Takaya, H.; Noyori, R. Asymmetric induction in carbenoid reaction by means of a dissymmetric copper chelate. Tetrahedron Lett., 1966, 7, 5239-5244.

[173] Williams, M.J.; Deak, H.L.; Snapper, M.L. Intramolecular cyclobutadiene cycloaddition/cyclopropanation/thermal rearrangement: An effective strategy for the asymmetric syntheses of pleocarpenene and pleocarpenone. $J$. Am. Chem. Soc., 2007, 129, 486-487.

[174] Sun, L.Q.; Takaki, K.; Chen, J.; Bertenshaw, S.; Iben, L.; Mahla, C.D.; Ryan, E.; Wu, D.; Gao, Q.; Xu C. (R)-2-(4-Phenylbutyl)Dihydrobenzofuran derivatives as melatoninergic agents. Bioorg. Med. Chem. Lett., 2005, 15, 1345 1349

[175] (a) McManus, H.A.; Guiry, P.J. Recent developments in the application of oxazoline-containing ligands in asymmetric catalysis. Chem. Rev., 2004, 104, 4151-4202. (b) Desimoni, G.; Faita, G.; Jørgensen, K.A. $C_{2}$-symmetric chira bis(oxazoline) ligands in asymmetric catalysis. Chem. Rev., 2006, 106, 35613651

[176] Honma, M.; Takeda, H.; Takano, M.; Nakada, M. Development of catalytic asymmetric intramolecular cyclopropanation of $\alpha$-diazo- $\beta$-keto sulfones and applications to natural product synthesis. Synlett, 2009, (11), 1695-1712.

[177] Minuth, T.; Boysen, M.M.K. Carbohydrate-Derived bis(oxazoline) ligand in the total synthesis of grenadamide. Synthesis, 2010, (16), 2799-2803.

[178] Ozoduru, G.; Schubach, T.; Boysen, M.M.K. Enantioselective cyclopropanation of indoles: Construction of all-carbon quaternary stereocenters. Org. Lett., 2012, 14, 4990-4993.

[179] Chen, S.; Rong, C.; Feng, P.; Li, S.; Shi, Y. Stereoselective construction of the tetracyclic core of cryptotrione. Org. Biomol. Chem., 2012, 10, 55185520 .

[180] Suenobu, K.; Itagaki, M.; Nakamura, E. Reaction pathway and stereoselectivity of asymmetric synthesis of chrysanthemate with the aratani $c_{1-}$ symmetric salicylaldimine-copper catalyst. J. Am. Chem. Soc., 2004, 126 , 7271-7280.

[181] (a) Doyle, M.P.; Pieters, R.J.; Martin, S.F.; Austin, R.E.; Oalmann, C.J.; Müller, P. High enantioselectivity in the intramolecular cyclopropanation of allyl diazoacetates using a novel rhodium(II) catalyst. J. Am. Chem. Soc., 1991, 113, 1423-1424. (b) Doyle, M.P.; Austin, R.E.; Bailey, A.S.; Dwyer, M.P.; Dyatkin, A.B.; Kalinin, A.V.; Kwan, M.M.Y.; Liras, S.; Oalmann, C.J.; Pieters, R.J.; Protopopova, M.N.; Raab, C.E.; Roos, G.H.P.; Zhou, Q.L.; Martin, S.F. Enantioselective intramolecular cyclopropanations of allylic and homoallylic diazoacetates and diazoacetamides using chiral dirhodium(II) carboxamide catalysts. J. Am. Chem Soc, 1995, $117,5763-5775$. (c) Colacot, T.J. An overview on the applications of 'Doyle catalysts' in asymmetric cyclopropanation, cyclopropenation and $\mathrm{C}-\mathrm{H}$ insertion reactions. Proc. Indian Acad. Sci., 2000, 112, 197-207. (d) Doyle, M.P. Modern RhodiumCatalyzed Organic Reactions; Wiley-VCH: Weinheim, 2005. (e) Doyle, M.P. Perspective on dirhodium carboxamidates as catalysts. J. Org. Chem., 2006, 71, 9253-9260. (f) Deng, Y.; Qiu, H.; Srinivas, H.D.; Doyle, M.P. Chiral dirhodium(II) catalysts for selective metal Carbene reactions. Curr. Org. Chem., 2016, 20, 61-81

[182] Davies, H.M.L.; Dai, X.; Long, M.S. Combined C-H activation/cope rearrangement as a strategic reaction in organic synthesis: Total synthesis of (-)colombiasin A and (-)-elisapterosin B. J. Am. Chem. Soc., 2006, 128, 248524906.

[183] Marcin, L.R.; Denhart, D.J.; Mattson, R.J. Catalytic asymmetric diazoacetate cyclopropanation of 1-tosyl-3-vinylindoles. A route to conformationally restricted homotryptamines. Org. Lett., 2005, 7, 2651-2654.

[184] (a) Lee, E.; Shin, I.J.; Kim, T.S. Enantiocontrolled synthesis of quaternary carbon centers via anionic oxy-Cope rearrangement: An efficient synthesis of (+)-dihydromayurone. J. Am. Chem. Soc., 1990, 112, 260-264. (b) Srikrishna, A.; Anebouselvy, K. An enantiospecific approach to tricyclic sesquiterpenes mayurone and thujopsenes. J. Org. Chem., 2001, 66, 71027106
[185] Srikrishna, A.; Nagamani, S.A.; Jagadeesh, S.G. The first enantioselective synthesis of (-)-microbiotol and (+)- $\beta$-microbiotene. Tetrahedron: Asymmetry, 2005, 16, 1569-1571.

[186] Srikrishna, A.; Vijaykumar, D. An enantiospecific approach to pinguisane from (R)-carvone. Total synthesis of (+)-pinguisenol. J. Chem. Soc., Perkin Trans. 1, 2000, (16), 2583-2589.

[187] (a) Honma, M.; Sawada, T.; Fujisawa, Y.; Utsugi, M.; Watanabe, H.; Umino, A.; Matsumura, T.; Hagihara, T.; Takano, M.; Nakada, M. Asymmetric catalysis on the intramolecular cyclopropanation of $\alpha$-Diazo- $\beta$-keto sulfones. $J$. Am. Chem. Soc., 2003, 125, 2860-2861. (b) Honma, M.; Nakada, M. Enantioselective intramolecular cyclopropanation of $\alpha$-diazo- $\beta$-keto sulfones: Asymmetric synthesis of bicyclo[4.1.0]heptanes and tricyclo[4.4.0.0]decenes. Tetrahedron Lett., 2003, 44, 9007-9011

[188] Takano, M.; Umino, A.; Nakada, M. Synthetic studies on cyathins: Enantioselective total synthesis of (+)-allocyathin $\mathrm{B}_{2}$. Org. Lett., 2004, 6, 48974900 .

[189] Miyamoto, H.; Iwamoto, M.; Nakada, M. A new asymmetric total synthesis of enantiopure (-)-malyngolide. Heterocycles, 2005, 66, 61-67.

[190] Takeda, H.; Watanabe, H.; Nakada, M. Asymmetric total synthesis of enantiopure (-)-methyl jasmonate via catalytic asymmetric intramolecular cyclopropanation of $\alpha$-diazo- $\beta$-keto sulfone. Tetrahedron, 2006, 62, 8054-8063.

[191] Ida, R.; Nakada, M. Highly enantioselective preparation of tricyclo[4.4.0. $\left.0^{5,7}\right]$ decene derivatives via catalytic asymmetric intramolecular cyclopropanation reactions of $\alpha$-diazo- $\beta$-keto esters. Tetrahedron Lett., 2007, $48,4855-4859$

[192] (a) Hirai, S.; Nakada, M. An enantioselective approach to (-)-platencin via catalytic asymmetric intramolecular cyclopropanation. Tetrahedron Lett., 2010, 51, 5076-5079. (b) Hirai, S.; Nakada, M. Enantioselective divergent approaches to both (-)-platensimycin and (-)-platencin. Tetrahedron, 2011, $67,518-530$.

[193] Honma, M.; Nakada, M. Enantioselective total synthesis of (+)digitoxigenin. Tetrahedron Lett, 2007, 48, 1541-1544.

[194] Uetake, Y.; Uwamori, M.; Nakada, M. Enantioselective approach to polycyclic polyprenylated acylphloroglucinols via catalytic asymmetric intramolecular cyclopropanation. J. Org. Chem., 2015, 80, 1735-1745.

[195] Sawada, T. Nakada, M. Enantioselective total synthesis of (+)-Colletoic acid via catalytic asymmetric intramolecular cyclopropanation of a $\alpha$-Diazo- $\beta$ keto diphenylphosphine oxide. Org. Lett., 2013, 15, 1004-1007.

[196] (a) Martin, S.F.; Austin, R.E.; Oalmann, C.J.; Baker, W.R.; Condon, S.L.; DeLara, E.; Rosenberg, S.H.; Spina, K.P.; Stein, H.H.; Cohen, J.; Kleinert, H.D. 1,2,3-Trisubstituted cyclopropanes as conformationally restricted peptide isosteres: Application to the design and synthesis of novel renin inhibitors. J. Med. Chem., 1992, 35, 1710-1721. (b) Hillier, M.C.; Davidson, J.P.; Martin, S.F. Cyclopropane-derived peptidomimetics. Design, synthesis, and evaluation of novel ras farnesyltransferase inhibitors. J. Org. Chem., 2001, 66, 1657-1671.

[197] Berberich, S.M.; Cherney, R.J.; Colucci, J.; Courillon, C.; Geraci, L.S.; Kirkland, T.A.; Marx, M.A.; Schneider, M.F.; Martin, S.F. Total synthesis of (+)-ambruticin S. Tetrahedron, 2003, 59, 6819-6832.

[198] Martin, S.F.; Spaller, M.R.; Liras, S.; Hartmann, B. Enantio- and diastereoselectivity in the intramolecular cyclopropanation of secondary allylic diazoacetates. J. Am. Chem. Soc., 1994, 116, 4493-4494.

[199] Ashfeld, B.L.; Martin, S.F. Enantioselective syntheses of tremulenediol A and tremulenolide A. Org. Lett., 2005, 7, 4535-4537.

[200] Reichelt, A.; Martin, S.F. Synthesis and properties of cyclopropane-derived peptidomimetics. Acc. Chem. Res., 2006, 39, 433-442.

[201] Nakagawa, Y.; Chanthamath, S.; Shibatomi, K.; Iwasa, S. Ru(II)-PheoxCatalyzed asymmetric intramolecular cyclopropanation of electron-deficient olefins. Org. Lett., 2015, 17, 2792-2795.

[202] Abramovitch, A.; Fensterbank, L.; Malacria, M.; Marek, I. Convergent preparation of enantiomerically pure polyalkylated cyclopropane derivatives. Angew. Chem. Int. Ed., 2008, 47, 6865-6868.

[203] Palko, J.W.; Buist, P.H.; Manthorpe, J.M. A flexible and modular stereoselective synthesis of $(9 R, 10 S)$-dihydrosterculic acid. Tetrahedron: Asymmetry, 2013, 24, 165-168.

[204] Misumi, A.; Iwanaga, K.; Furuta, K.; Yamamoto, H. Simple asymmetric construction of a carbocyclic framework. Direct coupling of dimenthyl succinate and 1,.Omega.-dihalides. J. Am. Chem. Soc., 1985, 107, 3343-3345.

[205] Trost, B.M.; Dirat, O.; Gunzner, J.L. Callipeltoside A: Assignment of absolute and relative configuration by total synthesis. Angew. Chem. Int. Ed., 2002, 41, 841-843.

[206] Pokorski, J.K.; Myers, M.C.; Appella, D.H. Cyclopropane PNA: Cbservable triplex melting in a PNA constrained with a 3-membered ring. Tetrahedron Lett., 2005, 46, 915-917.

[207] Hodgson, D.M.; Chung, Y.K.; Nuzzo, I.; Freixas, G.; Kulikiewicz, K.K Cleator, E.; Paris, J.M. Intramolecular cyclopropanation of unsaturated terminal epoxides and chlorohydrins. J. Am. Chem. Soc., 2007, 129, 4456-4462

[208] Pedroni, J.; Saget, T.; Donets, P.A.; Cramer, N. Enantioselective palladium(0)-catalyzed intramolecular cyclopropane functionalization: Access to dihydroquinolones, dihydroisoquinolones and the BMS-791325 ring system. Chem. Sci., 2015, 6, 5164-5171.

[209] (a) Kulinkovich, O.G.; De Meijere, A. 1,n-Dicarbanionic titanium intermediates from monocarbanionic organometallics and their application in organic synthesis. Chem. Rev., 2000, 100, 2789-2834. (b) Kulinkovich, O.G. The 
chemistry of cyclopropanols. Chem. Rev., 2003, 103, 2597-2300. (c) Casey, C.P.; Strotman, N.A. Stereochemistry of cyclopropane formation involving group IV organometallic complexes. J. Am. Chem. Soc., 2004, 126, 16991704 .
[210] Baktharaman, S.; Selvakumar, S.; Singh, V.K. Asymmetric synthesis of all the stereoisomers of tarchonanthuslactone. Tetrahedron Lett., 2005, 46 , the stereoison

[211] Movassaghi, M.; Piizzi, G.; Siegel, D.S.; Piersanti, G. Enantioselective total synthesis of (-)-acylfulvene and (-)-irofulven. Angew. Chem. Int. Ed., 2006 , $45,5859-5863$. 